\title{
The Relationship Between Iron and Nitrogen Fixation in Trichodesmium spp.
}

\author{
By \\ Phoebe Dreux Chappell
}

B.A., Amherst College, 2000

Submitted in partial fulfillment of the requirements for the degree of

Doctor of Philosophy

at the

MASSACHUSETTS INSTITUTE OF TECHNOLOGY

and the

WOODS HOLE OCEANOGRAPHIC INSTITUTION

June 2009

(C) 2009 Phoebe Dreux Chappell, All Rights Reserved

The author hereby grants to MIT and WHOI permission to reproduce and to distribute publicly paper and electronic copies of this thesis document in whole or in part in any medium now known or hereafter created.

Signature of Author.

Joint Program in Oceanography/Applied Ocean Science and Engineering Massachusetts Institute of Technology and Woods Hole Oceanographic Institution

May 13, 2009

Certified By

Dr. James W. Moffett Thesis Supervisor

Certified By

Dr. John B. Waterbury Thesis Supervisor

Certified By

Dr. Eric A. Webb Thesis Supervisor

Accepted By

Dr. Roger Summons

Chair, Joint Committee for Chemical Oceanography Massachusetts Institute of Technology/ Woods Hole Oceanographic Institution 


\title{
The Relationship Between Iron and Nitrogen Fixation in Trichodesmium spp.
}

\author{
By Phoebe Dreux Chappell \\ Submitted to the Department of Marine Chemistry and Geochemistry, \\ Massachusetts Institute of Technology - Woods Hole Oceanographic Institution, \\ Joint Program in Chemical Oceanography \\ on May 13, 2009, in partial fulfillment \\ of the requirements for the degree of \\ Doctor of Philosophy
}

\begin{abstract}
:
Trichodesmium spp. are considered the dominant nitrogen $(\mathrm{N})$ fixing cyanobacteria in tropical and subtropical oceans, regimes frequently characterized by low iron (Fe). Limited information exists about what levels of Fe limit Trichodesmium $\mathrm{N}$ fixation. I developed a diagnostic for Fe limitation using quantitative reverse transcription PCR (qRT-PCR) of the Fe stress response gene $i s i B$, which encodes for flavodoxin a non-Fe containing substitute for ferredoxin. I determined that high $i s i B$ gene expression corresponded to cell-specific reductions in $\mathrm{N}$ fixation rates in both phylogenetic clades of Trichodesmium grown on varying levels of Fe. Using these laboratory-determined thresholds, I assessed Fe limitation of Trichodesmium from the Sargasso Sea, equatorial Atlantic Ocean and Western Pacific Warm Pool in conjunction with other analytical measurements $(\mathrm{N}$, phosphorus $(\mathrm{P})$ and dissolved $\mathrm{Fe}(<0.4 \mu \mathrm{m}$ filtered)). I found widespread Fe limitation in Trichodesmium from the Pacific Ocean and minimal expression in the North Atlantic Ocean. I also found an inverse correlation between isiB expression and dissolved Fe:P ratios in seawater and data suggesting that most dissolved $\mathrm{Fe}$ in seawater, including organic ligand-bound $\mathrm{Fe}$, is available to Trichodesmium. These data support and refine previous model predictions and demonstrate, in situ, the importance of $\mathrm{Fe}$ to the marine $\mathrm{N}$ cycle.
\end{abstract}

Thesis Supervisors:

Dr. James W. Moffett

Title: Professor of Biological Sciences, Earth Sciences and Civil and Environmental Engineering, University of Southern California

Dr. Eric A. Webb

Title: Assistant Professor of Biological Sciences, University of Southern California

Dr. John B. Waterbury

Title: Scientist Emeritus, Biology Department, Woods Hole Oceanographic Institution 


\section{ACKNOWLEDGMENTS}

Throughout my graduate career, I received funding from the Henry Houghton Fund, the Center for BioInorganic Chemistry, the National Science Foundation (grants OCE0220945 and OCE-0623499), a National Defense Science and Engineering Graduate Fellowship and the WHOI Academic Programs Office.

I would not have been able to accomplish most of the work in this thesis without the guidance and support I received from my three advisors: Jim Moffett, Eric Webb and John Waterbury. Jim, thanks for taking a chance on a biology student that wanted to play with chemicals. You have always been very supportive of me, letting me figure out where I wanted to go with my research, even when it led me back to biology. You never hovered, but offered help and guidance when I needed it. I really appreciate all the opportunities you gave me to go to sea and felt comfortable knowing that you always had my back. Eric, thanks for taking me in that first summer when I had a conflict during Jim's cruise. I'm sure he'll never let that happen again. It's been great being in your lab. You have so many ideas, it can be almost overwhelming at times meeting with you to discuss data, but I've really enjoyed it. I've definitely become a much more careful (paranoid?) scientist thanks to your guidance and am well aware that there's no such thing as oversampling. I have to thank you and Jim both for all of the opportunities you gave me to go to meetings as well as to sea. My passport has definitely gotten much more interesting in my almost six years here. John, thanks for taking in Jim and Eric's stray and making the jump from committee member to advisor. Thank you for being so careful and patient that you managed to tame the wild beast of Trichodesmium so that I had something to study and then taking the time to teach me at least a few of the tricks of the tricho (I don't imagine I'm anywhere close to learning all of them). Between the three of you, you taught me trace metal clean sampling and analyses, molecular microbiology and how to culture one of the trickiest bugs in the ocean. I can honestly say, I couldn't have done this without you guys and I really appreciate all the time you spent helping me.

I'd like to thank my committee member, Ed Boyle. Ed, thank you for always being willing to squeeze a meeting in if you were down in Woods Hole or out at USC as well as making special trips down just for my meetings. Thank you for always being willing to discuss sampling methods, analyses and even results with me. I also want to thank the members of your lab for their help: Jessica Fitzsimmons, Seth John, Rick Kayser, JongMi Lee, and Ruifeng Zhang.

Thanks to the chair of my defense, Scott Doney. You probably should have been on the committee given the amount of advice I've gotten from you over the years and I'm really glad you were able to participate in the defense. Thank you also for the support when I was your TA in my first teaching stint.

To the Academic Programs Office: as you well know, none of us would make it without you. Your office is the place to go for answers, support (emotional probably more appreciated than financial, though you give us both) and fabulous people that always fight for us. 
Thank you Mak Saito, Carl Lamborg and Tracy Mincer for letting me continue to work in your lab spaces after Jim and Eric moved to USC. Thanks to Dave Schneider and Scot Birdwhistel of the WHOI ICP facility. Thank you to both the MC\&G and Biology Department administrative staff for all of your help with getting paperwork processed and keeping printers and copiers working (thus keeping all of us saner).

Thanks to the past and present members of the Moffett, Webb and Waterbury labs. Rachel, thank you for teaching me so much about trace metal sampling and packing all the stuff you knew I'd forget for my first cruise. Tyler, Dan, and Andrew (Rosey), it was always fun sampling with you, tearing down a bubble with you or having a muchdeserved beverage at the end of a cruise. Yoshiko, Jagruti, Florence, and Jeremy, I appreciate the fun times we had in LA. Adam and Whitney, it was great being Eric's first students with you. I think we broke him in for the new kids. Emily and Maria, I appreciate all your help and support. Jill, it was great going to sea with you and I'm glad you joined Eric's group while I was still out there. Freddy, I can't believe that you retired before I started grad school and still come into work, but I'm so happy that you do. Justin, our fabulous high-school student now college graduate, you were a joy to have around and the best dishwasher ever. Nan, between your organizational skills and baking abilities, you made the Webb-Waterbury lab a wonderful place to work. Annette, my tricho twin, it's been great having you as a friend, a labmate, an officemate and occasionally a roommate at meetings. Brian, my savior, I would not have survived in Eric's lab if you hadn't made the move to LA. With all the travel I had to do, it was really comforting knowing I could email you a list of things and they'd be there when I arrived or leave you with Tricho to watch and know it would be alive when I returned.

Kate, Desiree, and Annette, you ladies are awesome supportive friends. Des, I wouldn't have made it through those first two years of classes without you there to teach me the pchem that I missed and who else would have shoveled out a road with me. Kate and Annette, thanks for being my TV, movie and curling buddies. It's wonderful having friends that will bring you goodies when you're stressed or sad and go out and celebrate when something good happens.

Thank you to all the rest of my WHOI and non-WHOI support network: WHOI: Nick Drenzek, Paul Craddock, Christian Miller, Kristen Whalen, Sheean Haley, Liz Orchard, Louis Wurch, Erin Bertrand, Erin Banning, Travis Meador; LA: Beth! Orcutt, Jason Sylvan, Ashley Jones, The Webb-Edwards Family; Life: Karrie Radloff, Jonathan Nowak, Molly Eaton Thomas, Rachel Bobuff, David Bobruff, Danielle Grove-Strawser, and Alexandra Dowling.

Thank you especially Betsy Farnham for helping to anchor Hyatt Rd. It's nice looking out at night and knowing someone else is home. Thanks for the dinners, the movies and generally being around when I need to escape the world of science.

Last, but certainly not least, I have to thank my amazing, supportive, wonderful family. Carol, you're a great sister and I love you with all my heart. Mom and Dad, I don't have the words to express how grateful I am for all of the love and support you've given me through the years. You are my inspiration and my strength and I love you very much. 


\section{Dedication}

This thesis is dedicated to the memory of Benedicta Y Duterte and Celeste Fowler, two amazing women that taught me to strive for my dreams and never give up. My world was brighter for having you in it. 


\section{TABLE OF CONTENTS}

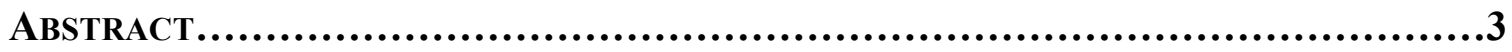

ACKNOWLEDGEMENTS..........................................................5

DEDICATION.........................................................................

TABLE OF CONTENTS....................................................................9

CHAPTER 1: InTRODUCTION........................................................13

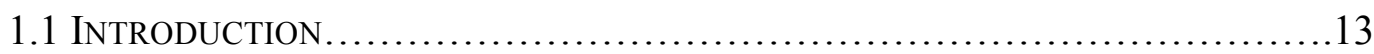

1.2 REFERENCES........................................................ 18

Chapter 2: Distribution of Dissolved Fe and Organic Fe Binding Ligands in

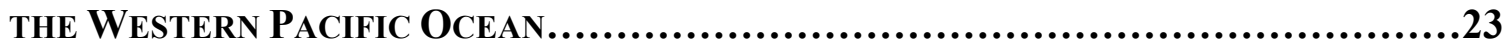

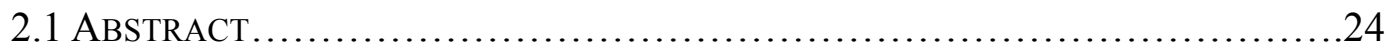

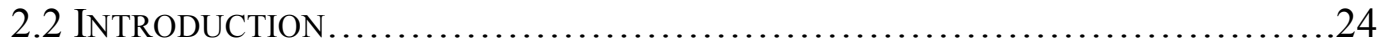

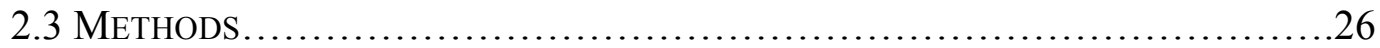

2.3.1. Sample Collection........................................26

2.3.2. Dissolved Fe Analysis........................................27

2.3.3. Organic Ligand Analysis..................................27

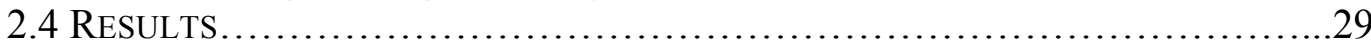

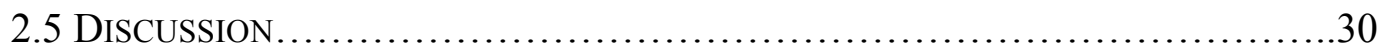

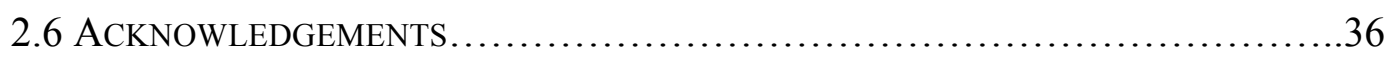

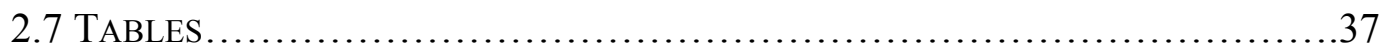

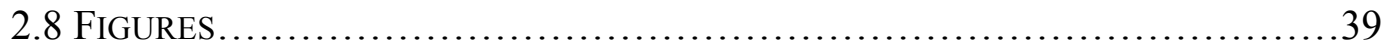

2.9 REFERENCES.....................................................43

Chapter 3: A Molecular Assessment of the Iron Stress Response in the Two Phylogenetic Clades of Trichodesmium......................................49

3.1 ABSTRACT ........................................................ 50

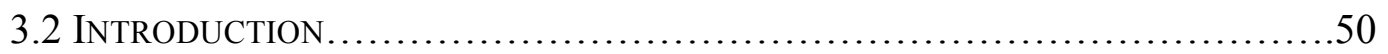

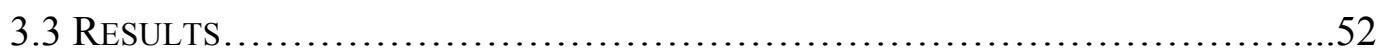

3.3.1 Genomic Database Analysis..............................52

3.3.2 Sequence Analysis..........................................54

3.3.3 Axenic IMS101 Nutrient Stress Experiment....................55

3.3.4 Physiological Growth Response of the Ten and Tery Clades.........55

3.3.5 Quantified Fe stress response..............................56 


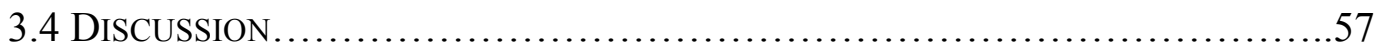

3.4.1 Genomic Capabilities and Conservation Within the Genus..........58

3.4.2 Axenic IMS101 Expression Analyses.............................59

3.4.3 Clade Differentiation.........................................60

3.5 EXPERIMENTAL PROCEDURES.................................................64

3.5.1 Genomic Database Searching...................................64

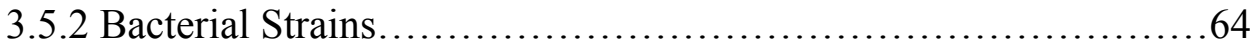

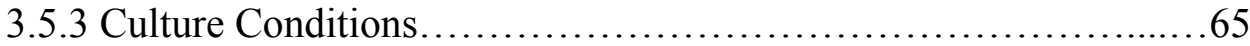

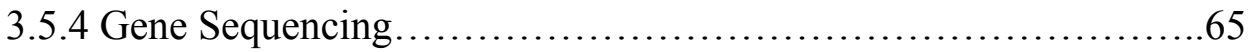

3.5.5 Nutrient Stress Experiments with Axenic IMS101 ..................66

3.5.6 Temperature Optimization....................................66

3.5.7 Culture experiment with different Fe levels......................67

3.5.8 Chl $a /$ DNA Normalization........................................68

3.5.9 RNA Extraction and cDNA Synthesis...........................68

3.5.10 RT Analysis of Gene Expression IMS101 Nutrient Experiment...69

3.5.11 qPCR Analysis of Gene Expression: Fe Titration Experiment......69

3.5.12 Alleviation of Fe Limitation Experiment...........................70

3.6 ACKNOWLEDGEMENTS.................................................

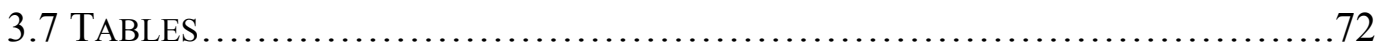

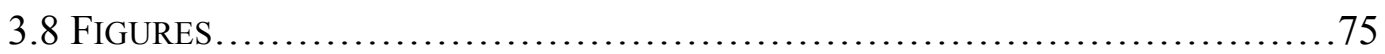

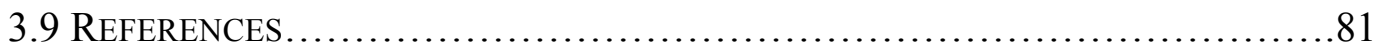

Chapter 4: A Molecular Demonstration of Trichodesmium-SPECific Fe Limitation Of $\mathbf{N}_{2}$ FiXation in the PaCific ANd Atlantic OCEANS.................87

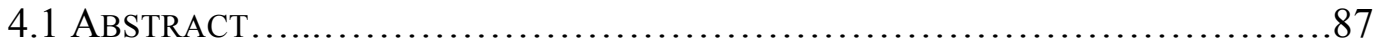

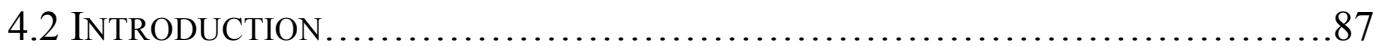

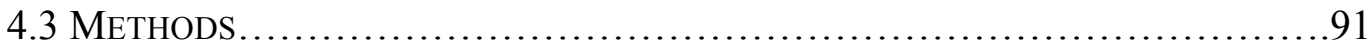

4.3.1 Dissolved Fe Sampling Procedure................................91

4.3.2 Dissolved Fe Analysis.............................................91

4.3.3 Collection of Trichodesmium Samples............................99

4.3.4 Nitrogen Fixation Measurements.................................92

4.3.5 RNA Extraction and cDNA Synthesis...........................99

4.3.6 Quantitative PCR Analysis of Gene Expression......................93

4.3.7 DNA qPCR Test for Specificity of Primers...........................94

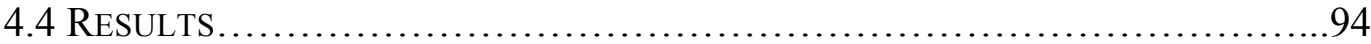

4.4.1 Sampling Locations......................................... 94

4.4.2 Fe, $\mathrm{PO}_{4}$ and Expression Data.................................... 95

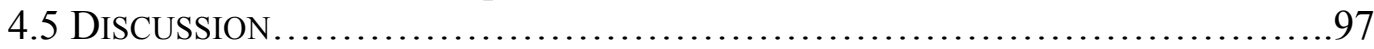

4.5.1 Ten Clade Predominance in the Open Ocean.......................98

4.5.2 Basin-wide differences in Fe limitation of Trichodesmium...........98

4.5.3 Relationship between $i s i B$ expression and dissolved Fe............100

4.5.4 Relationship between $i s i B$ expression and $\mathrm{Fe} / \mathrm{P}$....................102

4.5.5 Relationship between isiB expression and $\mathrm{N}_{2}$ fixation rates.........103 


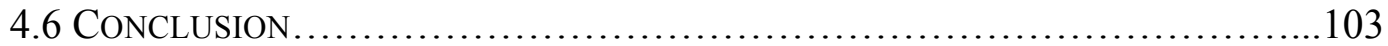

4.7 ACKNOWLEDGEMENTS.............................................. 104

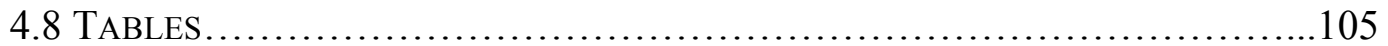

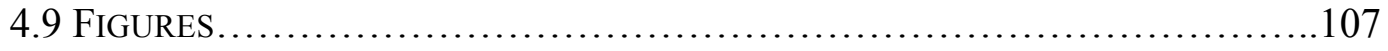

4.10 REFERENCES......................................................111

Chapter 5: Conclusions ANd Future Directions...........................117

5.1 Conclusions and Future Directions................................. 117

5.2 REFERENCES.................................................... 123

ApPendix A: Table of Fe Speciation Raw Data.............................127

ApPendix B: Fe Profile Data from SJ0609....................................129 


\section{CHAPTER 1. INTRODUCTION}

\subsection{INTRODUCTION}

Primary producers are important to the oceanic food chain and the overall biogeochemistry of the ocean (Falkowski et al., 1998). Diazotrophic cyanobacteria impact the carbon (C) cycle directly through primary production and indirectly through their contribution of "new" nitrogen $(\mathrm{N})$ to the euphotic zone via $\mathrm{N}_{2}$ fixation (Capone et al., 2005). So far no eukaryotic phytoplankton have been found that are capable of fixing $\mathrm{N}_{2}$ without a symbiont. Thus, the new $\mathrm{N}$ that diazotrophs provide to the surface ocean is vital to the $\mathrm{N}$ and $\mathrm{C}$ cycles both regionally (Capone et al., 1997; Zehr et al., 2001) and globally (Gruber and Sarmiento, 1997). Of the diazotrophs, Trichodesmium is of particular importance to the global $\mathrm{N}$ cycle where some estimates associate its biological $\mathrm{N}_{2}$ fixation with up to $50 \%$ of global $\mathrm{N}$ sequestration (Karl et al., 1997). Although we now know that there is a much greater diversity of diazotrophs actively fixing $\mathrm{N}$ in the oceans than previously believed (Zehr et al., 2001; Montoya et al., 2004; Grabowski et al., 2008), Trichodesmium is still considered to be one of the most important diazotrophs globally (LaRoche and Breitbarth, 2005).

An important step in determining the impact of Trichodesmium on the $\mathrm{N}$ and $\mathrm{C}$ cycles and how this might change in the future is elucidating the physical and chemical factors that control its distribution and activity in situ. Trichodesmium is typically found in oligotrophic tropical and subtropical environments in clear stable water columns with deep light penetration and a mixed layer depth of around $100 \mathrm{~m}$ (Capone et al., 1997). Recent work with Trichodesmium erythraeum cultures has determined that the temperature range for growth and $\mathrm{N}_{2}$ fixation in the species is $22-34{ }^{\circ} \mathrm{C}$, with an optimal temperature of about $28^{\circ} \mathrm{C}$ (Breitbarth et al., 2007). Above this optimal temperature, there is a precipitous drop in $\mathrm{N}_{2}$ fixation rates and a more gradual decline in growth rates (Breitbarth et al., 2007). In addition to these physical constraints, both iron (Fe) (Berman-Frank et al., 2001; Webb et al., 2001; Fu and Bell, 2003b; Kustka et al., 2003a; Kustka et al., 2003b; Berman-Frank et al., 2007; Shi et al., 2007; Kupper et al., 2008), phosphorus (P) (Hynes, In Press; Sanudo-Wilhelmy et al., 2001; Dyhrman et al., 2002; 
Fu and Bell, 2003a; Fu et al., 2005; Moutin et al., 2005; Sohm and Capone, 2006; Webb et al., 2007; Sohm et al., 2008) or a combination of the two (Mills et al., 2004) have been implicated in controlling Trichodesmium abundance and productivity throughout the world's oceans.

There are currently six described species of Trichodesmium: T. erythraeum, Trichodesmium thiebautii, Trichodesmium tenue, Trichodesmium hildebrandtii, Trichodesmium contortum and Trichodesmium spiralis (formerly known as Katagnymene spiralis) (Orcutt et al., 2002; Lundgren et al., 2005). Early distinctions between the species were made using morphological differences, but the potential for overlapping morphological characteristics between species has led to the development of genetic tools that can be used to complement morphological distinctions (Orcutt et al., 2002; Lundgren et al., 2005). These genetic techniques have shown that there are two distinct clades of Trichodesmium (Orcutt et al., 2002), which split into the T. erythraeum strains in one group and T. tenue, T. thiebautii, T. spiralis and T. hildebrandtii in the other group. Recent work has shown that $T$. contortum is part of the T. erythraeum group (Annette Hynes personal communication). Though these two distinct clades of Trichodesmium are known to exist, not much is known about the potential for niche differentiation between the species and what impact this might have on estimates of $\mathrm{N}_{2}$ fixation in the ocean. For example, all of the studies looking at Fe stress in Trichodesmium culture experiments have focused on one species, T. erythraeum (Berman-Frank et al., 2001; Webb et al., 2001; Fu and Bell, 2003b; Kustka et al., 2003b; Berman-Frank et al., 2007; Shi et al., 2007). Prior to the work presented in this thesis, there were no physiological data from laboratory cultures of the other clade at all, including the impact of Fe limitation on $\mathrm{N}_{2}$ fixation.

It appears that the two main morphologies of Trichodesmium, puffs and tufts, may exist at different depths in the ocean (Post et al., 2002; Davis and McGillicuddy, 2006). A study in the Red Sea determined not only that puff forming colonies were more abundant deeper in the water column than tuft colonies, but that these deep water puff colonies contained more chlorophyll a and had higher carbon fixation rates per colony at 
ambient light than the tuft colonies from higher in the water column (Post et al., 2002). Another study found consistent differences in nitrogen fixation rates, photosynthetic compounds and distribution of two morphologies of Trichodesmium in the ocean (Carpenter et al., 1993). It is important to note that these distinctions were made based on morphology, not genetic differences, which makes attributing them to one particular subset of Trichodesmium complicated. They do, however, support the theory that there are differences between the members of the genus, which should be explored if we are going to adequately model how $\mathrm{N}_{2}$ fixation rates might be affected by changing dust deposition, temperature and carbon dioxide levels.

$\mathrm{N}_{2}$-fixing cyanobacteria are believed to have evolved in an anoxic ocean where $\mathrm{Fe}$ was readily available, and they have Fe requirements 5 to 8 times higher than other phytoplankton when they are growing without a fixed nitrogen source (Berman-Frank et al., 2001; Kustka et al., 2003b). In the modern oxygenated ocean, dissolved Fe is not as prevalent because of the low solubility of its thermodynamically stable form, $\mathrm{Fe}^{3+}$ (Liu and Millero, 2002). There are many forms of $\mathrm{Fe}$ found in the oceans (i.e., colloidal, ligand bound, dissolved, free ion, etc), and it is uncertain which forms are bioavailable to Trichodesmium. In most regions of the ocean, including the oligotrophic ocean gyres, dissolved $(<0.4 \mu \mathrm{m}$ filtered) $\mathrm{Fe}$ has been found to be almost completely $(>99 \%)$ complexed by organic molecules (Gledhill and van den Berg, 1994; Rue and Bruland, 1995; van den Berg, 1995; Wu and Luther, 1995). The role that these organic ligands play in controlling the distribution of the dissolved pool of Fe complicates our understanding of what is biologically available to organisms. It remains difficult to identify which organic molecules are acting as ligands in ocean water, and there is evidence that many marine phytoplankton, including Trichodesmium, are able to obtain Fe from some but not all of these organic complexes (Hutchins et al., 1999; Achilles et al., 2003).

While there have been many studies of organic complexation of Fe in the Atlantic Ocean (Witter and Luther, 1998; Boye et al., 2003; Powell and Wilson-Finelli, 2003; Cullen et al., 2006; Rijkenberg et al., 2008) and the Southern Ocean (Boye et al., 2001; 
Croot et al., 2004; Boye et al., 2005; Gerringa et al., 2008), other areas of the ocean that are important habitats for Trichodesmium have been sparsely investigated. In the Pacific Ocean, for example, most Fe speciation studies have focused on the North Pacific (Rue and Bruland, 1995; van den Berg, 1995; van den Berg, 2006; Buck and Bruland, 2007; Kondo et al., 2007; Kondo et al., 2008) and Eastern Equatorial Pacific (Rue and Bruland, 1997), leaving vast portions of the ocean unstudied.

Prior to the work in this thesis, no studies had looked at Fe speciation in the South Western Pacific or the Western Pacific Warm Pool, a region of the Pacific Ocean that is defined by temperatures higher than $29^{\circ} \mathrm{C}$, salinity below 35 and very low macro nutrient concentrations (Blanchot et al., 1997). In fact, few studies with any Fe measurements have been done in this part of the Pacific Ocean (Campbell et al., 2005; Obata et al., 2008). This region is of particular interest to studies of Fe chemistry because it has very low predicted dust deposition (Duce and Tindale, 1991; Jickells, 1999; Wagener et al., 2008). It is also of interest biologically because based on flow-cytometric and pigment analyses, cyanobacteria appear to be the dominant phytoplankton in this highly oligotrophic region (Blanchot et al., 1997; Neveux et al., 2006; Matsumoto and Ando, 2009) and blooms of Trichodesmium can be quite prevalent in the region close to New Caledonia (Dupouy et al., 1988).

In addition to there being regions of the oceans where there is a paucity of $\mathrm{Fe}$ measurements and incomplete information regarding Fe bioavailability, a further complication associated with connecting Fe levels in the ocean with Fe status of Trichodesmium is that they are capable of luxury uptake and storage of Fe during periods of high Fe abundance (Kustka et al., 2003b). This ability to store Fe is an important adaptation in areas of episodic Fe deposition, which can lead to confusing results when trying to assess Fe limitation in the field, as cells can be Fe replete when the Fe levels in the waters around them would suggest limitation. Attempts to assess the relationship between $\mathrm{Fe}$ and the global $\mathrm{N}$ cycle using analytical geochemical measurements, $\mathrm{Fe}$ quotas of different organisms and dust deposition models have made great strides in understanding the interconnectedness of these global cycles (Moore et al., 2004; Moore 
and Doney, 2007). These studies have underscored the need for biological markers to assess in situ Fe stress. An in situ biological marker for Fe could be used to directly explore the linkages between $\mathrm{Fe}$ geochemistry, $\mathrm{Fe}$ status and $\mathrm{N}_{2}$-fixation in natural populations of Trichodesmium, avoiding the difficulties associated with determining the best measurement of bioavailable $\mathrm{Fe}$ and complications relating to Fe storage capabilities.

The goals of this thesis were to address questions raised in the preceding paragraphs regarding distribution and speciation of $\mathrm{Fe}$ in the southwestern Pacific Ocean as well as to assess Fe limitation of Trichodesmium in different ocean regimes using a quantitative molecular method. Chapter 2 deals with measurements of dissolved Fe and Fe speciation in a region of the ocean where there have been few measurements made, the southwestern Pacific Ocean. Chapter 3 explores clade differentiation in Trichodesmium spp., specifically focusing on temperature optima and the response to $\mathrm{Fe}$ limitation. Chapter 3 also includes the development of clade-specific molecular markers for $\mathrm{Fe}$ limitation, which are calibrated to reductions in $\mathrm{N}_{2}$ fixation rates in response to $\mathrm{Fe}$ limitation. Chapter 4 looks at Fe stress in field populations of Trichodesmium from both the Pacific and Atlantic Oceans using the molecular marker for Fe limitation developed in Chapter 3. The results from Chapter 4 validate model predictions of where $\mathrm{Fe}$ limitation of Trichodesmium is occurring with calibrated measurements of Fe limitation of $\mathrm{N}_{2}$ fixation. The region where Fe limitation of Trichodesmium is most apparent is the Pacific Ocean. The dissolved Fe values from the field associated with Fe limitation are similar to those associated with Fe limitation in the lab, suggesting that much of the organically bound Fe in the open ocean is available to Trichodesmium. In addition, the correlation of expression of the Fe stress response gene, isiB, and the measured dissolved $\mathrm{Fe} / \mathrm{PO}_{4}$ ratio of seawater samples enables calculation of the critical $\mathrm{Fe} / \mathrm{PO}_{4}$ value associated with Fe limitation of Trichodesmium. The similarity between this calculated critical Fe/ $/ \mathrm{PO}_{4}$ value with the one used in some models to predict $\mathrm{Fe}$ limitation of Trichodesmium, serves as further validation of those models with empirical data. Overall, this thesis provides insight into how Fe controls $\mathrm{N}_{2}$ fixation in Trichodesmium, 
where in the ocean this control is important and what parameters are important to measure to determine the likelihood that Trichodesmium is experiencing Fe limitation.

\subsection{REFERENCES}

Achilles, K.M., Church, T.M., Wilhelm, S.W., Luther, G.W., and Hutchins, D.A. (2003) Bioavailability of iron to Trichodesmium colonies in the western subtropical Atlantic Ocean. Limnol Oceanogr 48: 2250-2255.

Berman-Frank, I., Quigg, A., Finkel, Z.V., Irwin, A.J., and Haramaty, L. (2007) Nitrogen-fixation strategies and $\mathrm{Fe}$ requirements in cyanobacteria. Limnol Oceanogr $\mathbf{5 2}$ : 2260-2269.

Berman-Frank, I., Cullen, J.T., Shaked, Y., Sherrell, R.M., and Falkowski, P.G. (2001) Iron availability, cellular iron quotas, and nitrogen fixation in Trichodesmium. Limnol Oceanogr 46: 1249-1260.

Blanchot, J., Andre, J.M., Navarette, C., and Neveux, J. (1997) Picophytoplankton dynamics in the equatorial Pacific: diel cycling from flow-cytometer observations. $\mathrm{Cr}$ Acad Sci Iii-vie 320: 925-931.

Boye, M., Aldrich, A.P., van den Berg, C.M.G., de Jong, J.T.M., Veldhuis, M., and de Baar, H.J.W. (2003) Horizontal gradient of the chemical speciation of iron in surface waters of the northeast Atlantic Ocean. Mar Chem 80: 129-143-PII S03044203(02)00102-0.

Boye, M., Nishioka, J., Croot, P.L., Laan, P., Timmermans, K.R., and de Baar, H.J.W . (2005) Major deviations of iron complexation during 22 days of a mesoscale iron enrichment in the open Southern Ocean. Mar Chem 96: 257-271.

Boye, M., van den Berg, C.M.G., de Jong, J.T.M., Leach, H., Croot, P., and de Baar, H.J.W. (2001) Organic complexation of iron in the Southern Ocean. Deep Sea Research 48: $1477-1497$.

Breitbarth, E., Oschilies, A., and LaRoche, J. (2007) Physiological constraints on the global distribution of Trichodesmium - effect of temperature on diazotrophy. Biogeosciences 4: 53-61.

Buck, K.N., and Bruland, K.W . (2007) The physicochemical speciation of dissolved iron in the Bering Sea, Alaska. Limnol Oceanogr 52: 1800-1808.

Campbell, L., Carpenter, E.J., Montoya, J.P., Kustka, A.B., and Capone, D.G. (2005) Picoplankton community structure within and outside a Trichodesmium bloom in the southwestern Pacific Ocean. Vie Milieu 55: 185-195.

Capone, D.G., Burns, J.A., Montoya, J.P., Subramaniam, A., Mahaffey, C., Gunderson, T. et al. (2005) Nitrogen fixation by Trichodesmium spp.: An important source of new 
nitrogen to the tropical and subtropical North Atlantic Ocean. Global Biogeochemical Cycles 19:

Capone, D.G., Zehr, J.P., Paerl, H.W., Bergman, B., and Carpenter, E.J. (1997)

Trichodesmium, a globally significant marine cyanobacterium. Science 276: 1221-1229.

Carpenter, E.J., O'Neil, J.M., Dawson, R., Capone, D.G., Siddiqui, P.J.A., Roenneberg, T., and Bergman, B. (1993) The tropical diazotrophic phytoplankter Trichodesmium: Biological characteristics of two common species. Mar Ecol Prog Ser 95: 295-304.

Croot, P.L., Andersson, K., Ozturk, M., and Turner, D.R. (2004) The distribution and specification of iron along 6 degrees E in the Southern Ocean. Deep-sea Res Pt Ii 51: 2857-2879.

Cullen, J.T., Bergquist, B.A., and Moffett, J.W. (2006) Thermodynamic characterization of the partitioning of iron between soluble and colloidal species in the Atlantic Ocean. Mar Chem 98: 295-303.

Davis, C.S., and McGillicuddy, D.J. (2006) Transatlantic Abundance of the $\mathrm{N}_{2}$-Fixing Colonial Cyanobacterium Trichodesmium. Science 312: 1517-1520.

Duce, R.A., and Tindale, N.W. (1991) Atmospheric Transport of Iron and its Deposition in the Ocean. Limnol Oceanogr 36: 1715-1726.

Dupouy, C., Petit, M., and Dandonneau, Y. (1988) Satellite Detected Cyanobacteria Bloom in the Southwestern Tropical Pacific - Implication for Oceanic Nitrogen-Fixation. Int J Remote Sens 9: 389-396.

Dyhrman, S.T., Webb, E.A., Anderson, D.M., Moffett, J.W., and Waterbury, J.B. (2002) Cell specific detection of phosphate stress in Trichodesmium from the Western North Atlantic. Limnol Oceanogr 47: 1832-1836.

Falkowski, P.G., Barber, R.T., and Smetacek, V. (1998) Biogeochemical controls and feedbacks on ocean primary production. Science 281: 200-206.

Fu, F.X., Zhang, Y.H., Bell, P.R.F., and Hutchins, D.A. (2005) Phosphate uptake and growth kinetics of Trichodesmium (Cyanobacteria) isolates from the North Atlantic Ocean and the Great Barrier Reef, Australia. Journal of Phycology 41: 62-73.

Fu, F.X., and Bell, P.R.F. (2003a) Factors affecting $\mathrm{N}_{2}$ fixation by the cyanobacterium Trichodesmium sp GBR-TRLI101. Fems Microbiol Ecol 45: 203-209.

$\mathrm{Fu}$, F.X., and Bell, P.R.F. (2003b) Growth, $\mathrm{N}_{2}$ fixation and photosynthesis in a cyanobacterium, Trichodesmium sp., under Fe stress. Biotechnol Lett 25: 645-649.

Gerringa, L.J.A., Blain, S., Laan, P., Sarthou, G., Veldhuis, M.J.W., Brussaard, C.P.D. et al. (2008) Fe-binding dissolved organic ligands near the Kerguelen Archipelago in the Southern Ocean (Indian sector). Deep-sea Res Pt Ii 55: 606-621.

Gledhill, M., and van den Berg, C.M.G. (1994) Determination of Complexation of Iron(III) with Natural Organic Complexing Ligands in Seawater Using Cathodic Stripping Voltammetry. Mar Chem 47: 41-54. 
Grabowski, M.N.W., Church, M.J., and Karl, D.M. (2008) Nitrogen fixation rates and controls at Stn ALOHA. Aquat Microb Ecol 52: 175-183.

Gruber, N., and Sarmiento, J.L. (1997) Global patterns of marine nitrogen fixation and denitrification. Glob Biogeochem Cycles 11: 235-266.

Hutchins, D.A., Witter, A.E., Butler, A., and Luther, G.W., III (1999) Competition among marine phytoplankton for different chelated iron species. Nature 400: 858-861.

Hynes, A.M., Chappell, P.D., Dyhrman, S.T., Doney, S.C. and Webb, E. A. (In Press) Cross-basin comparison of phosphorus stress and nitrogen fixation in Trichodesmium. Limnol Oceanogr

Jickells, T.D. (1999) The inputs of dust derived elements to the Sargasso Sea: A synthesis. Mar Chem 68: 5-14.

Karl, D.M., Letlier, R., Tupas, L., Dore, J., Christian, J., and Hebel, D. (1997) The role of nitrogen fixation in biogeochemical cycling in the subtropical North Pacific Ocean.

Nature 388: 533-538.

Kondo, Y., Takeda, S., and Furuya, K. (2007) Distribution and speciation of dissolved iron in the Sulu Sea and its adjacent waters. Deep-sea Res Pt Ii 54: 60-80.

Kondo, Y., Takeda, S., Nishioka, J., Obata, H., Furuya, K., Johnson, W.K., and Wong, C.S. (2008) Organic iron(III) complexing ligands during an iron enrichment experiment in the western subarctic North Pacific. Geophys Res Lett 35: ARTN L12601.

Kupper, H., Setlik, I., Seibert, S., Prasil, O., Setlikova, E., Strittmatter, M. et al. (2008) Iron limitation in the marine cyanobacterium Trichodesmium reveals new insights into regulation of photosynthesis and nitrogen fixation. New Phytol 179: 784-798.

Kustka, A., Sanudo-Wilhelmy, S., Carpenter, E.J., Capone, D.G., and Raven, J.A. (2003a) A revised estimate of the iron use efficiency of nitrogen fixation, with special reference to the marine cyanobacterium Trichodesmium spp. (Cyanophyta). J Phycol 39: $12-25$.

Kustka, A.B., Sanudo-Wilhelmy, S.A., Carpenter, E.J., Capone, D., Burns, J., and Sunda, W.G. (2003b) Iron requirements for dinitrogen- and ammonium-supported growth in cultures of Trichodesmium (IMS 101): Comparison with nitrogen fixation rates and iron: carbon ratios of field populations. Limnology and Oceanography 48: 1869-1884.

LaRoche, J., and Breitbarth, E. (2005) Importance of the diazotrophs as a source of new nitrogen in the ocean. Journal of Sea Research 53: 67-91.

Liu, X.W., and Millero, F.J. (2002) The solubility of iron in seawater. Mar Chem 77: 4354.

Lundgren, P., Janson, S., Jonasson, S., Singer, A., and Bergman, B. (2005) Unveiling of novel radiations within Trichodesmium cluster by hetR gene sequence analysis. Appl Environ Microbiol 71: 190-196. 
Matsumoto, K., and Ando, K. (2009) Use of cyanobacterial pigments to characterize the ocean surface mixed layer in the western Pacific warm pool. J Marine Syst 75: 245-252.

Mills, M.M., Ridame, C., Davey, M., La Roche, J., and Geider, R.J. (2004) Iron and phosphorus co-limit nitrogen fixation in the eastern tropical North Atlantic. Nature 429: 292-294.

Montoya, J.P., Holl, C.M., Zehr, J.P., Hansen, A., Villareal, T.A., and Capone, D.G. (2004) High rates of $\mathrm{N}_{2}$ fixation by unicellular diazotrophs in the oligotrophic Pacific Ocean. Nature 430: 1027-1031.

Moore, J.K., and Doney, S.C. (2007) Iron availability limits the ocean nitrogen inventory stabilizing feedbacks between marine denitrification and nitrogen fixation. Global Biogeochem Cy 21: ARTN GB2001.

Moore, J.K., Doney, S.C., and Lindsay, K. (2004) Upper ocean ecosystem dynamics and iron cycling in a global three-dimensional model. Global Biogeochem Cy 18: ARTN GB4028.

Moutin, T., Van Den Broeck, N., Beker, B., Dupouy, C., Rimmelin, P., and Le Bouteiller, A. (2005) Phosphate availability controls Trichodesmium spp. biomass in the SW Pacific Ocean. Marine Ecology-Progress Series 297: 15-21.

Neveux, J., Tenorio, M.M.B., Dupouy, C., and Villareal, T.A. (2006) Spectral diversity of phycoerythrins and diazotroph abundance in tropical waters. Limnol Oceanogr 51: 1689-1698.

Obata, H., Shitashima, K., Isshik, K., and Nakayama, E. (2008) Iron, manganese and aluminum in upper waters of the western South Pacific ocean and its adjacent seas. $J$ Oceanogr 64: 233-245.

Orcutt, K.M., Rasmussen, U., Webb, E.A., Waterbury, J.B., Gundersen, K., and Bergman, B. (2002) Characterization of Trichodesmium spp. by genetic techniques. Appl Environ Microbiol 68: 2236-2245.

Post, A.F., Dedej, Z., Gottlieb, R., Li, H., Thomas, D.N., El-Absawi, M. et al. (2002) Spatial and temporal distribution of Trichodesmium spp. in the stratified Gulf of Aqaba, Red Sea. Marine Ecology-Progress Series 239: 241-250.

Powell, R.T., and Wilson-Finelli, A. (2003) Importance of organic Fe complexing ligands in the Mississippi River plume. Estuar Coast Shelf S 58: 757-763.

Rijkenberg, M.J.A., Powell, C.F., Dall'Osto, M., Nielsdottir, M.C., Patey, M.D., Hill, P.G. et al. (2008) Changes in iron speciation following a Saharan dust event in the tropical North Atlantic Ocean. Mar Chem 110: 56-67.

Rue, E.L., and Bruland, K.W. (1995) Complexation of iron(III) by natural organic ligands in the Central North Pacific as determined by a new competitive ligand equilibration/adsorptive cathodic stripping voltammetric method. Mar Chem 50: 117-138. 
Rue, E.L., and Bruland, K.W. (1997) The role of organic complexation on ambient iron chemistry in the equatorial Pacific Ocean and the response of a mesoscale iron addition experiment. Limnol Oceanogr 42: 901-910.

Sanudo-Wilhelmy, S.A., Kustka, A.B., Gobler, C.J., Hutchins, D.A., Yang, M., Lwiza, K. et al. (2001) Phosphorus limitation of nitrogen fixation by Trichodesmium in the central Atlantic Ocean. Nature 411: 66-69.

Shi, T., Sun, Y., and Falkowski, P.G. (2007) Effects of iron limitation on the expression of metabolic genes in the marine cyanobacterium Trichodesmium erythraeum IMS 101. Environmental Microbiology 9: 2945-2956.

Sohm, J.A., and Capone, D.G. (2006) Phosphorus dynamics of the tropical and subtropical North Atlantic: Trichodesmium spp. versus bulk plankton. Mar Ecol-prog Ser 317: 21-28.

Sohm, J.A., Mahaffey, C., and Capone, D.G. (2008) Assessment of relative phosphorus limitation of Trichodesmium spp. in the North Pacific, North Atlantic, and the north coast of Australia. Limnol Oceanogr 53: 2495-2502.

van den Berg, C.M.G. (1995) Evidence for Organic Complexation of Iron in Seawater. Mar Chem 50: 139-157.

van den Berg, C.M.G. (2006) Chemical speciation of iron in seawater by cathodic stripping voltammetry with dihydroxynaphthalene. Anal Chem 78: 156-163.

Wagener, T., Guieu, C., Losno, R., Bonnet, S., and Mahowald, N. (2008) Revisiting atmospheric dust export to the Southern Hemisphere ocean: Biogeochemical implications. Global Biogeochem Cy 22: ARTN GB2006.

Webb, E.A., Moffett, J.W., and Waterbury, J.B. (2001) Iron stress in open-ocean cyanobacteria (Synechococcus, Trichodesmium, and Crocosphaera spp.): identification of the IdiA protein. Appl Environ Microbiol 67: 5444-5452.

Webb, E.A., Jakuba, R.W., Moffett, J.W., and Dyhrman, S.T. (2007) Molecular assessment of phosphorus and iron physiology in Trichodesmium populations from the western Central and western South Atlantic. Limnol Oceanogr 52: 2221-2232.

Witter, A.E., and Luther, G.W. (1998) Variation in Fe-organic complexation with depth in the Northwestern Atlantic Ocean as determined using a kinetic approach. Mar Chem 62: $241-258$.

Wu, J., and Luther, G.W., III (1995) Complexation of Fe(III) by natural organic ligands in the Northwest Atlantic Ocean by a competitive ligand equilibration method and a kinetic approach. Mar Chem 50: 159-177.

Zehr, J.P., Waterbury, J.B., Turner, P.J., Montoya, J.P., Omoregie, E., Steward, G.F. et al. (2001) Unicellular cyanobacteria fix $\mathrm{N}_{2}$ in the subtropical North Pacific Ocean. Nature 412: 635-638. 
Chapter 2: Distribution of Dissolved Fe and Organic Fe Binding Ligands in the WESTERN PACIFIC OCEAN

\section{P. Dreux Chappell ${ }^{1,2}$ and James W. Moffett ${ }^{3 *}$}

${ }^{1}$ MIT-WHOI Joint Program in Oceanography/Applied Ocean Science and Engineering

${ }^{2}$ Department of Marine Chemistry and Geochemistry, Woods Hole Oceanographic Institution, Woods Hole, MA 02543

${ }^{3}$ Department of Biological Sciences

Marine Environmental Biology

University of Southern California

3616 Trousdale Parkway

Los Angeles, CA 90089-0371

*Corresponding author (jmoffett@usc.edu)

In preparation for submission to Marine Chemistry 


\subsection{AbStract}

Dissolved iron $(\mathrm{Fe})$ and the concentration of organic Fe-binding ligands were measured in the Western Pacific Ocean on a transect from Hawaii to Australia. Fe complexation was measured using competitive ligand exchange adsorptive cathodic stripping voltammetry (CLE-ACSV) with the competitive ligand 2,3dihydroxynaphthalene (DHN). Dissolved Fe in surface samples ranged from $0.09-1.4$ nM. Ligand concentrations ranged from $0.44-2.2 \mathrm{nM}$ with binding constants ranging from $10^{11.6}-10^{12.9}$. There appeared to be a linear relationship between Fe and ligand concentrations when $[\mathrm{Fe}]>0.2 \mathrm{nM}$ and a wide range of ligand concentrations when $[\mathrm{Fe}]$ $<0.2 \mathrm{nM}$. Our data supports the hypothesis that organic ligands are a ubiquitous part of Fe speciation in the oceans, even in regions of low dust deposition where Fe inputs are small.

\subsection{INTRODUCTION}

Iron $(\mathrm{Fe})$ is an essential micronutrient for almost all organisms. Because of solubility constraints in its oxidized state (Liu and Millero, 2002), Fe can be low enough in surface waters to limit phytoplankton growth in the ocean (Martin et al., 1991; Morel et al., 1991; Falkowski et al., 1998; Boyd et al., 2007) even though it is the fourth most abundant element in the Earth's crust. The discovery of the role that Fe plays in controlling productivity in High Nutrient Low Chlorophyll (HNLC) regimes (Martin and Fitzwater, 1988; Martin et al., 1990) prompted significant research to determine what controls the bioavailability of Fe in the Ocean.

A major development in understanding Fe chemistry in the ocean was the discovery, using competitive ligand exchange adsorptive cathodic stripping voltammetry (CLE-ACSV), that organic ligands are ubiquitous and bind $>99 \%$ of the dissolved Fe in the oceans (Gledhill and van den Berg, 1994; Rue and Bruland, 1995; Wu and Luther, 1995). Since those first studies determined that organic complexation is an important component of Fe speciation in the ocean, evidence of Fe-binding ligands has been found in every area of the ocean that has been studied (Hunter and Boyd, 2007), including the recent discovery that they are associated with hydrothermal vent plumes (Bennett et al., 2008). 
While it remains unclear what the structures of these ligands are, there is evidence that the stability constants that have been measured are in line with the stability constants of known siderophores when analyzed in a seawater medium (Witter et al., 2000) as well as with unknown compounds with siderophore-like functional groups that were extracted from seawater (Macrellis et al., 2001). A recent study found evidence of two characterized sideophores in samples throughout the Atlantic Ocean (Mawji et al., 2008). It is known that marine bacteria and cyanobacteria are capable of making siderophorelike complexes (Wilhelm and Trick, 1994; Lewis et al., 1995; Soria-Dengg et al., 2001; Ito and Butler, 2005). It also appears that Fe bound to siderophores is available to at least some subset of phytoplankton (Hutchins et al., 1999; Maldonado and Price, 2001; SoriaDengg et al., 2001; Achilles et al., 2003), although the type of chelator appears to be important in determining the bioavailability to different phytoplankton (Hutchins et al., 1999). Considering that this organically bound fraction may be bioavailable to some phytoplankton groups in the surface ocean, it is important to determine if there are areas where the amount of ligand is different in the ocean and potentially determine what controls this distribution.

There have been many studies looking at dissolved Fe and Fe speciation in the Atlantic Ocean (Witter and Luther, 1998; Powell and Donat, 2001; Boye et al., 2003; Cullen et al., 2006; Rijkenberg et al., 2008) and Southern Ocean (Boye et al., 2001; Croot et al., 2004; Boye et al., 2005; Gerringa et al., 2008). There have been fewer studies looking at Fe speciation in the Pacific Ocean and those have focused on the Northern Pacific Ocean (Rue and Bruland, 1995; van den Berg, 1995; van den Berg, 2006; Buck and Bruland, 2007; Kondo et al., 2007; Kondo et al., 2008) and the Eastern Equatorial Pacific Ocean (Rue and Bruland, 1997). Only two studies so far have looked at Fe in the open ocean of the South Western Pacific (Campbell et al., 2005; Obata et al., 2008). One was focused on the most western part of the basin and only looked at the total dissolvable fraction of $\mathrm{Fe}$, which is measured on unfiltered seawater that has been acidified to $\mathrm{pH} 3.2$ immediately following collection (Obata et al., 2008). The other study focused on total dissolved $\mathrm{Fe}(<0.22 \mu \mathrm{m}$ filtered $\mathrm{Fe})$ and looked at the region around New Caledonia and between New Caledonia and New Zealand (Campbell et al., 2005). 
The data set presented in this work, which includes dissolved Fe and ligand concentrations, provides data on Fe geochemistry in the understudied region of the South Western Pacific Ocean, a region of very low dust inputs (Duce and Tindale, 1991; Jickells, 1999; Wagener et al., 2008). The transect includes the first measurements of Fe and Fe speciation through the hydrologic feature known as the Western Pacific Warm Pool (WPWP). The WPWP is a region defined by very warm surface temperatures ( $>$ $29^{\circ} \mathrm{C}$ ), low surface salinity $(<35)$ and low macronutrients (Blanchot et al., 1997). It is an oligotrophic region where the predominant phytoplankton are cyanobacteria (Blanchot et al., 1997; Neveux et al., 2006; Matsumoto and Ando, 2009). The cruise track also included a region of the ocean where there are reports of periodic blooms of the cyanobacterium Trichodesmium (Dupouy et al., 1988; Campbell et al., 2005; Rodier and Le Borgne, 2008). As cyanobacteria appear to be able to access Fe bound to some organic ligands (Hutchins et al., 1999; Achilles et al., 2003), it is important to determine the role of organic ligands in the Fe chemistry of the surface oceans in the region to understand Fe bioavailability to the predominant phytoplankton. In comparing the amount of organic ligand ([L]) present in each sample with various auxiliary chemical and biological parameters, the most striking relationship appeared to be between the amounts of dissolved $\mathrm{Fe}([\mathrm{Fe}])$ verses [L] in a given sample, which is consistent with data from other regions of the ocean. The data we present is an addition to global datasets of dissolved $\mathrm{Fe}$ and Fe speciation in surface waters, covering an area where few values have been reported.

\subsection{MeThODS}

2.3.1 Sample Collection. Samples were collected aboard the R/V Kilo Moana as part of the Western Pacific Warm Pool (WPWP) cruise between January 12, 2007 and February 9, 2007 (Figure 1). Samples were collected using acid cleaned 5L Tefloncoated exterior spring niskin bottles (Ocean Test Equipment) mounted on a powdercoated rosette deployed on a Kevlar line. After recovery, the bottles were transferred into a trace metal clean "bubble" in the laboratory of the ship with positive pressure maintained by HEPA filtered air units. The headspace of each bottle was pressurized with $0.2 \mu \mathrm{m}$ filtered ultra high purity (UHP) nitrogen pushing the water through a 142 
$\mathrm{mm} 0.4 \mu \mathrm{m}$ acid-cleaned polycarbonate filter held in a polycarbonate filter sandwich (Geotech Environmental Equipment, Inc.). Water for dissolved Fe analysis was collected in acid-cleaned $250 \mathrm{ml}$ low density polyethylene (LDPE) bottles and acidified to $\mathrm{pH} 1.7$ with concentrated $\mathrm{HCl}$ (Seastar). Water for speciation analysis was collected in $1 \mathrm{~L}$ acid-cleaned Teflon bottles and stored at $4^{\circ} \mathrm{C}$ until analysis.

2.3.2 Dissolved Fe Analysis. Fe in the seawater samples was determined using isotope dilution and magnesium hydroxide preconcentration followed by analysis using inductively coupled mass spectrometry (Wu and Boyle, 1998; Saito and Schneider, 2006). Roughly $13.5 \mathrm{ml}$ of sample (exact volume determined gravimetrically) was poured into a $15 \mathrm{ml}$ polypropylene centrifuge tube (Globe Scientific Inc.) and equilibrated with a ${ }^{57} \mathrm{Fe}$ spike $(\sim 0.4 \mathrm{nM})$ overnight. The following day, the $\mathrm{Mg}(\mathrm{OH})_{2}$ and metals were precipitated out of the sample by the addition of a small amount $(\sim 100 \mu \mathrm{l})$ of high-purity ammonium hydroxide (Seastar Chemicals Inc.). Following ammonium hydroxide addition, the tubes were left undisturbed for $90 \mathrm{~s}$ and then they were inverted multiple times to fully mix them. After an additional $90 \mathrm{~s}$, the tubes were centrifuged at $3000 \mathrm{x} g$ for 3 minutes and the sample was decanted off. The tubes were then spun at $3000 \mathrm{x}$ g for an additional 3 minutes forming a compact pellet, following which the remaining liquid was shaken off. The sample pellets were kept dry until the day of analysis (from a day to a week). On the morning of analysis, pellets were resuspended and dissolved in 1-2 ml 0.8 N Nitric Acid (Seastar). Samples were analyzed on a Thermo-Finnigan Element 2 (E2) inductively coupled mass spectrometer (ICP-MS) in medium resolution mode. A procedural blank was determined by processing $1 \mathrm{ml}$ of low Fe seawater (which provides a negligible amount of $\mathrm{Fe}$ ) and calculating its $\mathrm{Fe}$ value as though it were a $13.5 \mathrm{ml}$ sample.

2.3.3 Organic Ligand Analysis. The titration of organic Fe complexing ligands was carried out in a manner closely following that described by van den Berg (van den Berg, 2006). Briefly, $20 \mathrm{ml}$ of sample was added to a series of $30 \mathrm{ml}$ preconditioned Teflon vials (Savillex Corporation). $10 \mu \mathrm{l}$ of $1 \mathrm{mM}$ 2,3-dihydroxynaphthalene (DHN) (final concentration $0.5 \mu \mathrm{M}$ ) and $\mathrm{Fe}$ in a series of concentrations of $0,0.25,0.5,0.75,1$, $1.5,2,3,5$ and $8 \mathrm{nM}$ was added to each vial from an acidified Fe stock solution of 0.5 $\mu \mathrm{M}$ Fe. Samples were allowed to equilibrate overnight (17-24 hrs). After equilibration, 
$10 \mathrm{ml}$ of each sample in order of increasing Fe was transferred to a

polytetrafluoroethylene (PTFE) voltametric cell, $0.5 \mathrm{ml}$ EPPS (3-(4-(2-hydroxyethyl)-1piperazinyl)propanesulfonic acid)/bromate solution (final concentration $5 \mathrm{mM}$ EPPS/20 $\mathrm{mM}$ bromate) was added, purging was initiated and reactive Fe was determined by cathodic stripping voltammetry (CSV). This was repeated with the second $10 \mathrm{ml}$ of sample, and calculations were based on the results from the second scan. The scan conditions included a 5 minute purge of the sample with $0.2 \mu \mathrm{m}$ filtered ultra high purity nitrogen gas, $90 \mathrm{~s}$ adsorption at $-0.1 \mathrm{~V}, 10 \mathrm{~s}$ equilibration and a scan using sampled direct current (DC), step size $4 \mathrm{mV}$, frequency $10 \mathrm{~s}^{-1}$.

Cathodic stripping voltammetry (CSV) was carried out using a Metrohm VA 663 Stand with a Hanging Mercury Drop Electrode (HMDE), glassy carbon working electrode, a double junction $\mathrm{Ag} / \mathrm{AgCl}$ and a $3 \mathrm{M} \mathrm{KCl}$ reference electrode (Metrohm AG, Switzerland), which was connected to a $\mu$ Autolab II potentiostat (Eco Chemie BV, The Netherlands). The $\mu$ Autolab was connected to a laptop PC and was controlled using GPES software (Eco Chemie BV, The Netherlands).

Peak currents were plotted against $[\mathrm{Fe}]_{\text {total }}$ for each sample (natural Fe in sample and added $\mathrm{Fe}$ ) to get a titration curve. Linear regression of the final 3-5 points of a titration was used to obtain the sensitivity of the titration (the slope of that line, $S$ ). This calculated sensitivity and the $\alpha$ coeffecient for DHN complexation with Fe' of $0.5 \mu \mathrm{M}$ DHN (166) previously determined (van den Berg, 2006) were then used to calculate [Fe'] and $[\mathrm{FeL}]$ for each sample in the titration.

Briefly, $[\mathrm{FeDHN}]$ is related to the current measured at individual point in the titration $\left(i_{\mathrm{p}}\right)$ and the sensitivity of the titration $(S)$ and can be calculated using the equation: $i_{\mathrm{p}}=S \times[\mathrm{FeDHN}]$. [Fe'] is related to [FeDHN] by the $\alpha$ coeffecient for DHN complexation with $\mathrm{Fe}^{\prime}$ and can be calculated using the equation: $\left[\mathrm{Fe}^{\prime}\right]=[\mathrm{FeDHN}] / \alpha$. $[\mathrm{FeL}]$ is related to $[\mathrm{Fe}]_{\text {total }},\left[\mathrm{Fe}^{\prime}\right]$ and $[\mathrm{FeDHN}]$ and can be calculated using the equation: $[\mathrm{Fe}]_{\text {total }}=\left[\mathrm{Fe}^{\prime}\right]+[\mathrm{FeL}]+[\mathrm{FeDHN}]$.

[Fe'], [FeL] and [L] are in equilibrium in natural waters: Fe' $+\mathrm{L} \leftrightarrow \mathrm{FeL}$. The conditional stability constant for this equilibrium reaction, $\mathrm{K}_{\mathrm{FeL}, \mathrm{Fe}}$, is defined by the equation: $\mathrm{K}^{\prime}{ }_{\mathrm{FeL}, \mathrm{Fe}}=\left([\mathrm{FeL}] /\left[\mathrm{Fe}^{\prime}\right]\right) \times[\mathrm{L}]$. To obtain values for $[\mathrm{L}]$ and $\mathrm{K}^{\prime}{ }_{\mathrm{FeL}, \mathrm{Fe}}$, we used our calculated values for [Fe'] and [FeL] and analyzed them using a non-linear fitting 
program to fit the equation: $[\mathrm{FeL}]=\left([\mathrm{L}] \times\left[\mathrm{Fe}^{\prime}\right] \times \mathrm{Fe}^{\prime}{ }_{\mathrm{FeL}, \mathrm{Fe}^{\prime}}\right) /\left(1+\mathrm{K}^{\prime}{ }_{\mathrm{FeL}, \mathrm{Fe}}{ }^{\prime} \times\left[\mathrm{Fe}^{\prime}\right]\right)$. This method has been described by Wilkinson (1961) (Wilkinson, 1961) and Gerringa et. al (Gerringa et al., 1995). [FeL] was also plotted against [FeL]/[Fe'] to evaluate whether or not there was a two-ligand system at any station, which is indicated by two lines with different slopes when $[\mathrm{FeL}]$ is plotted against $[\mathrm{FeL}] /\left[\mathrm{Fe}^{\prime}\right]$. Station 16a was the only station where a two-ligand analysis seemed necessary based on plotting [FeL] verses $[\mathrm{FeL}] /\left[\mathrm{Fe}^{\prime}\right]$. Calculations at this station were done using the Scatchard linearization (Ruzic, 1982; van den Berg, 1982), where the linear regression of each of the lines from the $[\mathrm{FeL}]$ vs $[\mathrm{FeL}] /\left[\mathrm{Fe}^{\prime}\right]$ plot has a $\mathrm{x}$-intercept equal to $[\mathrm{L}]$ and a $y$-intercept equal to [L] $\times \mathrm{K}^{\prime}{ }_{\mathrm{FeL}, \mathrm{Fe}}$.

Once [L] and $\mathrm{K}^{\prime}{ }_{\mathrm{FeL}, \mathrm{Fe}}$ ' are determined either using the Scatchard linearization or the non-linear Wilkinson-Gerringa method, ambient [Fe'] and [FeL] from the initial sample can be calculated using the following two equations: $[\mathrm{Fe}]_{\text {natural }}=\left[\mathrm{Fe}^{\prime}\right]+[\mathrm{FeL}]$ and $\mathrm{K}_{\mathrm{FeL}, \mathrm{Fe}}^{\prime}=\left([\mathrm{FeL}] /\left[\mathrm{Fe}^{\prime}\right]\right) \times[\mathrm{L}]$.

\subsection{RESULTS}

A map of the stations from the Western Pacific Warm Pool (WPWP) cruise is show in Figure 1. In order to be able to compare data from different groups that publish data from this cruise, we have left the station numbers the same even though we do not have ligand data from all stations along the cruise.

The values for dissolved [Fe] (0.4 $\mu \mathrm{m}$ filtered Fe concentration), [L] (calculated ligand concentration), $\log _{10} \mathrm{~K}_{\mathrm{FeL}, \mathrm{Fe}}$ ' (binding constant of the ligand with respect to the inorganically bound fraction of $\mathrm{Fe}$ ) and [Fe'] (calculated inorganically bound $\mathrm{Fe}$ concentration) for the surface samples (15 m unless otherwise noted) are listed in Table 1. [Fe] values ranged from $0.09-1.4 \mathrm{nM}$ at the surface. Despite scrupulous cleaning of Niskin bottles prior to the beginning of the cruise, there is a possibility that the total $\mathrm{Fe}$ samples from the first four stations are erroneously high as a result of residual Fe leaching from the insides of the bottles. We believe this high Fe was washed out after the first few stations of the cruise. Because we suspect contamination of these samples, they have been left out of later analysis of the relationship between [Fe] and [L]. Station 17, which also had a high [Fe] of $0.95 \mathrm{nM}$ at $15 \mathrm{~m}$, was very close to one of the Vanuatu 
islands and we believe that the high $[\mathrm{Fe}]$ value recorded there was a result of $\mathrm{Fe}$ input from the islands and not contamination. [L] values ranged from $0.4-2.02 \mathrm{nM} \cdot \log _{10}$ $\mathrm{K}_{\mathrm{FeL}, \mathrm{Fe}}$, values ranged from $11.6-12.9$. At station 16a, there was evidence of two ligand classes with [L1] $=0.86 \mathrm{nM}$ with a $\log _{10} \mathrm{~K}_{\mathrm{FeL}, \mathrm{Fe}}=12.6$ and [L2] $=2.02 \mathrm{nM}$ with a $\log _{10}$ $\mathrm{K}_{\mathrm{FeL}, \mathrm{Fe}}=11.6$.

Depth profiles of [Fe] down to $500 \mathrm{~m}$ shown in Figure 2 for Station 14 (2A), Station 15 (2B) and Station 20 (2C) correspond to the values listed in Table 2. At all three stations, $[\mathrm{Fe}]$ is lowest in the surface waters above $100 \mathrm{~m}$ and then begins to rise around the $300 \mathrm{~m}$ sample. Figure 3 shows [Fe], [L] and [Fe'] (inorganically bound $\mathrm{Fe}$ ) for station 14 to a depth of $100 \mathrm{~m}$. While [L] varies with depth more than $[\mathrm{Fe}]$, it is clear that it always exceeds $[\mathrm{Fe}]$.

Figure 4 shows the relationship between [L] and [Fe] for samples where [Fe] $>$ $0.2 \mathrm{nM}$ and $[\mathrm{Fe}]<0.2 \mathrm{nM}$. The dashed line shows $[\mathrm{Fe}]=[\mathrm{L}]$. The solid line is the linear regression of $[\mathrm{L}]$ vs. $[\mathrm{Fe}]$ for the samples where $[\mathrm{Fe}]>0.2 \mathrm{nM}$. The equation for the line including error associated with each parameter is $[\mathrm{Fe}]=(0.54+/-0.09) \times[\mathrm{L}]+(0.01+/-$ $0.08)$. The $\mathrm{R}^{2}$ value for the relationship is 0.75 .

\subsection{DISCUSSION}

Given the importance of Fe to phytoplankton productivity, knowing the distribution of $\mathrm{Fe}$ in the surface oceans is imperative to understanding global primary production. While their source and composition remains unclear, organic ligands appear to play a key role in stabilizing Fe in the ocean as it is apparent that organic ligands complex $>99 \%$ of dissolved $\mathrm{Fe}$ in most of the ocean (Gledhill and van den Berg, 1994; Rue and Bruland, 1995; Wu and Luther, 1995). Because of the uncertainty regarding bioavailability of the Fe bound to these organic ligands (Hutchins et al., 1999; Maldonado and Price, 2001; Soria-Dengg et al., 2001; Achilles et al., 2003), it is important that we increase our understanding of ligand concentrations in the ocean. With this work, we have added to the growing dataset of oceanic ligand concentrations and dissolved Fe values, providing values for a region of the ocean that has been understudied with respect to trace metal geochemistry, the Western Pacific Warm Pool (WPWP). 
Excluding potentially contaminated Fe samples, our measured WPWP surface $[\mathrm{Fe}]$ (dissolved $<0.4 \mu \mathrm{m}$ Fe concentration) values ranging from $0.09-0.95 \mathrm{nM}$ (Table 1) are within range of what has been seen in other regions of the ocean (Johnson et al., 1997). With a few notable exceptions, our surface values were low, between $0.1-0.4$ $\mathrm{nM}$ (Table 1), and comparable with other recent measurements of dissolved Fe in surface samples from the South Pacific Ocean (R.F. Zhang and E. Boyle, personal communication). The exceptions to these low surface values are the first few stations of the transect after we left Hawaii (Stations 3-6), a station where we were in the midst of a surface slick of the $\mathrm{N}_{2}$-fixing cyanobacterium Trichodesmium (Station 16a) and two stations in the islands close to New Caledonia (Stations 17 and 19). The higher surface values at the start of the transect, $0.6-1.4 \mathrm{nM}$ for stations $3-6$, could be the result of deep winter mixing and a recent rain event in this region close to Hawaii. Alternatively, and potentially more likely given that these are higher than values we would expect as a result of deep mixing and recent time-series data suggesting that January is a time of particularly low Fe deposition to this area (Boyle et al., 2005), these values might be high as a result of residual Fe contamination leaching from the inside of the Niskin bottles at the beginning of the cruise despite rigorous acid-cleaning of the bottles on land in between cruises. The high values in the midst of the surface slick of Trichodesmium could indicate that the slick was the result of a bloom caused by an input of $\mathrm{Fe}$ to an $\mathrm{Fe}$ starved region. Alternatively, the surface slick could have been the result of a convergence of water masses bringing areas of moderate Trichodesmium biomass together, resulting in some accumulation of biomass near the surface where high light intensity bleached and killed the Trichodesmium. If the latter were the case, high Fe values could result from releases of cellular Fe as Trichodesmium cells burst. Another potential source of Fe could be the result of Trichodesmium biomass from a bloom, which may or may not have been caused by high Fe, being broken down by grazers and releasing cellular Fe. Both hypotheses involving cellular Fe release would also explain the ligand results from that station, which will be discussed later. The high Fe values close to the islands are in line with what others have found for the region (Campbell et al., 2005) and are potentially the result of river run-off and other coastal sources of Fe. Station 17, which had the higher Fe value, $0.95 \mathrm{nM}$, was also closer to an island than 
Station 19. Station 17 was less than $4 \mathrm{~km}$ away from land and had a bottom depth of only $350 \mathrm{~m}$. It is not as simple to attribute the slightly elevated value of $0.5 \mathrm{nM}$ at Station 19 to coastal influences as the bottom depth was $\sim 1400 \mathrm{~m}$ and the closest island was roughly $50 \mathrm{~km}$ away, though this is not of great concern as others have seen high values of $\mathrm{Fe}$ in oceanic surface samples from this region (Campbell et al., 2005). It appears surprising that Fe values in the surface waters of the southwestern Pacific Ocean are not that much lower than those observed in regions of the Atlantic Ocean given that the dust deposition to the Pacific Ocean is predicted to be so low (Duce and Tindale, 1991; Jickells, 1999; Wagener et al., 2008). Recent work looking at the annual cycle of Fe in surface waters near Hawaii indicates that Fe values in the surface of the Pacific might be high as result of a higher solubility of the dust deposited in the Pacific Ocean (Boyle et al., 2005), though at least during the period of peak dust deposition, this did not appear to be the case (Wu et al., 2007). Further study looking at the solubility of Fe in the South Pacific Ocean and the role that organic ligands play in controlling that solubility may help clarify questions about why Fe remains detectable in the surface waters despite low dust deposition.

Our profiles of [Fe] (Figure 2, Table 2) are typical of what is expected in the open ocean (Johnson et al., 1997). We found surface values around $0.2 \mathrm{nM}$ with a small nearsurface maximum in $\mathrm{Fe}$ that is potentially the result of atmospheric deposition of $\mathrm{Fe}$ that has not been completely been drawn down by scavenging and biological uptake (Bruland et al., 1994; Wu et al., 2001; Boyle et al., 2005). Below this near-surface Fe maximum, we find otherwise low $\mathrm{Fe}$ values in the upper $100 \mathrm{~m}$. When we look at the region of our profiles below $100 \mathrm{~m}$, we see that $[\mathrm{Fe}]$ rises in a typical "nutrient-type" distribution that has been observed in profiles from other areas of the Ocean (Bruland et al., 1994; Johnson et al., 1997). While it is apparent that $\mathrm{Fe}$ rises below the euphotic zone, it is no longer believed that there is one particular deep ocean value for Fe as was once hypothesized (Johnson et al., 1997). Our limited deep ocean data set has values that vary between $0.4 \mathrm{nM}$ and $0.7 \mathrm{nM}$ (Table 2), while other data from the North Pacific shows deep ocean dissolved Fe values around 0.4 nM (Bruland et al., 1994; Wu et al., 2001; Boyle et al., 2005). Profiles from a number of different ocean regions have shown that there is not just one deep ocean value for Fe, but rather the value can vary from $0.4 \mathrm{nM}$ to 
$1 \mathrm{nM}$ (Bruland et al., 1994; Wu et al., 2001; Boyle et al., 2005; Johnson et al., 2007) and is more likely influenced by the source of Fe to a given water mass.

Our results for ligand concentrations ([L]) ranging from $0.44 \mathrm{nM}-2.2 \mathrm{nM}$ and binding constants of ligands with respect to the inorganically complexed $\mathrm{Fe}\left(\mathrm{K}_{\mathrm{FeL}, \mathrm{Fe}}\right)$ ranging from $10^{11.6}-10^{12.9}$ are in line with the oceanic values that have been presented elsewhere in the literature, with [L] reported from $0.33-2.5 \mathrm{nM}$ and $\mathrm{K}_{\mathrm{Fe}, \mathrm{L}}$ from $10^{10.6}$ $10^{13.9}$ (Rue and Bruland, 1995; van den Berg, 1995; Rue and Bruland, 1997; Boye et al., 2001; Powell and Donat, 2001; Boye et al., 2003; Croot et al., 2004; Boye et al., 2005; Cullen et al., 2006; van den Berg, 2006; Buck and Bruland, 2007; Kondo et al., 2007; Kondo et al., 2008; Rijkenberg et al., 2008). There was only one station where it appeared that we observed at a two-ligand system, 16a, which was in the middle of a surface slick of the $\mathrm{N}_{2}$-fixing cyanobacterium Trichodesmium. There is considerable debate over the causes and status of Trichodesmium when they appear as these surface slicks, some of which were described above. Regardless of the cause, an accumulation of a large amount of biomass is likely to lead to a significant amount of grazing by copepods and viral or bacterial degradation of organic matter. It could be that a large amount of cell lysis in the patch resulted in the release of lower $\mathrm{K}_{\mathrm{Fe}, \mathrm{L}}$ "L2-type" ligands, which have been surmised to be porphyrins based on their lower conditional stability constants (Witter et al., 2000) and their predominance in deeper waters where the majority of organic matter degradation takes place (Hunter and Boyd, 2007). Further studies of ligand composition during and after phytoplankton blooms or in senescent cultures of phytoplankton in the laboratory could help determine if cell lysis is a significant potential source of L2 ligands.

Some studies have found a linear relationship between [Fe] and [L1] (Boye et al., 2003; Buck and Bruland, 2007; Buck et al., 2007). These relationships seem to work best on samples with higher Fe values and appear to break down completely at [Fe] values below $0.2 \mathrm{nM}$ (Buck and Bruland, 2007). When we exclude data from samples where Fe was below $0.2 \mathrm{nM}$ and the L2 ligand contribution to [L] from station 16a, we also get a linear relationship between [L] and [Fe] in our samples (Figure 4). The slope of the relationship for our data, 0.54, is lower than that determined by Buck and Bruland (2007), 0.69 , but the difference may have something to do with both our small data set and that 
the range of $[\mathrm{Fe}]$ for our samples is not as large. Another dataset from three marginal seas on the western boundary of the Pacific Ocean, exhibits a relationship closer to and sometimes above the $[\mathrm{Fe}]:[\mathrm{L}]=1: 1$ relationship (Kondo et al., 2007). Kondo et al (2007) hypothesize that one of the main reasons that different studies end up with varying relationships for $[\mathrm{Fe}]:[\mathrm{L}]$ could be the result of many diverse methods for determining [L], including the use of a variety of competitive ligands and quantitative analyses. Certainly, a comparison of different methodology would help determine if the varying linear relationships between $[\mathrm{L}]$ and $[\mathrm{Fe}]$ are the result of experimental differences or if they might be site specific. If these differences are site specific it could be indicative of varying ligand sources and should be studied further.

Recent reports demonstrate that there seems to be a significant amount of L1-type ligands (i.e., ligands with high binding constants) associated with the colloidal fraction of Fe (Wu et al., 2001; Boye et al., 2003; Cullen et al., 2006), but siderophores are generally low molecular weight molecules and as such would be expected to be associated with the $0.02 \mu \mathrm{m}$ fraction of Fe. Hunter and Boyd (2007) in their review of oceanic speciation data conclude that if L1 consists mainly of siderophores, those siderophores must become closely associated with colloidal Fe to explain their distribution. This conclusion could be supported by the close relationship between [L1] and [Fe] when [Fe] $>0.2 \mathrm{nM}$ (Buck and Bruland, 2007) (Figure 4) when viewed in light of recent work showing that most of the variation in dissolved Fe concentrations in the upper ocean is associated with the colloidal fraction of $\mathrm{Fe}$ and that while the $<0.02 \mu \mathrm{m}$ fraction of Fe shows some variability, it is almost never above $0.4 \mathrm{nM}$ (Bergquist et al., 2007). If the dissolved [Fe] $>0.2 \mathrm{nM}$ is predominantly colloidal, as that work suggests, then the linear relationship between [L] and [Fe] at higher Fe values indicates that L1 is associated with colloids. It could be that the association with colloidal Fe is what keeps L1 ligands, whether they are siderophores or not, at such high values throughout the oceans, despite the fact that they might not be produced everywhere.

While our results are within the range of [L] values that have been observed in the open ocean, with most of our values below $1 \mathrm{nM}$ they appear low when compared with the [L] values in the Atlantic Ocean (Witter and Luther, 1998; Powell and Donat, 2001; Boye et al., 2003; Cullen et al., 2006; Rijkenberg et al., 2008) or Northeastern Pacific 
(van den Berg, 1995; van den Berg, 2006; Buck and Bruland, 2007). The lower values for [L] that we observed in the Pacific gyre could be a result of the low dust deposition, which is predicted for this area (Duce and Tindale, 1991; Jickells, 1999; Wagener et al., 2008). In fact, they are comparable to the values in other low dust deposition regions like the Southern Ocean (Boye et al., 2001; Boye et al., 2005; Gerringa et al., 2008) and other regions of the Pacific Ocean (Rue and Bruland, 1995; Rue and Bruland, 1997; Kondo et al., 2007; Kondo et al., 2008). The hypothesis that ligands are produced in response to Fe inputs is based on the number of studies that have shown an increase in ligands following mesoscale addition of Fe to surface waters (Rue and Bruland, 1997; Boye et al., 2005; Kondo et al., 2008). If ligands are produced in response to Fe inputs, then one of the lower dust input regions of the ocean would be expected to have low ligand production values. In addition to potentially low production values, another facet to consider is the destruction of ligands by UV light. While the photodestruction of many siderophores is generally accepted (Barbeau et al., 2003), there is some debate about the photoreactivity of all oceanic ligands (Barbeau, 2006). Two studies on ligands from natural waters show conflicting results, with one group seeing a reduction in ligands in response to UV light (Powell and Wilson-Finelli, 2003) and another seeing no reduction (Rijkenberg et al., 2006). A study looking at the speciation of Fe in samples of surface waters $(<2 \mathrm{~m})$ saw a reduction in ligands in those waters that receive the most UV irradiation (Powell and Donat, 2001). A recent review of ligand photochemistry suggests that the reduction in siderophore-like ligands in the Rijkenberg study could have been masked by a large amount of colloidal Fe (Barbeau, 2006). Considering the dominance of colloidal Fe in the ocean and its association with L, it could be this protection from UV degradation that keeps L that is associated with colloidal Fe at high levels in the surface ocean. This also might explain why the fraction of $L$ that is associated with lower Fe waters $(<0.2 \mathrm{nM})$ is not related to Fe levels, because ligands that are not associated with colloidal Fe may be more susceptible to UV degradation. Future studies, looking at the effects of UV on the ligand composition of ultrafiltered $(<0.02 \mu \mathrm{m})$ seawater samples could help answer these questions. Alternatively, it could be that the siderophores that persist in areas of high UV penetration are those that are not susceptible to UV degredation, such as the ferrioxamine 
siderophores (Barbeau et al., 2003), which appear to be dominant in the Atlantic Ocean (Mawji et al., 2008).

While questions remain regarding the source and composition of ligands in the open ocean, it is clear that organic ligands are ubiquitous and play a key role in stabilizing dissolved Fe in the ocean. In this study, we have shown that ligands are prevalent even in the low Fe waters of the Western Pacific ocean and have found that the relationship between $[\mathrm{L}]$ and $[\mathrm{Fe}]$ is similar to that of other regions of the open ocean. The data presented here is an addition to the growing datasets of dissolved $\mathrm{Fe}$ and $\mathrm{Fe}$ speciation in the ocean, covering a region where few measurements have been made.

\subsection{ACKNOWLEDGEMENTS}

The authors would like to thank chief scientists Zachary Johnson and Erik Zinser and the captain and crew of the R/V Kilo Moana cruise KM0701. We also wish to thank Tyler Goepfert, Dan Ohnemus and Andrew Rose for assistance with sample collection and Dave Schneider of the WHOI Plasma Mass Spectrometry Facility for assistance with sample processing. This work was funded by the NSF Chemical Oceanography Program grant OCE-0623499 to J.W.M. Funding for P.D.C was supplied by the Woods Hole Oceanographic Institution Academic Programs Office and a National Defense Science and Engineering Graduate Fellowship. 
Table 1. Dissolved Fe, organic Fe-binding ligand concentrations, conditional stability constants and calculated free inorganic Fe for $<0.4 \mu \mathrm{m}$ filtered samples

\begin{tabular}{ccccccccc}
\hline Station & $\begin{array}{c}\text { Depth } \\
(\mathrm{m})\end{array}$ & Latitude & Longitude & {$[\mathrm{Fe}](\mathrm{nM})$} & $\begin{array}{c}\text { Ligand } \\
\text { Class }\end{array}$ & {$[\mathrm{L}](\mathrm{nM})$} & $\log _{10} \mathrm{~K}$ & $\begin{array}{c}{\left[\mathrm{Fe} \mathrm{e}^{\prime}\right]} \\
(\mathrm{pM})\end{array}$ \\
\hline \hline 3 & 15 & 19.53 & -159.90 & $0.70+/-0.05 *$ & & & & \\
4 & 15 & 17.38 & -162.44 & $0.95+/-0.04 *$ & L1 & $1.06+/-0.02$ & 12.5 & 2.64 \\
5 & 15 & 14.96 & -165.05 & $1.40+/-0.05 *$ & L1 & $1.40+/-0.06$ & 12.9 & 12.09 \\
6 & 15 & 12.43 & -167.73 & $0.63+/-0.03^{*}$ & & & & \\
7 & 15 & 7.88 & -172.34 & $0.16+/-0.02$ & & & & \\
8 & 15 & 5.65 & -174.53 & $0.41+/-0.03$ & & & & \\
9 & 15 & 3.24 & -176.88 & $0.21+/-0.02$ & L1 & $0.53+/-0.03$ & 12.3 & 0.33 \\
10 & 15 & 0.37 & -179.64 & $0.11+/-0.04$ & L1 & $0.38+/-0.09$ & 12.0 & 0.26 \\
11 & 15 & -2.30 & 177.44 & $0.11+/-0.04$ & L1 & $0.79+/-0.06$ & 11.8 & 0.26 \\
12 & 15 & -4.72 & 174.73 & $0.28+/-0.11$ & L1 & $0.52+/-0.06$ & 12.0 & 1.00 \\
13 & 15 & -7.07 & 172.31 & $0.31+/-0.11$ & L1 & $0.44+/-0.08$ & 11.9 & 2.80 \\
14 & 15 & -9.25 & 170.00 & $0.20+/-0.04$ & L1 & $1.57+/-0.10$ & 11.8 & 0.22 \\
14 & 25 & & & $0.24+/-0.02$ & L1 & $0.59+/-0.06$ & 12.1 & 0.56 \\
14 & 50 & & & $0.18+/-0.01$ & L1 & $0.88+/-0.14$ & 11.9 & 0.24 \\
14 & 100 & & & $0.16+/-0.01$ & L1 & $0.57+/-0.10$ & 11.6 & 1.04 \\
15 & 15 & -12.58 & 169.86 & $0.11+/-0.03$ & L1 & $1.07+/-0.10$ & 11.7 & 0.20 \\
16 & 15 & -15.89 & 169.72 & $0.29+/-0.03$ & & & & \\
$16 \mathrm{a}$ & 7 & -15.98 & 169.77 & $0.63+/-0.02$ & L1 & $0.85+/-0.00$ & 12.6 & 0.41 \\
& & & & & L2 & $2.02+/-0.59$ & 11.6 & \\
17 & 15 & -19.22 & 169.57 & $0.95+/-0.02$ & L1 & $1.52+/-0.06$ & 12.5 & 0.55 \\
19 & 15 & -21.62 & 168.66 & $0.50+/-0.08$ & L1 & $1.06+/-0.09$ & 12.5 & 0.28 \\
20 & 15 & -25.67 & 165.42 & $0.09+/-0.02$ & L1 & $0.38+/-0.04$ & 11.7 & 0.69 \\
21 & 15 & -29.04 & 164.34 & $0.24+/-0.02$ & L1 & $0.62+/-0.03$ & 12.8 & 0.10 \\
22 & 15 & -31.92 & 163.36 & $0.21+/-0.08$ & & & & \\
23 & 15 & -34.16 & 162.55 & $0.29+/-0.02$ & & & & \\
24 & 15 & -36.17 & 161.79 & $0.19+/-0.02$ & & & & \\
25 & 15 & -34.23 & 160.35 & $0.21+/-0.03$ & L1 & $0.93+/-0.04$ & 12.3 & 0.31 \\
26 & 15 & -32.42 & 159.09 & $0.20+/-0.02$ & L1 & $0.86+/-0.03$ & 12.6 & 0.07 \\
28 & 15 & -30.26 & 157.30 & $0.51+/-0.12$ & L1 & $0.81+/-0.04$ & 12.2 & 0.96 \\
29 & 15 & -29.76 & 156.62 & $0.41+/-0.00$ & & & & \\
30 & 15 & -28.76 & 155.37 & $0.32+/-0.11$ & L1 & $0.49+/-0.03$ & 12.8 & 0.33 \\
\hline 0516 & & & & & & &
\end{tabular}

*possible Fe contamination 
Table 2. Dissolved $(<0.4 \mu \mathrm{m}$

filtered) Fe with depth

Standard

Station Depth (m) [Fe] (nM) Deviation

\begin{tabular}{cccc}
\hline \hline 14 & 15 & 0.20 & 0.04 \\
14 & 25 & 0.24 & 0.02 \\
14 & 50 & 0.18 & 0.01 \\
14 & 100 & 0.16 & 0.01 \\
14 & 150 & 0.07 & 0.00 \\
14 & 300 & 0.11 & 0.03 \\
14 & 500 & 0.71 & 0.00 \\
15 & 15 & 0.09 & 0.00 \\
15 & 25 & 0.26 & 0.05 \\
15 & 50 & 0.09 & 0.00 \\
15 & 75 & 0.11 & 0.00 \\
15 & 100 & 0.06 & 0.01 \\
15 & 150 & 0.07 & 0.01 \\
15 & 300 & 0.35 & 0.04 \\
15 & 500 & 0.52 & 0.01 \\
20 & 15 & 0.09 & 0.02 \\
20 & 25 & 0.37 & 0.00 \\
20 & 50 & 0.04 & 0.00 \\
20 & 75 & 0.07 & 0.01 \\
20 & 100 & 0.05 & 0.00 \\
20 & 150 & 0.08 & 0.01 \\
20 & 300 & 0.19 & 0.01 \\
20 & 500 & 0.40 & 0.03 \\
\hline
\end{tabular}




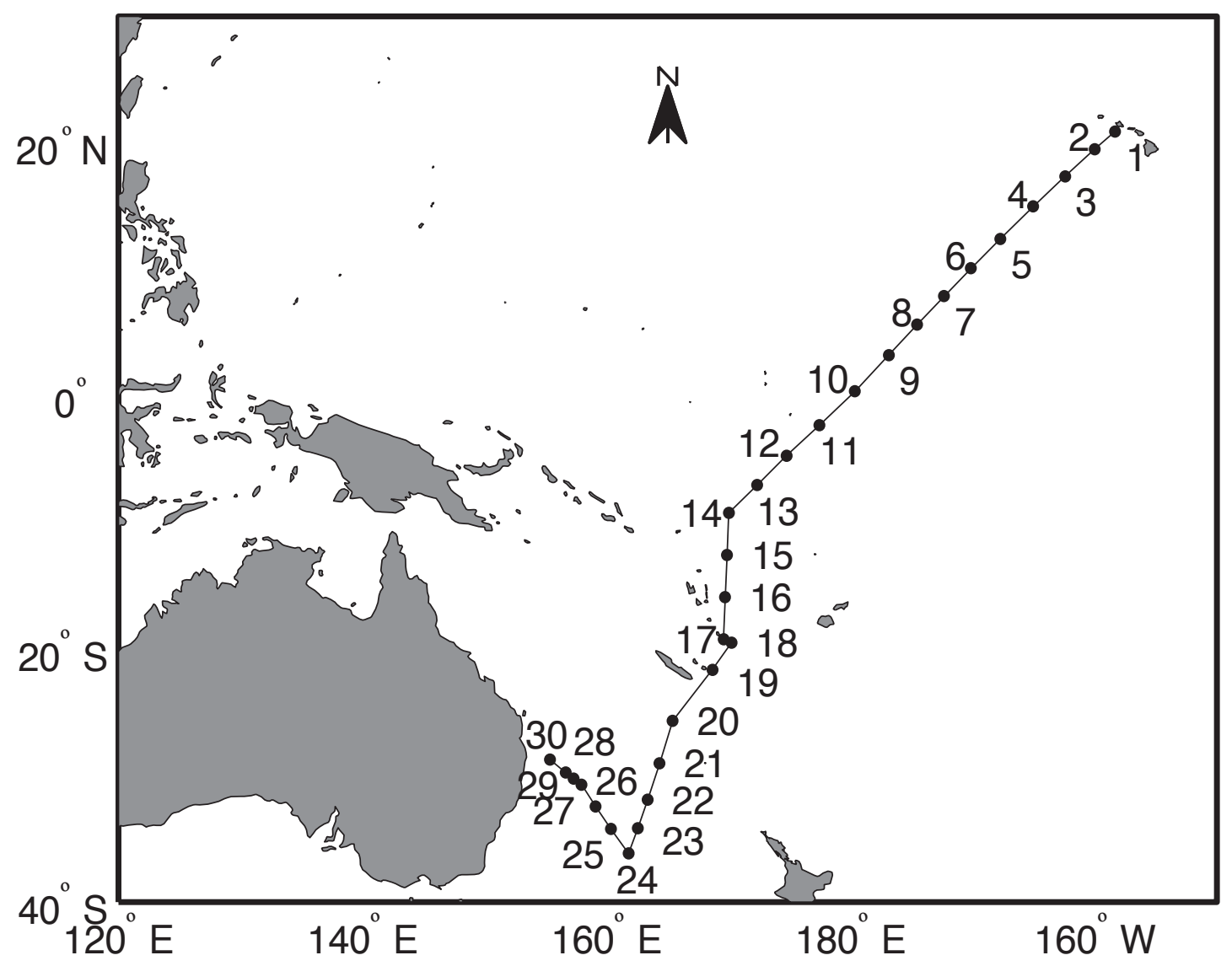

Figure 1. Map of sampling stations from the Western Pacific Warm Pool cruise (KM0701) on the R/V Kilo Moana. 


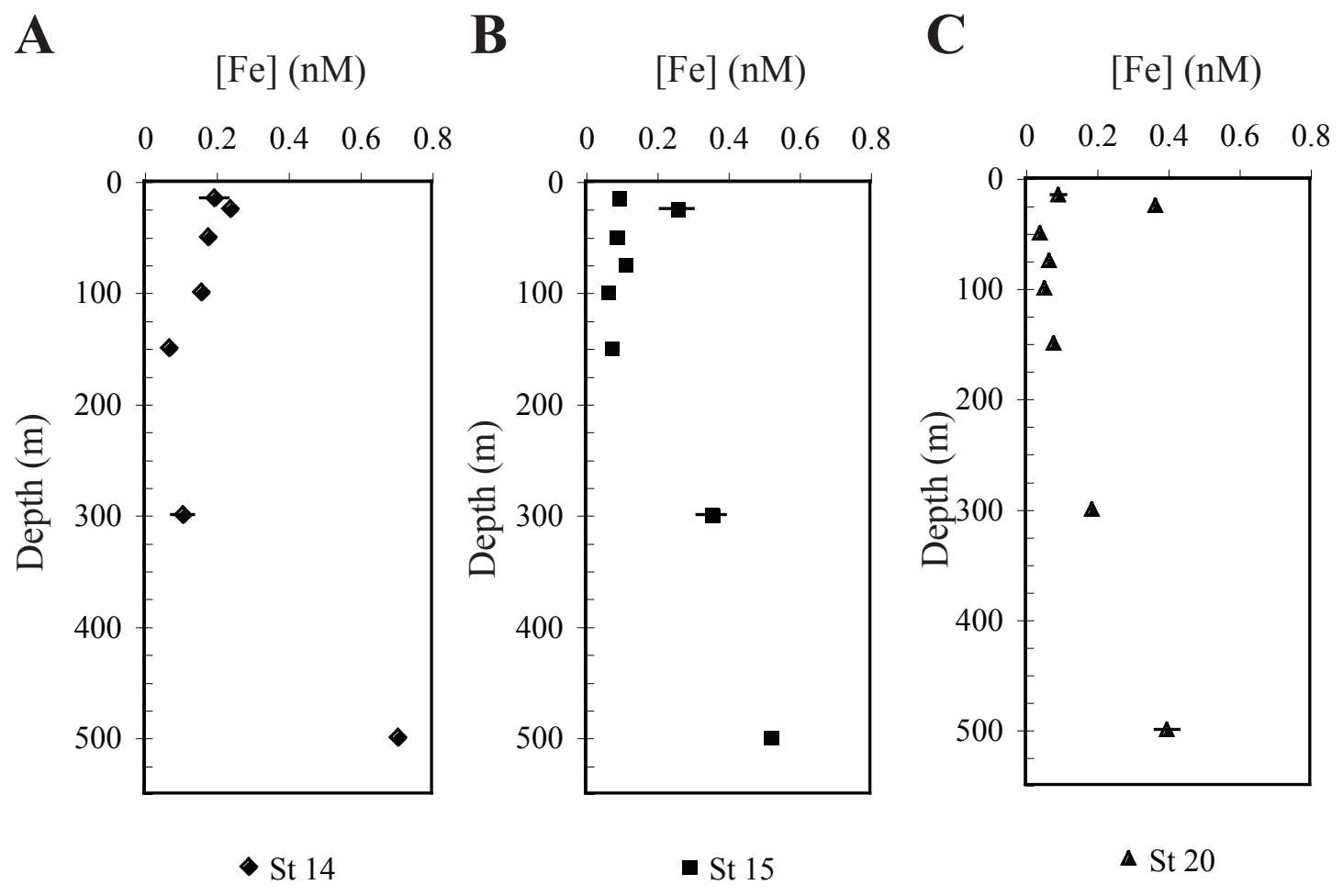

Figure 2. Dissolved $\mathrm{Fe}(<0.4 \mu \mathrm{m}$ filtered $)$ depth profiles from three stations along the cruise track. (A) Station 14. (B) Station 15. (C) Station 20. Error bars are standard deviations of triplicate analyses. 


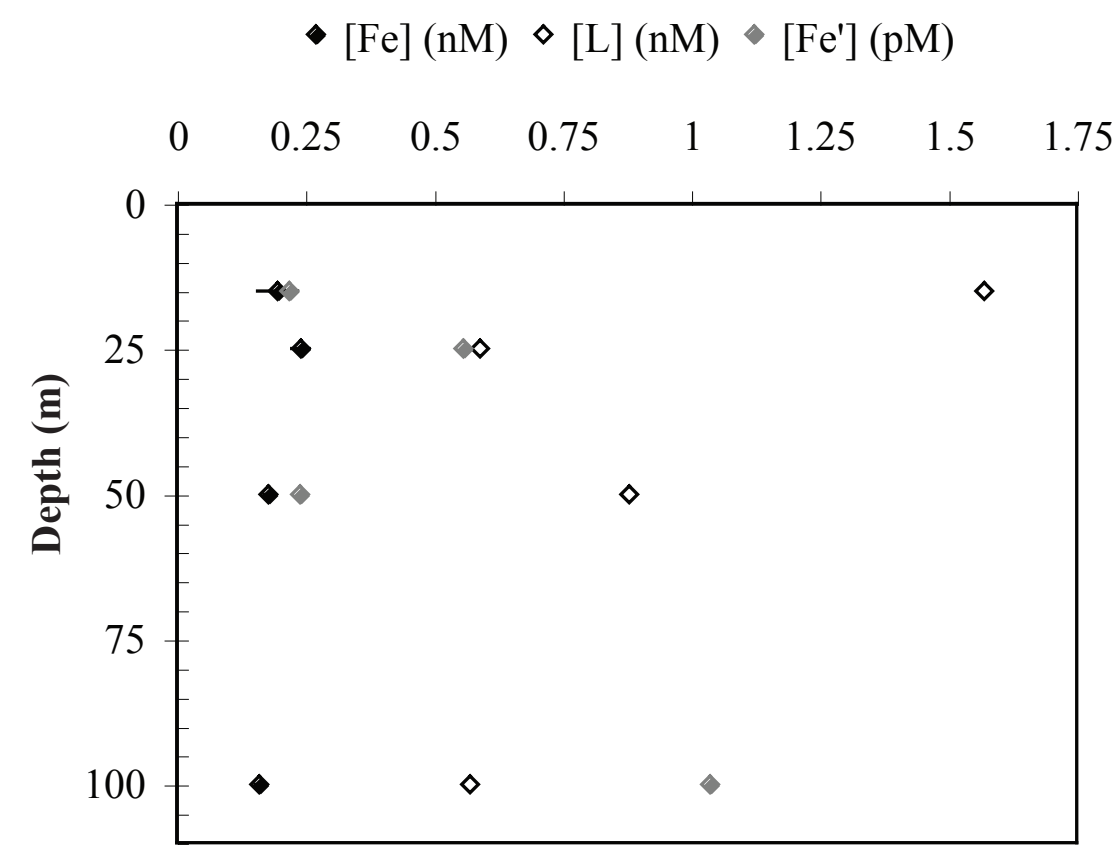

Figure 3. Dissolved Fe ([Fe]), inorganically bound $\mathrm{Fe}([\mathrm{Fe}$ '] $]$ )and organic ligand ([L]) concentrations at Station 14 up to $100 \mathrm{~m}$ depth. Dissolved Fe and the organic ligand concentrations are plotted on a nM scale while inorganically bound $\mathrm{Fe}$ is plotted on a pM scale. 


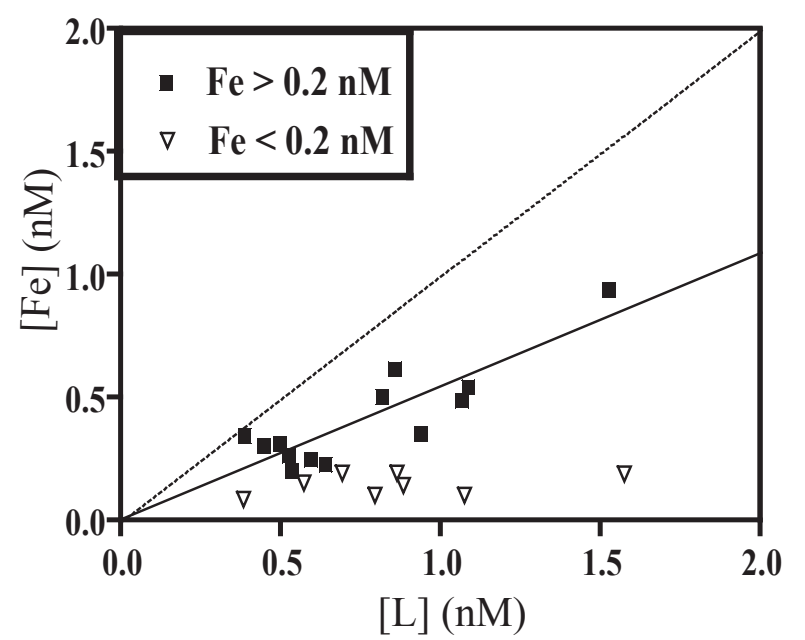

Figure 4. The concentration of dissolved $\mathrm{Fe}$ as it relates to ligand concentrations. The solid triangles are for samples where $[\mathrm{Fe}]>0.2 \mathrm{nM}$ and the open triangles are samples where $[\mathrm{Fe}]<$ $0.2 \mathrm{nM}$. The dashed line represents $1: 1=$ [Fe]:[L]. The solid line is the linear regression of $[\mathrm{Fe}]$ vs $[\mathrm{L}]$ when $[\mathrm{Fe}]>0.2 \mathrm{nM}$ (solid triangles). 


\subsection{REFERENCES}

Achilles, K.M., Church, T.M., Wilhelm, S.W., Luther, G.W., and Hutchins, D.A. (2003) Bioavailability of iron to Trichodesmium colonies in the western subtropical Atlantic Ocean. Limnol Oceanogr 48: 2250-2255.

Barbeau, K. (2006) Photochemistry of organic iron(III) complexing ligands in oceanic systems. Photochem Photobiol 82: 1505-1516.

Barbeau, K., Rue, E.L., Trick, C.G., Bruland, K.T., and Butler, A. (2003) Photochemical reactivity of siderophores produced by marine heterotrophic bacteria and cyanobacteria based on characteristic Fe(III) binding groups. Limnol Oceanogr 48: 1069-1078.

Bennett, S.A., Achterberg, E.P., Connelly, D.P., Statharn, P.J., Fones, G.R., and German, C.R. (2008) The distribution and stabilisation of dissolved Fe in deep-sea hydrothermal plumes. Earth Planet Sc Lett 270: 157-167.

Bergquist, B.A., Wu, J., and Boyle, E.A. (2007) Variability in oceanic dissolved iron is dominated by the colloidal fraction. Geochim Cosmochim Ac 71: 2960-2974.

Blanchot, J., Andre, J.M., Navarette, C., and Neveux, J. (1997) Picophytoplankton dynamics in the equatorial Pacific: diel cycling from flow-cytometer observations. $\mathrm{Cr}$ Acad Sci Iii-vie 320: 925-931.

Boyd, P.W., Jickells, T., Law, C.S., Blain, S., Boyle, E.A., Buesseler, K.O. et al. (2007) Mesoscale iron enrichment experiments 1993-2005: Synthesis and future directions. Science 315: 612-617.

Boye, M., Aldrich, A.P., van den Berg, C.M.G., de Jong, J.T.M., Veldhuis, M., and de Baar, H.J.W. (2003) Horizontal gradient of the chemical speciation of iron in surface waters of the northeast Atlantic Ocean. Mar Chem 80: 129-143-PII S03044203(02)00102-0.

Boye, M., Nishioka, J., Croot, P.L., Laan, P., Timmermans, K.R., and de Baar, H.J.W. (2005) Major deviations of iron complexation during 22 days of a mesoscale iron enrichment in the open Southern Ocean. Mar Chem 96: 257-271.

Boye, M., van den Berg, C.M.G., de Jong, J.T.M., Leach, H., Croot, P., and de Baar, H.J.W. (2001) Organic complexation of iron in the Southern Ocean. Deep Sea Research 48: 1477-1497.

Boyle, E.A., Bergquist, B.A., Kayser, R.A., and Mahowald, N. (2005) Iron, manganese, and lead at Hawaii Ocean Time-series station ALOHA: Temporal variability and an intermediate water hydrothermal plume (vol 69, pg 933, 2005). Geochim Cosmochim Ac 69: $5165-5166$.

Bruland, K.W., Orians, K.J., and Cowen, J.P. (1994) Reactive Trace-Metals in the Stratified Central North Pacific. Geochim Cosmochim Ac 58: 3171-3182.

Buck, K.N., and Bruland, K.W. (2007) The physicochemical speciation of dissolved iron in the Bering Sea, Alaska. Limnol Oceanogr 52: 1800-1808. 
Buck, K.N., Lohan, M.C., Berger, C.J.M., and Bruland, K.W. (2007) Dissolved iron speciation in two distinct river plumes and an estuary: Implications for riverine iron supply. Limnol Oceanogr 52: 843-855.

Campbell, L., Carpenter, E.J., Montoya, J.P., Kustka, A.B., and Capone, D.G. (2005) Picoplankton community structure within and outside a Trichodesmium bloom in the southwestern Pacific Ocean. Vie Milieu 55: 185-195.

Croot, P.L., Andersson, K., Ozturk, M., and Turner, D.R. (2004) The distribution and specification of iron along 6 degrees E in the Southern Ocean. Deep-sea Res Pt Ii 51: 2857-2879.

Cullen, J.T., Bergquist, B.A., and Moffett, J.W. (2006) Thermodynamic characterization of the partitioning of iron between soluble and colloidal species in the Atlantic Ocean. Mar Chem 98: 295-303.

Duce, R.A., and Tindale, N.W. (1991) Atmospheric Transport of Iron and its Deposition in the Ocean. Limnol Oceanogr 36: 1715-1726.

Dupouy, C., Petit, M., and Dandonneau, Y. (1988) Satellite Detected Cyanobacteria Bloom in the Southwestern Tropical Pacific - Implication for Oceanic Nitrogen-Fixation. Int J Remote Sens 9: 389-396.

Falkowski, P.G., Barber, R.T., and Smetacek, V. (1998) Biogeochemical controls and feedbacks on ocean primary production. Science 281: 200-206.

Gerringa, L.J.A., Blain, S., Laan, P., Sarthou, G., Veldhuis, M.J.W., Brussaard, C.P.D. et al. (2008) Fe-binding dissolved organic ligands near the Kerguelen Archipelago in the Southern Ocean (Indian sector). Deep-sea Res Pt Ii 55: 606-621.

Gerringa, L.J.A., Herman, P.M.J., and Poortvliet, T.C.W. (1995) Comparison of the Linear van den Berg Ruzic Transformation and a Nonlinear Fit of the Langmuir Isotherm Applied to CU Speciation Data in the Estuarine Environment. Mar Chem 48: 131-142.

Gledhill, M., and van den Berg, C.M.G. (1994) Determination of Complexation of Iron(III) with Natural Organic Complexing Ligands in Seawater Using Cathodic Stripping Voltammetry. Mar Chem 47: 41-54.

Hunter, K.A., and Boyd, P.W. (2007) Iron-binding ligands and their role in the ocean biogeochemistry of iron. Environ Chem 4: 221-232.

Hutchins, D.A., Witter, A.E., Butler, A., and Luther, G.W., III (1999) Competition among marine phytoplankton for different chelated iron species. Nature 400: 858-861.

Ito, Y., and Butler, A. (2005) Structure of synechobactins, new siderophores of the marine cyanobacterium Synechococcus sp PCC 7002. Limnol Oceanogr 50: 1918-1923.

Jickells, T.D. (1999) The inputs of dust derived elements to the Sargasso Sea: A synthesis. Mar Chem 68: 5-14.

Johnson, K.S., Boyle, E., Bruland, K.W., Coale, K.H., Measures, C.I., Moffett, J.W. et al. (2007) Developing Standards for Dissolved Iron in Seawater. EOS 88: 131-132. 
Johnson, K.S., Gordon, R.M., and Coale, K.H. (1997) What controls dissolved iron concentrations in the world ocean? Mar Chem 57: 137-161.

Kondo, Y., Takeda, S., and Furuya, K. (2007) Distribution and speciation of dissolved iron in the Sulu Sea and its adjacent waters. Deep-sea Res Pt Ii 54: 60-80.

Kondo, Y., Takeda, S., Nishioka, J., Obata, H., Furuya, K., Johnson, W.K., and Wong, C.S. (2008) Organic iron(III) complexing ligands during an iron enrichment experiment in the western subarctic North Pacific. Geophys Res Lett 35: ARTN L12601.

Lewis, B.L., Holt, P.D., Taylor, S.W., Wilhelm, S.W., Trick, C.G., Butler, A., and Luther, G.W., III (1995) Voltammetric estimation of iron(III) thermodynamic stability constants for catecholate siderophores isolated from marine bacteria and cyanobacteria. Mar Chem 50: 179-188.

Liu, X.W., and Millero, F.J. (2002) The solubility of iron in seawater. Mar Chem 77: 4354.

Macrellis, H.M., Trick, C.G., Rue, E.L., Smith, G., and Bruland, K.W. (2001) Collection and detection of natural iron-binding ligands from seawater. Mar Chem 76: 175-187.

Maldonado, M.T., and Price, N.M. (2001) Reduction and transport of organically bound iron by Thalassiosira oceanica (Bacillariophyceae). J Phycol 37: 298-309.

Martin, J.H., Gordon, R.M., and Fitzwater, S.E. (1991) The Case for Iron.

LimnolOceanogr 36: 1793-1802.

Martin, J.H., and Fitzwater, S.E. (1988) Iron-Deficiency Limits Phytoplankton Growth in the Northeast Pacific Subarctic. Nature 331: 341-343.

Martin, J.H., Gordon, R.M., and Fitzwater, S.E. (1990) Iron in Antarctic Waters. Nature 345: $156-158$.

Matsumoto, K., and Ando, K. (2009) Use of cyanobacterial pigments to characterize the ocean surface mixed layer in the western Pacific warm pool. J Marine Syst 75: 245-252.

Mawji, E., Gledhill, M., Milton, J.A., Tarran, G.A., Ussher, S., Thompson, A. et al. (2008) Hydroxamate Siderophores: Occurrence and Importance in the Atlantic Ocean. Environ Sci Technol 42: 8675-8680.

Morel, F.M.M., Hudson, R.J.M., and Price, N.M. (1991) Limitation of productivity by trace metals in the sea. Limnology and Oceanography [Limnol Oceanogr] 36: 17421755.

Neveux, J., Tenorio, M.M.B., Dupouy, C., and Villareal, T.A. (2006) Spectral diversity of phycoerythrins and diazotroph abundance in tropical waters. Limnol Oceanogr 51: 1689-1698.

Obata, H., Shitashima, K., Isshik, K., and Nakayama, E. (2008) Iron, manganese and aluminum in upper waters of the western South Pacific ocean and its adjacent seas. $J$ Oceanogr 64: 233-245. 
Powell, R.T., and Donat, J.R. (2001) Organic complexation and speciation of iron in the South and Equatorial Atlantic. Deep-sea Res Pt Ii 48: 2877-2893.

Powell, R.T., and Wilson-Finelli, A. (2003) Photochemical degradation of organic iron complexing ligands in seawater. Aquat Sci 65: 367-374.

Rijkenberg, M.J.A., Gerringa, L.J.A., Velzeboer, I., Timmermans, K.R., Buma, A.G.J., and de Baar, H.J.W. (2006) Iron-binding ligands in Dutch estuaries are not affected by UV induced photochemical degradation. Mar Chem 100: 11-23.

Rijkenberg, M.J.A., Powell, C.F., Dall'Osto, M., Nielsdottir, M.C., Patey, M.D., Hill, P.G. et al. (2008) Changes in iron speciation following a Saharan dust event in the tropical North Atlantic Ocean. Mar Chem 110: 56-67.

Rodier, M., and Le Borgne, R. (2008) Population dynamics and environmental conditions affecting Trichodesmium spp. (filamentous cyanobacteria) blooms in the south-west lagoon of New Caledonia. J Exp Mar Biol Ecol 358: 20-32.

Rue, E.L., and Bruland, K.W. (1995) Complexation of iron(III) by natural organic ligands in the Central North Pacific as determined by a new competitive ligand equilibration/adsorptive cathodic stripping voltammetric method. Mar Chem 50: 117-138.

Rue, E.L., and Bruland, K.W. (1997) The role of organic complexation on ambient iron chemistry in the equatorial Pacific Ocean and the response of a mesoscale iron addition experiment. Limnol Oceanogr 42: 901-910.

Ruzic, I. (1982) Theoretical Aspects of the Direct Titration of Natural-Waters and its Information Yield for Trace-Metal Speciation. Anal Chim Acta 140: 99-113.

Saito, M.A., and Schneider, D.L. (2006) Examination of precipitation chemistry and improvements in precision using the $\mathrm{Mg}(\mathrm{OH})(2)$ preconcentration inductively coupled plasma mass spectrometry (ICP-MS) method for high-throughput analysis of open-ocean Fe and Mn in seawater. Anal Chim Acta 565: 222-233.

Soria-Dengg, S., Reissbrodt, R., and Horstmann, U. (2001) Siderophores in marine, coastal waters and their relevance for iron uptake by phytoplankton: experiments with the diatom Phaeodactylum tricornutum. Mar Ecol-prog Ser 220: 73-82.

van den Berg, C.M.G. (1982) Determination of Copper Complexation with Natural Organic-Ligands in Sea-Water by Equilibration with $\mathrm{MnO}_{2}$. Mar Chem 11: 307-322.

van den Berg, C.M.G. (1995) Evidence for Organic Complexation of Iron in Seawater. Mar Chem 50: 139-157.

van den Berg, C.M.G. (2006) Chemical speciation of iron in seawater by cathodic stripping voltammetry with dihydroxynaphthalene. Anal Chem 78: 156-163.

Wagener, T., Guieu, C., Losno, R., Bonnet, S., and Mahowald, N. (2008) Revisiting atmospheric dust export to the Southern Hemisphere ocean: Biogeochemical implications. Global Biogeochem Cy 22: ARTN GB2006. 
Wilhelm, S.W., and Trick, C.G. (1994) Iron-limited growth of cyanobacteria: Multiple siderophore production is a common response. Limnol Oceanogr 39: 1979-1984.

Wilkinson, G.N. (1961) Statistical estimations in enzyme kinetics. Biochemistry Journal 30: 324-332.

Witter, A.E., Hutchins, D.A., Butler, A., and Luther, G.W. (2000) Determination of conditional stability constants and kinetic constants for strong model Fe-binding ligands in seawater. Mar Chem 69: 1-17.

Witter, A.E., and Luther, G.W. (1998) Variation in Fe-organic complexation with depth in the Northwestern Atlantic Ocean as determined using a kinetic approach. Mar Chem 62: 241-258.

Wu, J., Rember, R., and Cahill, C. (2007) Dissolution of aerosol iron in the surface waters of the North Pacific and North Atlantic oceans as determined by a semicontinuous flow-through reactor method. Global Biogeochem Cy 21: ARTN GB4010.

Wu, J., Boyle, E., Sunda, W., and Wen, L. (2001) Soluble and colloidal iron in the oligotrophic North Atlantic and North Pacific. Science 293: 847-849.

$\mathrm{Wu}, \mathrm{J}$., and Boyle, E.A. (1998) Determination of trace levels of iron in seawater by isotope dilution high resolution ICPMS. Anal Chim Acta 267: 183-191.

Wu, J., and Luther, G.W., III (1995) Complexation of Fe(III) by natural organic ligands in the Northwest Atlantic Ocean by a competitive ligand equilibration method and a kinetic approach. Mar Chem 50: 159-177. 
Chapter 3. A Molecular Assessment of the Iron Stress Response in the Two

Phylogenetic Clades of Trichodesmium

\author{
P. Dreux Chappel1 ${ }^{1,2}$ and Eric A. Webb ${ }^{3 *}$ \\ ${ }^{1}$ MIT-WHOI Joint Program in Oceanography/Applied Ocean Science and Engineering \\ ${ }^{2}$ Department of Marine Chemistry and Geochemistry, Woods Hole Oceanographic \\ Institution, Woods Hole, MA 02543 \\ ${ }^{3}$ Department of Biological Sciences \\ Marine Environmental Biology \\ University of Southern California \\ 3616 Trousdale Parkway \\ Los Angeles, CA 90089-0371 \\ *Corresponding author (eawebb@usc.edu)
}

Submitted to Environmental Microbiology 


\subsection{Abstract}

Trichodesmium spp. play key roles in global carbon and nitrogen budgets and thus understanding what controls their activity is important for understanding climate change. While iron (Fe) availability has been shown to be an important chemical factor for controlling both growth and nitrogen fixation rates in Trichodesmium, all culture experiments to date have focused solely on representatives from one clade of Trichodesmium. Genomic sequence analysis determined that the T. erythraeum (IMS101) genome contains many of the archetypical genes involved in the prokaryotic iron stress response. Focusing on three of these genes, isiB, idiA, and $f e o B$, we found that all three showed an Fe stress response in axenic T. erythraeum (IMS101), and their sequences were well-conserved across four species in our Trichodesmium culture collection (consisting of two T. erythraeum strains (IMS101 and GBRTRLI101), two Trichodesmium tenue strains (Z-1 and H9-4), Trichodesmium thiebautii and Trichodesmium spiralis). With clade-specific quantitative PCR (QPCR) primers for one of these genes, $i s i B$, we found that high $i s i B$ expression at low Fe levels corresponded to specific reductions in $\mathrm{N}_{2}$ fixation rates in both major phylogenetic clades of

Trichodesmium (the T. erythraeum clade and T. tenue clade). With regard to the two clades, the most significant difference determined was temperature optima, while more subtle differences in growth, $\mathrm{N}_{2}$ fixation rate and gene expression responses to Fe stress were also observed. However the apparent conservation of the Fe stress response in the Trichodesmium genus suggests that it is an important adaptation for success in the oligotrophic ocean.

\subsection{INTRODUCTION}

Primary producers play important roles in controlling both the oceanic food chain and the overall biogeochemistry of the ocean. Open-ocean diazotrophic cyanobacteria, such as Trichodesmium spp. and Crocosphaera watsonii, are of particular interest to researchers studying global biogeochemical cycles, due to their contribution to both the 
carbon (C) cycle via primary production and to the nitrogen $(\mathrm{N})$ cycle because of their ability to fix $\mathrm{N}_{2}$ (Capone, 2001; Montoya et al., 2004). The "new" N, N that has not been regenerated from degradation of organic matter in the mixed layer, produced by these cyanobacteria is vital to the $\mathrm{N}$ and $\mathrm{C}$ cycles on regional (Zehr et al., 2001), and global scales (Capone et al., 1997; Gruber and Sarmiento, 1997), as well as potentially influencing $\mathrm{CO}_{2}$ sequestration over geologic time-scales (Capone et al., 1997; Falkowski, 1997; Gruber and Sarmiento, 1997). $\mathrm{N}_{2}$-fixing cyanobacteria are thought to have evolved in an anoxic ocean where iron $(\mathrm{Fe})$ was readily available as $\mathrm{Fe}^{2+}$, and despite changes in the availability of Fe in the modern ocean, these organisms still maintain high cellular Fe requirements, potentially because of the ancient evolution of $\mathrm{N}_{2}$ fixation biochemistry (Berman-Frank et al., 2001; Kustka et al., 2003). This increased Fe requirement has been argued to be an important constraint on $\mathrm{N}_{2}$ fixation in the modern ocean (Moore et al., 2004; Moore and Doney, 2007). Therefore, increased understanding of how diazotrophic cyanobacteria acquire $\mathrm{Fe}$, what forms of $\mathrm{Fe}$ are bioavailable and how they respond to $\mathrm{Fe}$ deprivation is important for predicting potential feedbacks on climate change.

Genetic analyses of laboratory cultures have shown there are two distinct clades within the genus Trichodesmium, one consisting of strains of Trichodesmium erythraeum and Trichodesmium contortum, which we will refer to as the Tery clade, and the other consisting of Trichodesmium tenue, Trichodesmium thiebautii, Trichodesmium spiralis and Trichodesmium hildebrandtii, which we will refer to as the Ten clade (Hynes and Waterbury unpublished results; Orcutt et al., 2002). Multiple experiments have shown that $\mathrm{Fe}$ is an important micronutrient for the Tery clade (Berman-Frank et al., 2001; Fu and Bell, 2003; Kustka et al., 2003), providing valuable information about the role that Fe plays in controlling growth and $\mathrm{N}_{2}$ fixation in Trichodesmium. Comparable data is not available for the Ten clade. Morphological data from the field suggests that representatives from the Ten clade might be more prevalent deeper in the water column (Carpenter et al., 1993; Post et al., 2002; Davis and McGillicuddy, 2006) and may even have different $\mathrm{N}_{2}$ fixation rates than the Tery clade (Carpenter et al., 1993), though this has not been proven using genetic techniques that distinguish between the clades. Thus 
understanding the impact that $\mathrm{Fe}$ has on $\mathrm{N}_{2}$ fixation in the Ten clade of Trichodesmium is important to improve our understanding of the genus' role in global carbon and nitrogen cycling.

To constrain the relationship between Fe and $\mathrm{N}_{2}$ fixation in Trichodesmium, we evaluated multiple indicators of $\mathrm{Fe}$ limitation including growth and $\mathrm{N}_{2}$ fixation rates with cultures from both clades of Trichodesmium grown on varying levels of Fe. In addition, we designed a molecular gene expression-based assay to look at the cellular Fe stress response of genes believed to be part of the Fe-uptake machinery or shown to be Fe stress-induced in other organisms (Bibby et al., 2001; Katoh et al., 2001; Webb et al., 2001; Michel et al., 2003; Shi et al., 2007). We found that the Ten clade had a lower optimum temperature for growth and slightly reduced $\mathrm{N}_{2}$ fixation rates at higher $\mathrm{Fe}$ values. The Ten clade also showed a lower basal expression of our molecular marker gene, $i s i B$, but a more pronounced increase in gene expression as Fe became limiting. While there were slight differences in the individual Fe stress responses in the two clades, overall we observed similar trends in the Fe level associated with a significant increase in gene expression and concomitant reductions in $\mathrm{N}_{2}$ fixation.

\subsection{RESULTS}

3.3.1 Genomic Database Analysis. We screened the genome of T. erythraeum (IMS101) to evaluate the potential Fe stress response in the genus. A list of IMS101 genes predicted to be involved in Fe transport and homeostasis, their closest orthologs and their closest experimentally-characterized orthologs (genes that have been characterized using genetic and proteomic techniques) as determined by BLAST analysis are presented in Table 1. A schematic of both the predicted Fe uptake system and the fate of Fe within the cell with labels corresponding to the genes described in Table 1 is shown in Figure 1.

Sensing and responding to Fe availability has been shown to have a transcriptional component (Escolar et al., 1999). Fitting with these data, Trichodesmium is predicted to have three homologs encoding the ferric uptake regulator (Fur) protein. In 
many microbes this protein has been shown to modulate the organism's response to Fe starvation (Andrews et al., 2003). Two of these Trichodesmium genes, YP_721684 and YP_722978, are highly similar to the furA gene of Anabaena PCC 7120, while the third gene, YP_721679, is most similar to the furB gene of Anabaena PCC 7120 and appears to be specific to cyanobacteria (Hernandez et al., 2004).

The IMS101 genome also contains genes with the potential to modulate Fe use and storage in response to changing environmental conditions. One such adaptation includes replacing the Fe-rich electron carrier ferredoxin with the flavin-containing electron carrier flavodoxin (IsiB) (Leonhardt and Straus, 1992; LaRoche et al., 1996). The IMS101 genome has two predicted IsiB homologs, encoded by genes YP_721410 and YP_722232. In addition to the ferredoxin/flavodoxin substitution, some gramnegative bacteria synthesize the IsiA protein in times of Fe deprivation, which forms a protective ring around photosystem I (Leonhardt and Straus, 1992; Bibby et al., 2001; Michel and Pistorius, 2004). The IMS101 genome has one predicted homolog for the IsiA protein encoded by gene YP_721411. Finally, the genome also shows evidence of Fe storage capabilities including a cytochrome b1 type bacterioferritin protein (Andrews et al., 1993; Keren et al., 2004) and a ferritin-like DPS protein (Michel et al., 2003; Castruita et al., 2006), predicted to be encoded by YP_722441 and YP_723752, respectively.

Although there are no clear siderophore biosynthetic genes in the IMS101 genome, it is predicted to encode for the uptake of a variety of Fe forms. These include genes that may facilitate the uptake of siderophore-bound Fe, such as a cluster of two genes predicted to encode the intermembrane proteins ExbB and ExbD, genes YP_723908 and YP_723909, respectively, and a possible quite divergent TonB protein, encoded by gene YP_721313. TonB-ExbB-ExbD complexes have been shown to translocate the energy stored in the proton gradient across the inner bacterial membrane to the outer membrane to allow the transport of large molecules like siderophores into the periplasm of gram-negative bacteria (Braun, 1995). Genes YP_722814, YP_722813, YP_722952 and YP_723445 are all predicted to encode proteins involved in an ABC- 
type $\mathrm{Fe}^{3+}$ transporter (Koster, 2001). YP_722814 is homologous to an inner membrane component of a binding protein dependent transport system and is clustered with a gene, YP_722813, which is homologous to an ATPase component of an ABC-type $\mathrm{Fe}^{3+}$ transporter (Katoh et al., 2001). The close proximity of the two genes and their related function, suggests that they may be part of the same operon. The IMS101 genome contains two potential periplasmic $\mathrm{Fe}^{3+}$ binding protein components of an $\mathrm{ABC}$ transport system (Koster, 2001), idiA, YP_722952, and a predicted hydroxamate-Fe-binding protein, YP_723445. The confirmed presence of a signal peptide region in the transcript of the idiA gene, which was not found for YP_723445, suggests that the IdiA protein is being processed through a membrane to outside of the cytoplasm and possibly moved into the periplasm, a step that is necessary in the maturation of a periplasmic protein (Fulda et al., 2000). However, it is important to note that our inability to discern a signal peptide region in the transcript of YP_723445 using SignalP 3.0 is not a definitive indication that the protein will not be found in the periplasm, as slight modification of the translational start codon has been shown to mask potential signal peptide regions (Fulda et al., 2000). Additionally Trichodesmium has the predicted ability to transport $\mathrm{Fe}^{2+}$ using the proteins FeoA and FeoB, encoded by genes YP_722525 and YP_722524, respectively (Kammler et al., 1993).

3.3.2 Sequence Analysis. Others have shown that there can be differences in nutrient scavenging strategies employed by closely related cyanobacteria (Martiny et al., 2006; Palenik et al., 2006; Rivers et al., 2009), therefore in order to determine how well conserved the Fe stress regulon was within the genus Trichodesmium, we sequenced genes predicted to be involved in Fe(III) uptake, Fe(II) uptake, and Fe quota reduction (idiA (YP_722952), feoB (YP_722524) and isiB (YP_721410), respectively) from isolates covering the range of Trichodesmium species in our culture collection. These results showed that all three genes are well conserved across the four species of Trichodesmium at the DNA level (Table 2), with the largest dissimilarity detected between the Tery clade (IMS101 and GBRTRLI101) and the three species of the Ten clade (93\%-96\% similarity between $T$. erythraeum and the other species, compared with 
98\%-100\% similarity within the Ten clade). No obvious shared promoter regions could be defined for the three genes using alignments of the intergenic spacer regions preceding each gene in the T. erythraeum IMS101 genome.

3.3.3 Axenic IMS101 Nutrient Stress Experiment. To verify the annotation and test the hypothesis that the $i d i A, f e o B$ and $i s i B$ genes were induced under Fe limitation, we monitored their expression using RT-PCR in Fe growth limitation experiments with axenic cultures of IMS101. At the onset of growth limitation (T1, Figure $2 \mathrm{~A}+\mathrm{B}$ ), RTPCR showed that all three genes were expressed only in the Fe-omitted culture. At the point when the Fe-omitted culture was beginning to senesce and the replete treatment was late in the exponential growth phase (T2, Figure 2 A), all three genes were expressed in both the replete and Fe-omitted treatments, but not in the P-omitted culture (T2, Figure 2 B).

\subsubsection{Physiological Growth Response of the Ten and Tery Clades. Optimal} growth temperatures were determined for representatives from both phylogenetic clades. In replicated experiments performed at the same light level $\left(140 \mu \mathrm{Ein} / \mathrm{m}^{2} / \mathrm{s}\right)$, the Ten clade consistently had a lower optimal temperature $\left(26^{\circ} \mathrm{C}\right)$ than the two Tery representatives tested $\left(28^{\circ} \mathrm{C}\right)$ (Figure 3$)$. The maximum growth rates were lower for the Ten clade representative $\left(0.33+/-0.01 \mu \mathrm{d}^{-1}\right)$ than GBRTRLI101 $\left(0.60+/-0.01 \mu \mathrm{d}^{-1}\right)$ and IMS101 $\left(0.78+/-0.01 \mu \mathrm{d}^{-1}\right)$. The error reported for growth rates is standard error calculated from triplicate biological replicates.

As Fe had been shown to be important for the growth of Trichodesmium, but its effect had only been studied in the Tery clade, we did growth limitation experiments using a range of $\mathrm{Fe}^{\prime}$ (inorganically bound $\mathrm{Fe}$ ) values ranging from $0.15 \mathrm{nM}$ to $4.5 \mathrm{nM}$ with representatives from both phylogenetic clades of Trichodesmium at their optimal growth temperature (the values of Fe' were calculated using VisualMintEQ as described in the Experimental Procedures). In both clades, growth rates increased as the concentration of inorganically bound $\mathrm{Fe}\left(\left[\mathrm{Fe}^{\prime}\right]\right)$ in the medium increased (Figs. 4A+B). In the Ten clade, growth rates increased from $0.13+/-0.01 \mu \mathrm{d}^{-1}$ to $0.19+/-0.01 \mu \mathrm{d}^{-1}$ with the maximal growth rate achieved at [Fe'] of $0.54 \mathrm{nM}$. In the Tery clade, growth 
rates increased from $0.12+/-0.00 \mu \mathrm{d}^{-1}$ to $0.21+/-0.00 \mu \mathrm{d}^{-1}$ with the maximal growth rate achieved at [Fe'] of $0.94 \mathrm{nM} . \mathrm{N}_{2}$ fixation rates also increased concomitantly with [Fe'] in the medium, and continued to do so even after the growth rates had plateaued (Figs. $4 \mathrm{~A}+\mathrm{B}$ ). In the Ten clade, $\mathrm{N}_{2}$ fixation rates increased from $3.2+/-0.2 \mathrm{nmol}$ $\mathrm{N} / \mathrm{hr} / \mu \mathrm{g}$ Chl to $10.1+/-0.3 \mathrm{nmol} \mathrm{N} / \mathrm{hr} / \mu \mathrm{g}$ Chl, with the maximal $\mathrm{N}_{2}$ fixation rates achieved at [Fe'] of $4.5 \mathrm{nM}$. In the Tery clade, $\mathrm{N}_{2}$ fixation rates increased from $3.6+/-$ $0.3 \mathrm{nmol} \mathrm{N} / \mathrm{hr} / \mu \mathrm{g} \mathrm{Chl}$ to $13+/-0.7 \mathrm{nmol} \mathrm{N} / \mathrm{hr} / \mu \mathrm{g}$ Chl with the maximal $\mathrm{N}_{2}$ fixation rates achieved at [Fe'] of $4.5 \mathrm{nM}$. Despite these differences, when the $\mathrm{N}_{2}$ fixation rates were normalized to growth rates a similar relationship was revealed for both phylogenetic clades (Figure 4C). To ensure that $\mathrm{N}_{2}$ fixation rate differences were not the result of changes in Chl/DNA ratios in the different treatments, we evaluated the Chl/DNA ratio for samples from low and high Fe treatments in both clades and found no significant Feassociated difference and a value of $1.6 \times 10^{-8}+/-3.0 \times 10^{-9} \mu \mathrm{g}$ chl/copy isiB (Figure 4D). Error reported for Tery clade growth and nitrogen fixation rates is standard error calculated from biological replicates (5-6 replicates at each Fe treatment). Error reported for Ten clade growth and nitrogen fixation rates is standard error calculated from triplicate biological replicates at each Fe treatment. Error reported for chl/copy DNA is standard error based on triplicate low and high Fe replicates from the Tery clade and duplicate low and high Fe replicates from the Ten clade (10 replicates total).

3.3.5 Quantified Fe stress response. Both clades of Trichodesmium show an inverse relationship between $i s i B$ expression and $\mathrm{N}_{2}$ fixation rates in response to changing [Fe'] in the medium, with $i s i B$ expression increasing and $\mathrm{N}_{2}$ fixation rates decreasing as the [Fe'] was reduced (Figure $5 \mathrm{~A}+\mathrm{B}$ ). In the Tery clade, the threshold associated with a $50 \%$ decrease in $\mathrm{N}_{2}$ fixation rates occurs at an isiB/rnpB ratio of $1.4+/-0.5$ and an [Fe'] of $0.54 \mathrm{nM}$ (Figure 5A), while in the Ten clade, the same threshold occurs at an isiB/rnpB ratio of $0.063+/-0.02$ at the same [Fe'] (Figure 5B). While the Ten clade shows a lower basal expression level than the Tery clade (Figure $5 \mathrm{~A}+\mathrm{B}$ ), it also shows a greater increase in expression at lower Fe conditions than the Tery clade (Figure 5C). The thresholds listed above are based on the actual values from these experiments, without 
curve fitting. The error reported for each measurement is standard error of biological replicates ( 3 for the Ten clade and 6 for the Tery clade at each Fe treatment). We fit the expression data with an exponential decay model and found that for the Tery clade $i s i B / r n p B=2.2 \times 10^{\left(1.9 \times\left[\mathrm{Fe}^{\prime}\right]\right)}+0.44$ with an $\mathrm{R}^{2}=0.61$ and for the Ten clade $i s i B / r n p B=$ $0.14 \times 10^{\left(1.5 \times\left[\mathrm{Fe}^{\mathrm{e}}\right]\right)}+0.011$ with an $\mathrm{R}^{2}=0.49$. We fit the $\%$ maximum $\mathrm{N}_{2}$ fixation data using a $2^{\text {nd }}$ order polynomial model and found that for the Tery clade $\%$ Maximum $\mathrm{N}_{2}$ Fixation $=24.9+50 \times\left[\mathrm{Fe}^{\prime}\right]-7.4 \times\left[\mathrm{Fe}^{\prime}\right]^{2}$ with an $\mathrm{R}^{2}=0.75$ and for the Ten clade $\%$ Maximum $\mathrm{N}_{2}$ Fixation $=29.4+32.2 \times\left[\mathrm{Fe}^{\prime}\right]-7.41 \times\left[\mathrm{Fe}^{\prime}\right]^{2}$ with an $\mathrm{R}^{2}=0.93$. Using these equations, $\mathrm{N}_{2}$ fixation is at $50 \%$ maximum in the Tery clade at [ $\left[\mathrm{Fe}^{\prime}\right]=0.56+/-0.14$ $\mathrm{nM}$ and in the Ten clade at [Fe'] $=0.70+/-0.10 \mathrm{nM}$ with corresponding isiB/rnpB expression values of $1.2+/-0.3$ and $0.062+/-0.017$, respectively. The error reported was calculated using error propagation analysis and the standard error of each regression.

In an experiment where we transferred Fe limited T. erythraeum (GBRTRLI101) into $\mathrm{Fe}$ replete medium, we found that the expression of $i s i B$ dropped to basal levels within 24 hours, while cultures that were transferred back into Fe-omitted medium retained expression above the threshold levels indicative of $\mathrm{Fe}$ limitation of $\mathrm{N}_{2}$ fixation (Figure 6).

\subsection{DisCUSSION}

Field studies indicate that Trichodesmium spp. are widely distributed and a significant source of new nitrogen in the tropical and subtropical Atlantic and Pacific Oceans (Capone, 2001). The high $\mathrm{Fe}$ requirement of $\mathrm{N}_{2}$ fixing cyanobacteria like Trichodesmium spp. creates a biological linkage between the geochemistries of $\mathrm{N}$ and $\mathrm{Fe}$ (Kustka et al., 2003). Despite the defined important relationship between Trichodesmium and Fe availability, prior physiological data has been limited to laboratory studies using strains representative of only the Tery clade of Trichodesmium (Berman-Frank et al., 2001; Fu and Bell, 2003; Kustka et al., 2003; Berman-Frank et al., 2007). As others have seen large difference in the genomic capability of marine cyanobacteria to compensate 
for Fe deprivation (Palenik et al., 2006; Rivers et al., 2009), the work described herein is both important and timely and represents the first physiological data comparing the response of the Tery and Ten clades of Trichodesmium to Fe deprivation.

\subsubsection{Genomic Capabilities and Conservation Within the Genus.}

Trichodesmium spp. inhabit environments typified by episodic inputs of Fe through dust deposition or mesoscale eddies, followed by long periods of deprivation. Thus it is not surprising that the IMS101 genome contains many genes predicted to encode for the uptake of different forms of Fe, Fe quota compensation, and Fe storage mechanisms (Table 1, Figure 1). To assess the importance of these adaptations throughout the genus as a whole, we evaluated the conservation of some of the genes involved in Fe uptake and quota compensation within the genus Trichodesmium.

The Trichodesmium IMS101 genome is predicted to encode the genetic capacity to transport both ferric (FeIII) and ferrous (FeII) Fe into the cell. However, since the oceans are oxidizing, Fe(III) is likely one of the main sources of Fe to open-ocean cyanobacteria. This is supported by the presence of a complete periplasmic binding protein-dependent ABC transport system for Fe (encoded by idiA (YP_722952), inner membrane channel (YP_722814), and ATPase (YP_722813)) and the knowledge that these types of systems have been shown to be critical for moving Fe through the periplasm into cytoplasm in bacteria and cyanobacteria (Koster, 2001). Although oceanic bulk water is oxidized, there are many redox microniches, including chemical environments that can become reducing (Shanks and Reeder, 1993; Azam, 1998; Moran et al., 2004). Consistent with these microniches, the IMS101 genome is also predicted to encode for genes of $\mathrm{Fe}(\mathrm{II})$ transport ( $f e o A$ and $f e o B$ : YP_722525 and YP_722524, respectively). While $f e o B$ has been found in some freshwater cyanobacterial genomes (Katoh et al., 2001) and three strains of coastal marine Synechococcus (Palenik et al., 2006; Rivers et al., 2009), in open-ocean cyanobacteria it has only been identified in the genomes of the diazotrophs T. erythraeum (IMS101) and C. watsonii (WH8501).

Trichodesmium's apparent genetic capacity for acquiring $\mathrm{Fe}^{2+}$ may indicate that there is an indirect or direct Fe (III) reduction scheme involved in Fe uptake, either 
extracellularly or within the periplasm. Others have shown that photolysis of Fe (III)siderophore complexes could be a source of $\mathrm{Fe}^{2+}$ for the oceans (Barbeau et al., 2003), and this could be a passive Fe (II) resource to Trichodesmium. This reduction might also occur in the microcosms associated with colony formation. Since bacteria are known to commonly dispense with genes not required for success in their natural habitat (Teuber M., 1992), the presence of the $f e o A$ and $f e o B$ genes in the IMS101 genome indicates that Trichodesmium may be actively pursuing $\mathrm{Fe}^{2+}$ as a cellular Fe source.

In addition to genes associated with Fe uptake, the IMS101 genome also contains a gene involved in Fe quota reduction, isiB (YP_721410). During times of Fe deprivation, organisms that have the $i s i B$ gene are able to synthesize the flavin-containing protein flavodoxin, and use it to replace the Fe-rich electron carrier ferredoxin in the Zscheme of photosynthesis (Leonhardt and Straus, 1992). The isiB gene that we sequenced, YP_721410, shows a greater similarity to flavodoxin genes that have been fully characterized and shown to be Fe stress induced in other organisms (Fillat et al., 1991) than the other putative flavodoxin-encoding gene, YP_722232.

Sequencing of $i s i B$, idiA, and $f e o B$ from various Trichodesmium species revealed high similarity across the genus (Table 2), with the largest differences consistently occurring between species from the two different clades. This separation is consistent with previous work looking at the genetic characteristics of different species of Trichodesmium, where the groups that comprise the Ten and Tery clades were first defined with cultured isolates (Orcutt et al., 2002). The conservation of the components of the Trichodesmium Fe stress regulon studied herein stand in contrast to the variation in gene content that has been seen in genomes of the unicellular cyanobacteria (Palenik et al., 2006; Rivers et al., 2009). While our analyses do prove that all of these genes are used in Trichodesmium, the conservation of all three genes across the genus suggests that these Fe limitation compensation mechanisms are important for success in the oligotrophic ocean.

3.4.2 Axenic IMS101 Expression Analyses. Initial gene expression analysis with axenic batch cultures of T. erythraeum IMS101 grown under replete, Fe-omitted and 
P-omitted conditions showed that all three genes (idiA, $f e o B$ and $i s i B$ ) were expressed only under Fe limitation (Figure 2). Importantly, if the expression of any of the genes had been part of a generalized stress response of the organism, we would have expected to see expression in the P-omitted treatment as well. The expression that appears at the later time point, "T2," in the replete experiment was expected, based on chemical modeling of the medium that suggests the cells will experience Fe limitation before $\mathrm{P}$ limitation. In order for this to occur in an EDTA-buffered medium, the culture would have had to grow to a "blown buffer" cell density (Saito et al., 2008), where the demand for Fe from the accumulated biomass exceeds the amount supplied by the dissociation of Fe from the EDTA buffer, which results in the inorganically bound $\mathrm{Fe}$ ([Fe']) being lower than calculated based on equilibrium dynamics. As the expression occurs before growth limitation, it suggests that upregulation of the Fe stress regulon begins as soon as the organism begins to experience a decrease in cellular Fe availability. This hypothesis is corroborated by results from our Fe titration experiments with representatives from the two Trichodesmium clades, which show that increases in expression of the $i s i B$ gene and decreases in $\mathrm{N}_{2}$ fixation rates occur throughout the range of Fe values we tested, while growth rates only decrease at the lowest Fe values.

3.4.3 Clade Differentiation. Our results show that the optimal temperature for growth for the Tery clade is $28^{\circ} \mathrm{C}$, which is consistent with the results of Breitbarth and colleagues (Breitbarth et al., 2007), while the optimal temperature for growth for the Ten clade is $2^{\circ} \mathrm{C}$ lower (Figure 3). Similar to what Breitbarth and colleagues found with $T$. erythraeum (Breitbarth et al., 2007), we also saw a significantly reduced $\mathrm{N}_{2}$ fixation rate when we grew $T$. tenue above its optimal temperature (data not shown). These data imply that there is a niche differentiation in the genus based on temperature, which could result in a differential depth distribution of the species, data that are consistent with the morphological distributions of Trichodesmium that have been described from the field (Post et al., 2002; Davis and McGillicuddy, 2006). Furthermore, our data suggest that temperature-based niche differentiation could lead to a species composition shift in the 
oceans if anthropogenic climate change leads to a significant increase in sea surface temperature.

Tery and Ten clade representatives grown in varying levels of Fe showed a direct correlation between $\mathrm{Fe}$ and growth rates (Figure $4 \mathrm{~A}$ ) and $\mathrm{Fe}$ and $\mathrm{N}_{2}$ fixation rates (Figure 4B). Both clades showed an eventual plateau in growth rates at high Fe values, which occurred at a slightly lower Fe value for the Ten clade than the Tery clade, [Fe'] of 0.54 $\mathrm{nM}$ and $0.94 \mathrm{nM}$, respectively. While this could suggest a lower Fe quota for the Ten clade, it could also be a by-product of imperfect culturing conditions, indicating that some other element or factor becomes limiting for the organism above this Fe value. In both clades of Trichodesmium, $\mathrm{N}_{2}$ fixation rates continue to increase even after growth rates have reached their plateau. These data suggest that Trichodesmium fixes more $\mathrm{N}_{2}$ than is strictly needed when growing in the presence of excess Fe. Alternatively, the reduction of $\mathrm{N}_{2}$ fixation rates prior to a reduction in growth rates could be evidence of the organism's sacrificing the high Fe-requiring $\mathrm{N}_{2}$ fixation in favor of carbon fixation at the onset of Fe stress (Kupper et al., 2008). If the former hypothesis is true, it could potentially explain the dissolved organic nitrogen (DON) excretions observed in many replete Fe culture experiments done with Trichodesmium (Capone et al., 1994; Mulholland and Capone, 2001). If Fe plays a role in excess $\mathrm{N}_{2}$ fixation and DON excretion, it could indicate an increased importance for Fe in modulating the $\mathrm{N}$ cycle in the oligotrophic gyres and should be explored further.

At the highest values of Fe in the medium, the Ten clade had reduced chlnormalized $\mathrm{N}_{2}$ fixation rates compared to the Tery clade. To ensure that this difference in $\mathrm{N}_{2}$ fixation rates was not a byproduct of our normalization of the rates to chl, we tested the chl/DNA ratio of the cultures across the different Fe treatments and found that they were constant in the species and experimental Fe conditions (Figure 4D). Thus, there was a real difference in the $\mathrm{N}_{2}$ fixation rates between the two clades. This could indicate that while the Ten clade does fix excess $\mathrm{N}_{2}$ when abundant $\mathrm{Fe}$ is available, it does not do so to the extent that the Tery clade does. However, when the lower maximal growth rates in the Ten clade are taken into account, the difference in $\mathrm{N}_{2}$ fixation rates appear to be a 
factor of growth rate (Figure 4C). While the absolute amount of $\mathrm{N}_{2}$ fixed by the two clades was different, the amount of [Fe'] associated with a $50 \%$ reduction in $\mathrm{N}_{2}$ fixation rates was very similar for both clades $(0.54 \mathrm{nM} \mathrm{Fe}$ without curve fitting and with curvefitting: $0.56+/-0.14 \mathrm{nM}$ for Tery and $0.70+/-0.10 \mathrm{nM}$ for Ten), indicating a similar impact of $\mathrm{Fe}$ on $\mathrm{N}_{2}$ fixation rates throughout the genus. These values are in line with what others have found for the critical [Fe'] value associated with a decrease in $\mathrm{N}_{2}$ fixation with the T. erythraeum clade (Berman-Frank et al., 2001; Berman-Frank et al., 2007).

To determine whether the cellular response to Fe limitation was the same in the two Trichodesmium clades, we designed a qRT-PCR method to look at the expression of one of the Fe stress response genes. This approach allows for the comparison of data on the onset of Fe limitation of growth, $\mathrm{N}_{2}$ fixation rates, and the cellular level Fe stress response. While all three genes showed the expected expression response with the axenic Trichodesmium cultures, we developed the qRT-PCR method with isiB because the role of $i s i B$ in the cell is well understood (Leonhardt and Straus, 1992) and it has been used as a marker for Fe stress in other phytoplankton (LaRoche et al., 1996; Bibby et al., 2001). Also, its role in photosynthesis suggests that it has the potential to be in high copy number when it is expressed, which will make it easier to detect using RT-PCR. In order to assess relative expression rates in non-axenic cultures, we normalized the number of $i s i B$ copies in a given sample to the number of copies of a constitutively expressed gene, rnpB, which we have chosen based on experiments comparing its stability in cDNA from cultures grown under different physical and chemical treatments (see experimental procedures). We designed primer sets for $i s i B$ and $r n p B$ that able to distinguish between both clades of Trichodesmium (see experimental procedures) that can be used to generate $i s i B$ expression data that is normalized to Trichodesmium RNA (rnpB).

Both Tery and Ten cultures show an inverse relationship between isiB expression and $\mathrm{N}_{2}$ fixation rates in response to changing [Fe'] with isiB expression highest at the lowest $\mathrm{N}_{2}$ fixation and [Fe'] values (Figure $5 \mathrm{~A}+\mathrm{B}$ ). The results from these experiments have provided us with valuable information on the threshold of expression that 
corresponds to a meaningful decrease in $\mathrm{N}_{2}$ fixation rates, which is 0.063 isiB/rnpB for the Ten clade and $1.2 \mathrm{isiB} / \mathrm{rnpB}$ for the Tery clade. Above these threshold $i s i B$ expression levels, $\mathrm{N}_{2}$ fixation rates had decreased by at least $50 \%$ from the maximal levels measured in both clades of Trichodesmium (Figure 5). Interestingly, the [Fe'] value where this reduction in $\mathrm{N}_{2}$ fixation rates and increase in $i s i B$ expression occurs is approximately the same [Fe'] in both clades of Trichodesmium $(0.56+/-0.14 \mathrm{nM}$ for Tery and $0.70+/-0.10 \mathrm{nM}$ for Ten), suggesting that there is not significant niche differentiation between the clades based on Fe availability. These data differ from genomic and physiological work in other cyanobacterial groups, which has found that the Fe stress response is an area of significant deviation between clades represented in a genus (Brand, 1991; Palenik et al., 2006; Rivers et al., 2009). Furthermore, these results suggest that other factors (possibly temperature, etc) are more important than Fe for niche differentiation in the Trichodesmium genus. The conservation of the Fe stress response across the two clades further implies that Fe is a common and important stressor for the genus.

Using the information on threshold $i$ siB expression of the Tery clade, we were also able to evaluate how quickly Trichodesmium is able to respond to an alleviation of Fe stress. We found that $i s i B$ expression dropped within 24-hours of cultures being returned to Fe replete medium (Figure 6). These results are similar to what has been seen with idiA gene expression (Shi et al., 2007) and much faster than what has been detected using IdiA protein analysis in another cyanobacteria, Synechococcus WH7803, where the protein remained detectable even three days after cultures were transferred to Fe replete medium (Webb et al., 2001). These results highlight one of the advantages and challenges of looking at RNA verses proteins; RNA is degraded much more rapidly than protein and thus reflects the immediate cellular status of the organism. Meanwhile, proteins can persist for some time after they have actively been translated, thus their presence does not always reflect the current status of the organism.

This study is the first demonstration of Fe limitation using representatives of the two major clades of Trichodesmium. In addition to traditional measurements quantifying 
the impact that $\mathrm{Fe}$ has on productivity, namely growth rates and $\mathrm{N}_{2}$ fixation rates, we have added a molecular assessment of Fe limitation for both clades of Trichodesmium. This calibrated clade-specific assay allows us to quantify the impact that Fe is having on $\mathrm{N}_{2}$ fixation, which should be quite relevant for the development of a field assay for $\mathrm{Fe}$ limitation in Trichodesmium and thereby improve oceanographic models.

\subsection{Experimental Procedures}

3.5.1 Genomic Database Searching. Genes associated with the Fe scavenging and control of Fe homeostasis systems in T. erythraeum IMS101 were identified using the Oak Ridge National Laboratory (ORNL) annotation of the genome accessed through the Joint Genome Institute (JGI) Internet portal (http://genome.jgipsf.org/finished_microbes/trier/trier.home.html). The closest experimentallycharacterized homolog was determined using Basic Local Alignment Search Tool (BLAST) analysis against the GenBank NR database using the Integrated Microbial Genomes system of JGI (http://img.jgi.doe.gov/v1.0/main.cgi) (Altschul et al., 1990). When appropriate, the presence of a signal peptide region was determined using SignalP 3.0 (Bendtsen et al., 2004).

3.5.2 Bacterial Strains. The four Trichodesmium spp. used in this study were $T$. erythraeum (IMS101 and GBRTRLI101), T. thiebautii (II-3), T. tenue (Z-1 and H94) and T. spiralis (KAT) (all but GBRTRLI101 and H94 have been described in Orcutt, 2002). All species are currently maintained in both the University of Southern California and the Woods Hole Oceanographic Institution culture collections. All but GBRTRLI101 and IMS101 were isolated by Dr. John Waterbury (Paerl et al., 1994; Fu and Bell, 2003). GBRTRLI101 was generously provided by Dr. F.X. Fu. Cultures of IMS101 used in the initial nutrient stress experiment were verified to be axenic by direct microscopic observations and lack of heterotrophic growth in marine purity medium as described (Waterbury et al., 1986). The five other species and the IMS101 culture used in the Fe titration experiment were maintained as bacterized enrichment cultures. 
3.5.3 Culture Conditions. With the exception of GBRTRLI101, stock Trichodesmium spp. used for sequencing were cultured in a 75\% Sargasso seawater medium prepared in a similar manner to that described previously (Webb et al., 2001). Sargasso seawater, stored in the dark in acid-washed polycarbonate carboys, was filtered successively through 1.0 and $0.2 \mu \mathrm{m}$ Millipore membrane filters and "Tyndalized" by heating to boiling in a microwave oven in Teflon containers. The "Tyndalized" Sargasso seawater was then diluted to $75 \%$ with steam-sterilized MilliQ-water (Millipore, Bedford, MA). The medium (PMP) was then prepared by addition of filter- or steam-sterilized nutrients and trace metals made from tissue-grade chemicals purchased from Sigma Chemical to the following concentrations: $5 \times 10^{-7} \mathrm{M}$ EDTA, $8 \times 10^{-6} \mathrm{M}$ phosphoric acid, $1 \times 10^{-7} \mathrm{M} \mathrm{Fe}$ (ferric citrate), $1 \times 10^{-5} \mathrm{M}$ Citric Acid, $1 \times 10^{-7} \mathrm{M} \mathrm{MnSO}_{4}, 1 \times 10^{-8} \mathrm{M}$ $\mathrm{ZnCl}_{2}, 1 \times 10^{-8} \mathrm{M} \mathrm{NaMoO}_{4}, 1 \times 10^{-10} \mathrm{M} \mathrm{CoCl}_{2}, 1 \times 10^{-10} \mathrm{M} \mathrm{NiCl}_{2}, 1 \times 10^{-10} \mathrm{M} \mathrm{NaSeO}_{3}$, and $1.5 \mu \mathrm{g}$ of vitamin $\mathrm{B}_{12} /$ liter. GBRTRLI101 stocks were grown in an artificial seawater medium YBCII (Chen et al., 1996) with Fe added as ferric citrate. All Trichodesmium stock cultures were grown in Nalgene ${ }^{\circledR}$ polycarbonate flasks or culture bottles (Nalge Nunc International Corporation, Rochester, NY) that had previously been cleaned with a $2 \%$ solution of Citranox ${ }^{\circledR}$ (Alconox, Inc. White Plains, NY), followed by rinses in hot tap water, MilliQ water and at least a 24-hour soak in $0.5 \mathrm{~N}$ trace metal grade $\mathrm{HCl}$ before finally being rinsed in MilliQ water and microwave sterilized with $\mathrm{pH} 2$ trace metal grade $\mathrm{HCl}$. Growth conditions typically consisted of a $14 \mathrm{hr}: 10 \mathrm{hr}$ light:dark cycle using cool white fluorescent lamps at $\sim 50 \mu \mathrm{Ein} / \mathrm{m}^{2} / \mathrm{s}$ and a temperature of $25^{\circ} \mathrm{C}$ unless stated otherwise. The cultures were kept gently shaking by placement on a model 3520 LabLine ${ }^{\circledR}$ Orbital Benchtop shaker (Barnstead International, Dubuque, IA) within a model I-36 Percival incubator (Percival Scientific Inc., Perry, IA).

3.5.4 Gene Sequencing. DNA for sequencing was extracted using a modified version of the xanthogenate DNA extraction protocol of Tillet and Neilan (Tillett and Neilan, 2000). Cultures were filtered onto $5-\mu \mathrm{m}$ polycarbonate filters and then resuspended in $100 \mu \mathrm{l}$ of TE buffer with $50 \mu \mathrm{g} / \mathrm{ml}$ RNaseA (Qiagen, Valencia, CA). The only other departures from the Tillet and Neilan protocol were mixing the supernatant 
following the ice incubation with $700 \mu 1$ phenol: $\mathrm{CHCl}_{3}$ :isoamyl alcohol (25:24:1), retaining the top layer of that mixture following centrifugation, and two additional $70 \%$ ethanol wash steps at the end of the procedure before resuspending the final pellet in 100 $\mu 1$ sterile MilliQ water. The genes isiB (234 bp out of a $516 \mathrm{bp}$ gene), feoB (995 bp out of a $1821 \mathrm{bp}$ gene), idiA (520 bp out of a $1050 \mathrm{bp}$ gene) and rnpB were amplified from the extracted DNA via PCR using iProof ${ }^{\mathrm{TM}}$ High-Fidelity DNA polymerase (Bio-Rad Laboratories, Hercules, CA) at a final concentration of 1.25 units/PCR reaction. The external primers used to amplify each of the genes from the different species of Trichodesmium were designed from the sequenced genome of T. erythraeum IMS101 and are listed in Table 3. The primers used to amplify the $\operatorname{rnpB}$ gene were the degenerate primers defined in Vioque (Vioque, 1997). Temperature gradient PCR was used to determine optimal annealing temperatures for amplifying $f e o B$, isiB, idiA and $r n p B$ from the Trichodesmium species: $55.7^{\circ} \mathrm{C}, 56.1^{\circ} \mathrm{C}, 56.1{ }^{\circ} \mathrm{C}$ and $55^{\circ} \mathrm{C}$, respectively. PCR reactions were carried out on a Mastercycler@ thermal cycler (Eppendorf AG, Hamburg, Germany) with the following holds and cycles: $98^{\circ} \mathrm{C}$ for $1 \mathrm{~min}$; followed by 35 cycles of $98^{\circ} \mathrm{C}$ for 15 seconds, annealing temperature (as listed above) for 30 seconds, $72^{\circ} \mathrm{C}$ for 45 seconds; and one dwell at $72^{\circ} \mathrm{C}$ for $10 \mathrm{~min}$. Amplified products were purified using the QIAquick gel extraction kit (Qiagen, Valencia, CA) and sequenced directly using the facilities and protocols of the Josephine Bay Paul Center of the Marine Biological Laboratory (Woods Hole, MA). Sequences were analyzed and assembled using Sequencher 4.1 (Gene Codes Corporation, Ann Arbor, MI). Alignments were generated with ClustalX (Thompson et al., 1997). Gene sequences determined in this study were submitted to GenBank with the following accession numbers (EF110575-EF110583).

3.5.5 Nutrient Stress Experiments with Axenic IMS101. Fe-limited, P-limited, and replete cultures were prepared using PMP medium as described above and omitting ferric citrate and phosphoric acid where appropriate. To generate the inocula, cells from a PMP-grown culture of IMS101 were filtered gently onto a 5- $\mu \mathrm{m}$ polycarbonate filter. The filter was then washed with 50 to $100 \mathrm{ml}$ "Tyndalized" Sargasso seawater before the cells were resuspended in a small amount of Sargasso seawater and distributed evenly 
among the various treatment media. For nutrient limitation experiments, cultures were grown in $250 \mathrm{ml}$ of medium in $500 \mathrm{ml} \mathrm{Nalgene}{ }^{\circledR}$ baffled polycarbonate flasks that were cleaned using the procedure described above. At least two replicate treatments were performed per limitation experiment, and the limitation experiments were repeated three times. The growth of the cultures was monitored throughout the experiment by removing aliquots and measuring in vivo fluorescence using an AquaFluor ${ }^{\mathrm{TM}}$ hand-held fluorometer (Turner Designs, Sunnyvale, CA). Cells from the culture experiments were collected via filtration onto $5-\mu \mathrm{m}$ polycarbonate filters and frozen in liquid nitrogen for later RNA extraction.

3.5.6 Temperature Optimization. Non-axenic cultures of two T. erythraeum strains (IMS101 and GBRTRLI101) and one T. tenue strain (H9-4) were grown in triplicate on the modified YBCII medium (Chen et al., 1996) with Fe added as ferric citrate. Cultures were grown in $50 \mathrm{ml}$ polycarbonate tubes with light levels $\sim 140$ $\mu \mathrm{Ein} / \mathrm{m}^{2} / \mathrm{s}$ at $24^{\circ} \mathrm{C}, 26^{\circ} \mathrm{C}, 28^{\circ} \mathrm{C}$ and $31^{\circ} \mathrm{C}$. Growth was monitored daily using a TD-700 fluorometer with an in vivo Chla filter set (Turner Designs, Sunnyvale, CA).

3.5.7 Culture experiment with different Fe levels. Cultures of two $T$. erythraeum strains (IMS101 and GBRTRLI101) and one T. tenue strain (H9-4) were grown on modified YBCII medium (Chen et al., 1996) with EDTA held constant and varying amounts of ferric citrate added (Berman-Frank et al., 2001). Media preparation and culture handling was carried out using trace-metal clean techniques under HEPA filtration and class 100 conditions. The ferric citrate additions were $0 \mathrm{nM}, 10 \mathrm{nM}, 25 \mathrm{nM}$, $50 \mathrm{nM}, 100 \mathrm{nM}$ and 250nM, which correspond to concentrations of inorganically complexed $\mathrm{Fe}$ ([Fe']) values of $0.15 \mathrm{nM}, 0.31 \mathrm{nM}, 0.54 \mathrm{nM}, 0.94 \mathrm{nM}, 1.8 \mathrm{nM}$ and 4.5 nM. The Visual MintEQ program (available for free download at http://www.lwr.kth.se/English/OurSoftware/vminteq/) was used to complete calculations of Fe speciation in the media based on known chemical additions and careful adjustment of $\mathrm{pH}$ to $8.15+/-0.02$. The experiments were done in triplicate for each treatment at the optimal temperature for each clade $\left(26^{\circ} \mathrm{C}\right.$ for Ten and $28^{\circ} \mathrm{C}$ for Tery). Culture growth was monitored daily between 2 and 3 hours after the lights turned on in the incubator by 
pouring an aliquot of each well mixed culture into an acid cleaned $50 \mathrm{ml}$ polycarbonate tube and monitoring fluorescence on a TD-700 fluorometer with an in vivo Chla filter set (Turner Designs, Sunnyvale, CA). Before the growth experiment started, cultures were acclimated in Fe adjusted media through at least one doubling of cells and then transferred into fresh media when growth was balanced. In some cases, multiple transfers were required before growth rates separated between the different treatments. Samples were filtered down and frozen in liquid nitrogen for later RNA analysis on the morning when all treatments were growing exponentially and growth rates had separated between the low and high Fe treatments. This filtering was done using $25 \mathrm{~mm} 5-\mu \mathrm{m}$ polycarbonate filters $\sim 3-4$ hours after the lights turned on in the incubator. On that same day, $30 \mathrm{ml}$ aliquots of the cultures were placed in $60 \mathrm{ml}$ Nalgene ${ }^{\circledR}$ polycarbonate bottles (Nalge Nunc International Corporation, Rochester, NY) and $\mathrm{N}_{2}$ fixation rates were measured using the acetylene reduction assay (Capone, 1993). $\mathrm{N}_{2}$ fixation rate measurements were based on a linear regression of ethylene concentrations measured over three hours after acetylene addition. Results were normalized to Chl $a$ (Herbland et al., 1985).

3.5.8 Chl $\boldsymbol{a} /$ DNA Normalization. To ensure that Fe limitation did not affect the $\mathrm{Chl} a / \mathrm{DNA}$ ratio of the cultures, we filtered $15 \mathrm{mls}$ in triplicate from three low $\mathrm{Fe}$ and three high Fe cultures of GBRTRLI101 (18 filters total) and two low Fe and two high Fe cultures of H9-4 (12 filters total). Two of the $15 \mathrm{ml}$ filters were used to determine the average $\mathrm{Chl} a / \mathrm{ml}$ of each samples/condition. DNA was extracted from the remaining duplicate filters from each biological replicate using the DNeasy Plant Kit (QIAGEN Inc., Valencia, CA) and the number of copies of isiB/extraction was determined using the standard curve qPCR protocol described below with the DNA extractions added at a 1:10 dilution. The number of copies of $i s i B / \mathrm{ml}$ culture was determined after taking into account all dilution steps involved in the extraction procedure. This value was then compared with the $\mathrm{Chl} a / \mathrm{ml}$ value to determine $\mathrm{Chl} a /$ copy of DNA.

3.5.9 RNA Extraction and cDNA Synthesis. RNA was extracted using the Ribo-Pure ${ }^{\mathrm{TM}}$-Bacteria kit (Ambion Inc., Austin, TX) including the optional DNase-I 
treatment. Total RNA extracts were quantified using a NanoDrop ${ }^{\circledR}$ ND-1000 Full Spectrum UV/Vis Spectrophotometer (NanoDrop Technologies, Wilmington, DE). Normalized quantities of total RNA extracts were then converted into cDNA using the iScript cDNA synthesis kit (Bio-Rad Laboratories, Hercules, CA). As a negative control for later RT-PCR reactions, normalized total RNA was also put through the iScript cDNA synthesis without the addition of the reverse transcriptase enzyme (later referred to as noRT).

\subsubsection{RT Analysis of Gene Expression Axenic IMS101 Nutrient Experiment.} PCR reactions were performed on cDNA extracts using internal primers for each gene designed from the sequenced genome of T. erythraeum (IMS101) (Table 3). The $15 \mu 1$ reactions were run on a Mastercycler $\odot$ thermal cycler (Eppendorf AG, Hamburg, Germany) with MasterTaq $\subset$ Taq DNA polymerase (Eppendorf AG, Hamburg, Germany) at a final concentration of 1.25 units/PCR reaction per manufacturer's instructions without additional $\mathrm{Mg}^{+2}(1 \mathrm{x})$. Template cDNA was added to a final concentration of 0.32 $\mathrm{ng} / \mu \mathrm{l}$ and primers were added at a final concentration of $1 \mu \mathrm{mol} / \mathrm{L}$. The PCR reactions had the following conditions for each gene: idiA $\left(95^{\circ} \mathrm{C}\right.$ for $5 \mathrm{~min} ; 30$ cycles of $95^{\circ} \mathrm{C}$ for $1 \mathrm{~min}, 56.1^{\circ} \mathrm{C}$ for $1 \mathrm{~min}, 72^{\circ} \mathrm{C}$ for $30 \mathrm{sec}$; and $72^{\circ} \mathrm{C}$ for $\left.10 \mathrm{~min}\right)$, isi $B\left(95^{\circ} \mathrm{C}\right.$ for $5 \mathrm{~min} ; 35$ cycles of $95^{\circ} \mathrm{C}$ for $1 \mathrm{~min}, 57.8^{\circ} \mathrm{C}$ for $1 \mathrm{~min}, 72^{\circ} \mathrm{C}$ for $30 \mathrm{sec}$; and $72^{\circ} \mathrm{C}$ for $10 \mathrm{~min}$ ), and feoB $\left(95^{\circ} \mathrm{C}\right.$ for $5 \mathrm{~min}$; 40 cycles of $95^{\circ} \mathrm{C}$ for $1 \mathrm{~min}, 56.1^{\circ} \mathrm{C}$ for $1 \mathrm{~min}, 72^{\circ} \mathrm{C}$ for $30 \mathrm{sec}$; and $72^{\circ} \mathrm{C}$ for $10 \mathrm{~min}$ ).

\subsubsection{Quantitative PCR Analysis of Gene Expression from Fe Titration}

Experiment. Separate qPCR primer sets for the T. erythraeum clade and the T. tenue clade were designed using AlleleID ${ }^{\circledR}$ (PREMIER Biosoft International, Palo Alto, CA) based on alignments made from our sequencing efforts (Table 3). The primers were tested and found to be specific for only the targeted clade, equally efficient across multiple representatives from each targeted clade and mixtures of DNA from target and non-target clades did not result in inhibition (data not shown). be the most stable housekeeping gene with $T$. erythraeum grown under different $\mathrm{Fe}$, light and temperature conditions using geometric averaging of multiple candidate control 
genes using the GeNorm method (Vandesompele et al., 2002). The GeNorm method calculates the most stable gene pair for a given set of data, and comparisons of our various conditions determined that the ranking of the normalization genes from best to worst was: $r n p B, 16 \mathrm{~s}, g l y A$ and $r e c F$. Relative expression of $i s i B$ verses $r n p B$ was determined using absolute quantification of each gene and dividing the number of copies of the $i s i B$ gene determined per sample by the number of copies of the rnpB gene determined per sample (Applied Biosystems User Bulletin \#2: http://dna-9.intmed.uiowa.edu/RealtimePCRdocs/Compar_Anal_Bulletin2.pdf) (Larionov et al., 2005). The standards used for absolute quantification were cloned PCR products prepared as described (Zinser et al., 2006) using the TOPO TA Cloning ${ }^{\circledR}$ Kit for Sequencing (Invitrogen Corporation, Carlsbad, CA). Once cloned, the plasmids were extracted with QIAGEN Mini Prep kit (QIAGEN Inc., Valencia, CA), linearized using PstI (New England Biolabs ${ }^{\circledR}$ Inc., Ipswich, MA) and quantifed with Quant-iT ${ }^{\mathrm{TM}}$ PicoGreen ${ }^{\circledR}$ (Invitrogen Corporation, Carlsbad, CA). qPCR reactions were done on a 7500 Fast RealTime PCR System (Applied Biosystems Inc., Foster City, CA) using PowerSYBR ${ }^{\circledR}$ Green PCR Master Mix (Applied Biosystems Inc., Foster City, CA) at 1x concentration in a $20 \mu \mathrm{l}$ reaction with a final cDNA concentration of 1-2 $\mathrm{nM}$ and a final primer concentration of $200 \mathrm{nM}$. Cycler conditions were $50^{\circ} \mathrm{C}$ for $2 \mathrm{~min}, 95^{\circ} \mathrm{C}$ for $10 \mathrm{~min} ; 40$ cycles of $95^{\circ} \mathrm{C}$ for $15 \mathrm{sec}, 55^{\circ} \mathrm{C}$ for $1 \mathrm{~min}$ with fluorescence being read at $55^{\circ} \mathrm{C}$ followed by dissociation curve analysis from $60^{\circ} \mathrm{C}$ to $95^{\circ} \mathrm{C}$.

3.5.12 Alleviation of Fe Limitation Experiment. Following sampling for $\mathrm{N}_{2}$ fixation and $i s i B$ expression, the remaining $\sim 100 \mathrm{ml}$ of two Fe limited cultures of GBRTRLI101 were each split into three aliquots and used to inoculate two culture flasks containing replete $\left(\left[\mathrm{Fe}^{\prime}\right]=4.5 \mathrm{nM}\right)$ YBCII medium and one culture flask containing $\mathrm{Fe}$ omitted $\left(\left[\mathrm{Fe}^{\prime}\right]=0.15 \mathrm{nM}\right)$ YBCII medium. This generated four $+\mathrm{Fe}$ treatments and two Fe treatments. Samples for $i s i B$ expression analysis were taken immediately following inoculation and 24 hours later and processed as described in sections 3.5.9 and 3.5.11. 


\subsection{ACKNOWLEDGEMENTS}

This work was supported by a National Science Foundation Biological Oceanography Program grant to E.A.W. (OCE-0220945 and OCE-0623499), the Woods Hole Oceanographic Institution, and the University of Southern California. Funding for P.D.C was supplied by the Woods Hole Oceanographic Institution Academic Programs Office, the Center for Environmental Bioinorganic Chemistry at Princeton University, and a National Defense Science and Engineering Graduate Fellowship. The US Department of Energy Joint Genome Institute (http://www.jgi.doe.gov/) produced the IMS101 genomic sequence data discussed in this work.

The authors would like to thank John Waterbury for his generous help with designing culturing experiments and providing a detailed review of an early version of the manuscript. The authors want to thank Jim Moffett for providing training and assistance in trace metal clean techniques. The authors also wish to thank Sonya Dyhrman, Annette Hynes, Adam Rivers, Elizabeth Orchard, Nan Trowbridge, Freddy Valois and Brian Wilson for helpful discussion and assistance. 


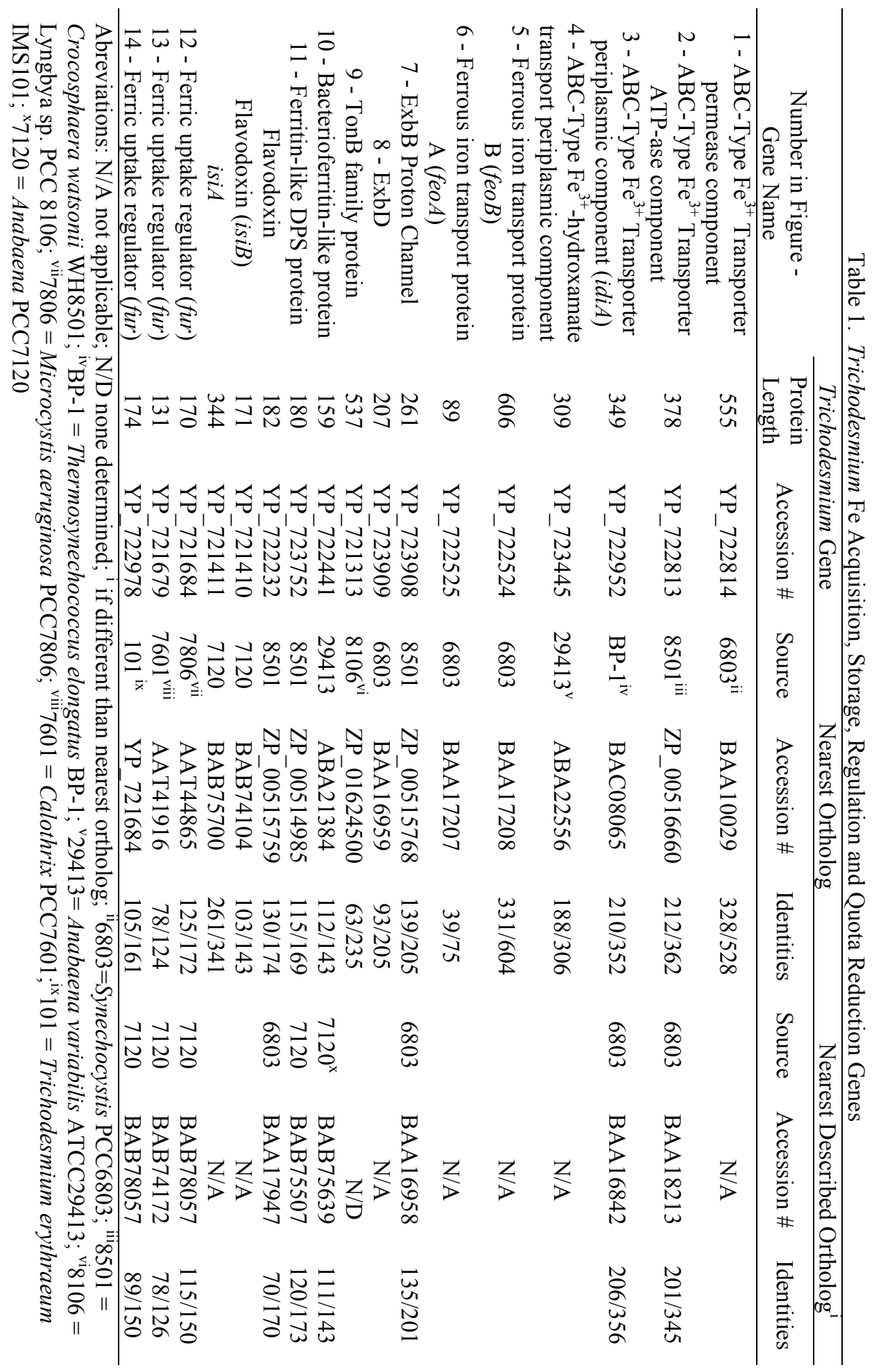


Table $2 \%$ Identity for Sequences

idiA (520 bp out of a 1050 bp gene)

Taxa T. erythraeum* T.thiebautii T.spiralis T. tenue**

T. erythraeum 100

T. thiebautii 93

T. spiralis 94

100

T. tenue 94

$98 \quad 100$

$99 \quad 99 \quad 100$

feoB (995 bp out of a 1821 bp gene)

Taxa T. erythraeum T.thiebautii T. spiralis T. tenue

T. erythraeum 100

T. thiebautii 95

T. spiralis 95

T. tenue 96

100

$98 \quad 100$

$98 \quad 98 \quad 100$

isiB (234 bp out of a 516 bp gene)

Taxa T. erythraeum T.thiebautii T. spiralis T. tenue

T. erythraeum 100

T. thiebautii 93

T. spiralis 94

100

T. tenue 94

$99 \quad 100$

* T. erythraeum includes IMS101 and GBRTRLI101 strains

** T. tenue includes Z-1 and H9-4 strains 
Table 3. Primers used in Sequencing (External) and Gene Expression Experiments (Internal and QPCR)

\begin{tabular}{|c|c|c|c|}
\hline $\begin{array}{l}\text { Primer } \\
\text { Name }\end{array}$ & 5' Primer & 3' Primer & $\begin{array}{l}\text { Target } \\
\text { Size } \\
\text { (BP) }\end{array}$ \\
\hline $\begin{array}{c}i d i A \\
\text { External }\end{array}$ & AATCTCTATTCTTCCCGTCAC & GCTTCTGGACTAACTAAATGTTC & 770 \\
\hline $\begin{array}{c}i d i A \\
\text { Internal }\end{array}$ & TCCAGCTAACCTCCGC & AATGCCAGCCGCAAC & 312 \\
\hline$i s i B$ & CAAGTCCCGAAGATTTTGATGG & CATAACCCTCTGTAGACCAAGACCC & 264 \\
\hline $\begin{array}{c}\text { isiB QPCR } \\
\text { (Ten) }\end{array}$ & AAGTGACTGGGCTGGTTTC & CAATAGTAGTACCTCСТTTCTCAG & 167 \\
\hline $\begin{array}{c}\text { isiB QPCR } \\
\text { (Tery) }\end{array}$ & AAAGTGACTGGAGTGGTTTC & GTAGTACCTCCAAGCCCA & 163 \\
\hline $\begin{array}{c}f e o B \\
\text { External }\end{array}$ & ATTTCTCTGAAGGTTCTTAAATG & TTATCAACTTAAAGCCAAAGCTC & 1983 \\
\hline & TGGAATTATTAGATGAGCTTTTCA & GCTCCTTGGTAAAAAATGAAAC & 1917 \\
\hline $\begin{array}{c}f e o B \\
\text { Internal } \\
\text { rnpB }\end{array}$ & TCCCAACCTACTAATGCCACA & CTTCGGAAAAACCATTGAAA & 217 \\
\hline $\begin{array}{l}\text { QPCR } \\
\text { (Ten) } \\
\text { rnpB }\end{array}$ & GAATCTATGAACGCAACGGAAC & ACCAGCAGTGTCGTGAGG & 102 \\
\hline $\begin{array}{c}\text { QPCR } \\
\text { (Tery) } \\
\text { rnpB }\end{array}$ & ACCAACCATTGTTCCTTCG & CAAGCCTGCTGGATAACG & 199 \\
\hline $\begin{array}{c}\text { degenerate } \\
\text { (Vioque, } \\
\text { 1997) }\end{array}$ & GRTYGAGGAAAGTCCGGRCT & RTAAGCCGGRTTCTGT & $\sim 324$ \\
\hline
\end{tabular}




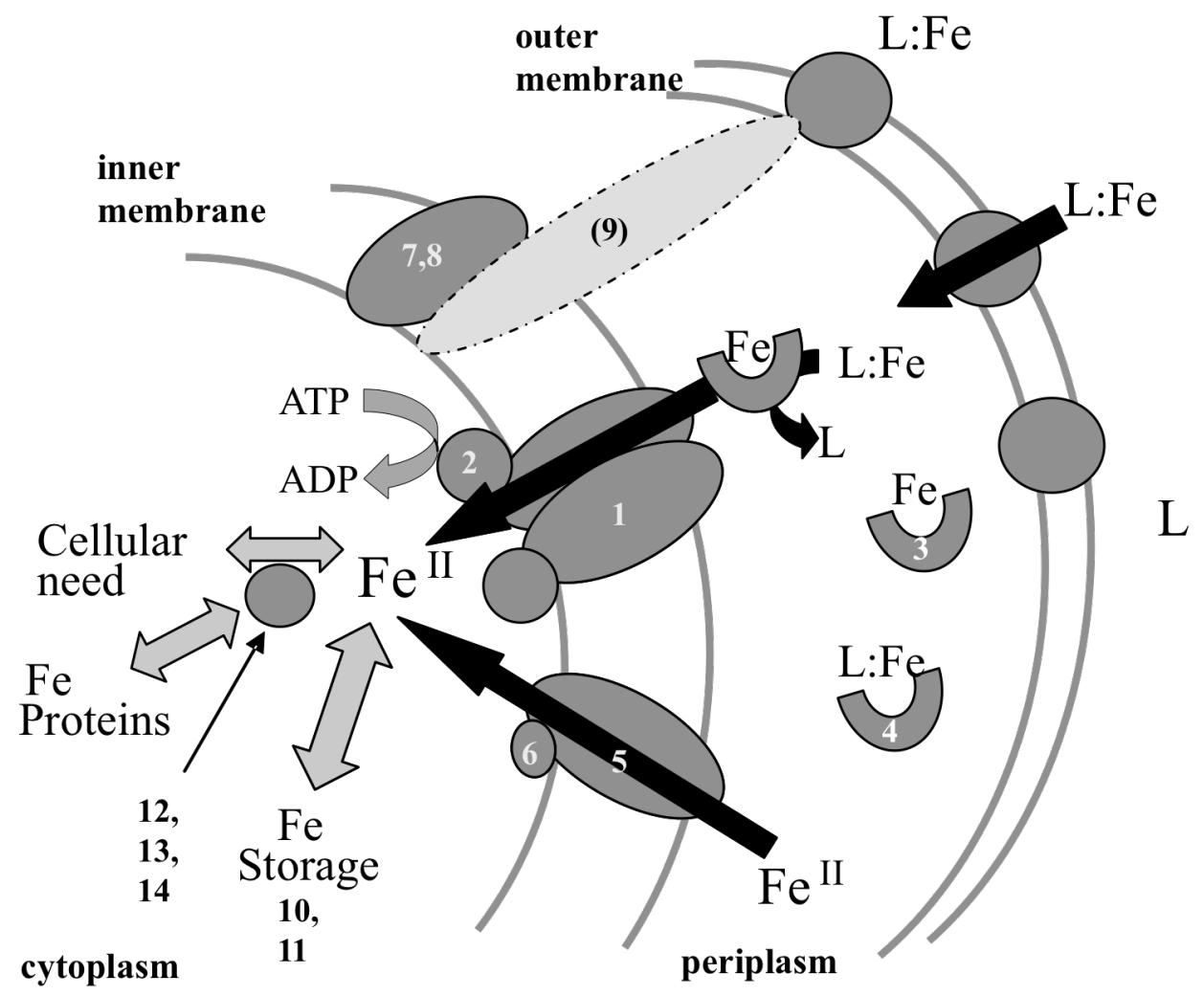

Figure 1: Schematic of iron (Fe) acquisition and cellular fate of $\mathrm{Fe}$ for T. erythraeum IMS101 as predicted from genome analysis. The numbers correspond to the proteins described in Table 1. Parentheses indicate that the corresponding protein in $T$. erythraeum IMS101 is divergent from experimentally described proteins. L represents Fe-binding ligands. 


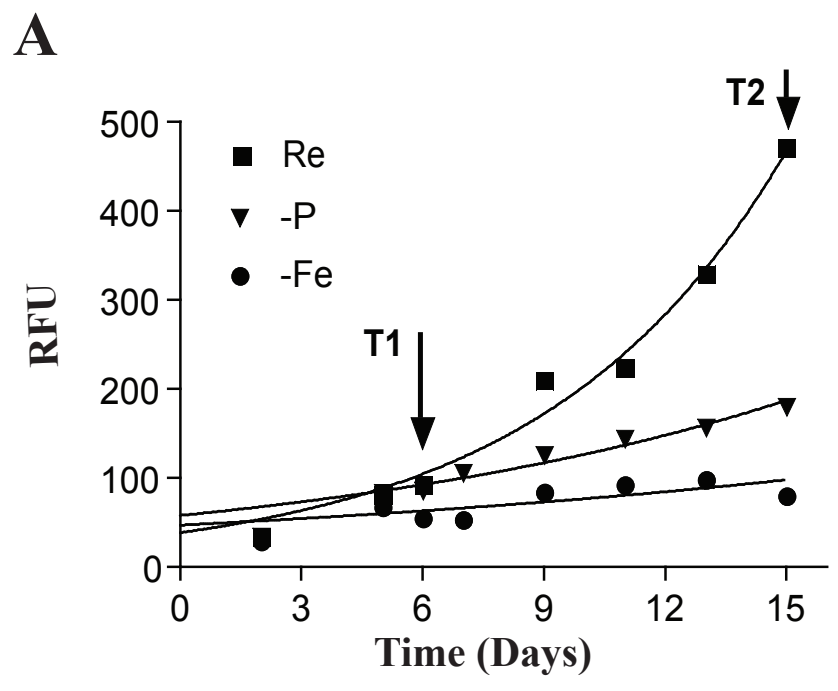

B

T1

idiA

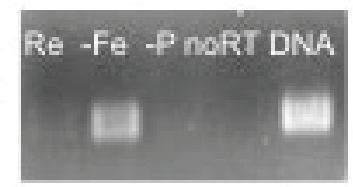

feoB

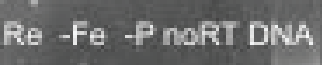

Re -Fe -P NORT DNA

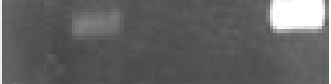

isiB

Re - Fe - P NORT DNA

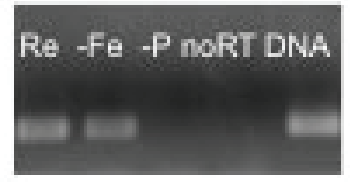

DNARE -Fe -P nORT

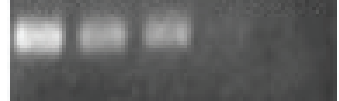

Re -Fe -P nORT DNA

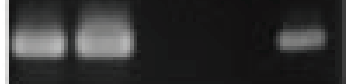

Fig. 2. Representative growth curve of nutrient limitation culture experiment with T. erythraeum IMS101 (A). RFU stands for relative fluorescence units and measures the orange fluorescence of the cultures. Arrows T1 and T2 indicate where on the growth curve samples were removed for gene expression analysis. (B) Agarose gel images showing expression of $i d i A, f e o B$ and $i s i B$ as determined by RT-PCR at T1 and T2 in replete culture (Re), Fe limited culture (-Fe), P limited culture (-P). Genomic IMS101 DNA was used as a positive control (DNA).

Absence of genomic DNA contamination in RNA preparation was confirmed by completing the reverse transcription reaction without reverse transcriptase (noRT) followed by RT-PCR. 


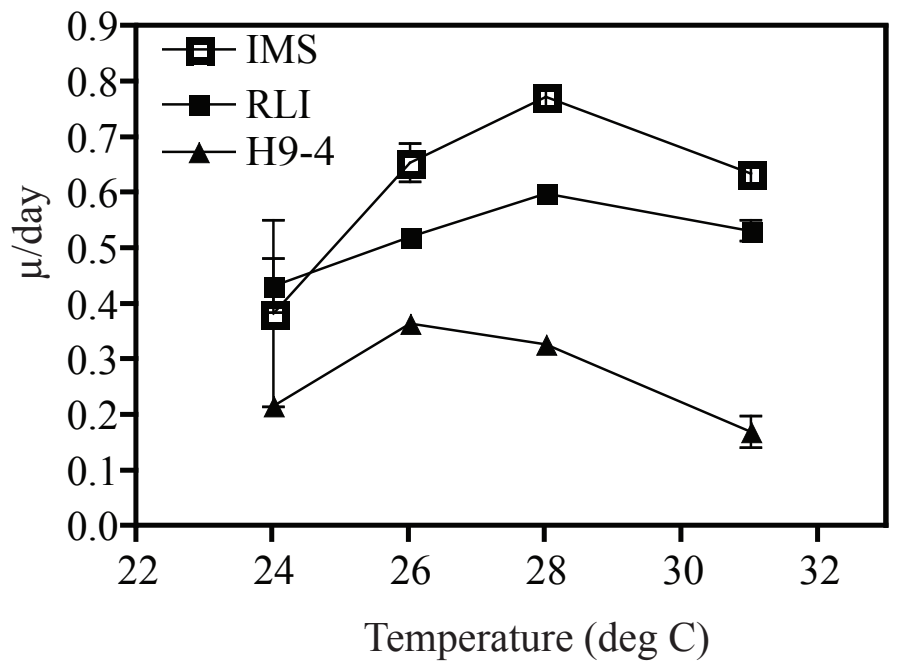

Fig. 3. Growth rate response of different Trichodesmium species grown at varying temperatures. 

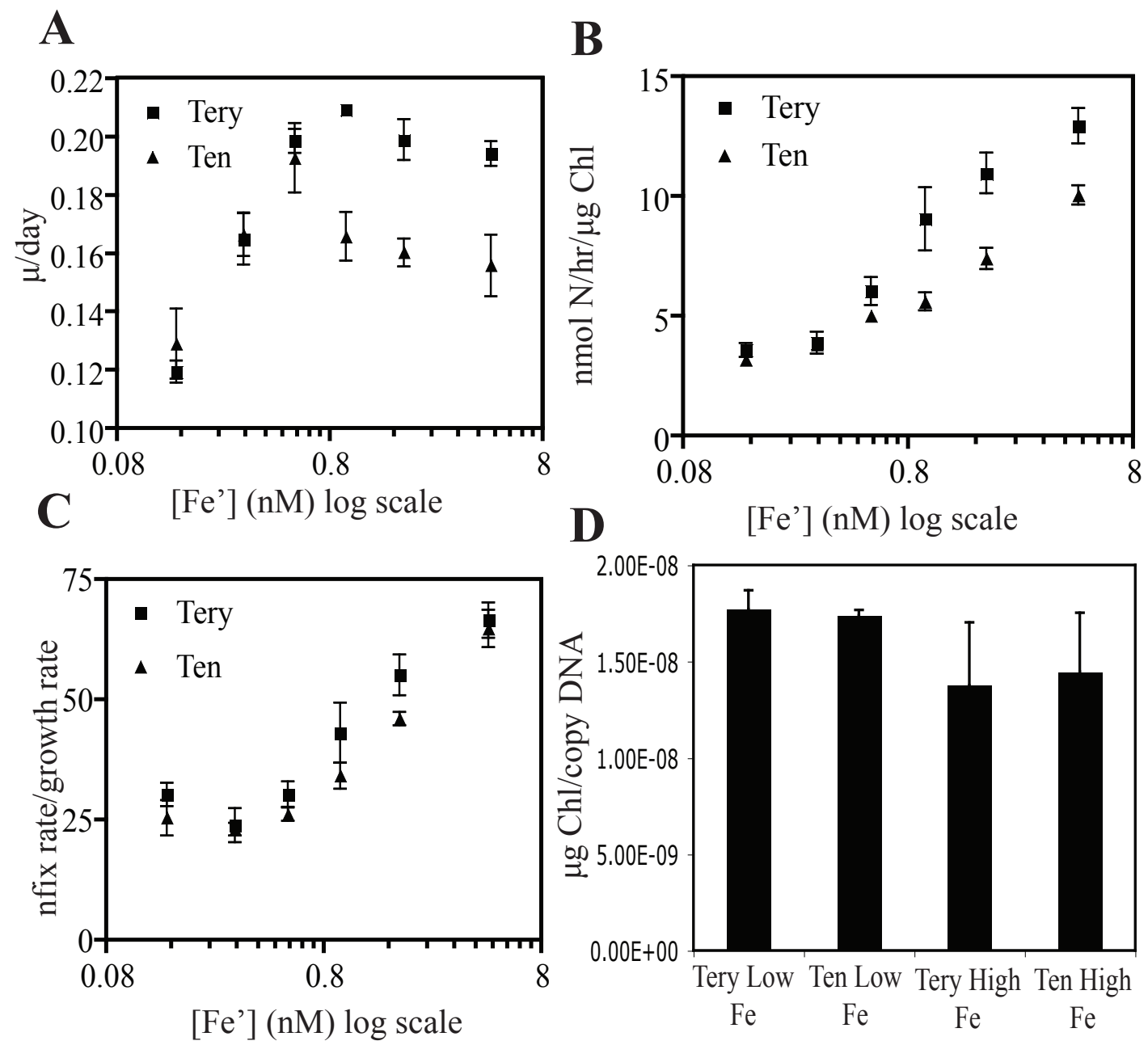

Fig. 4. Physiological responses to Fe limitation in two clades of Trichodesmium. (A) Growth rates of representatives of both clades of Trichodesmium grown on varying amounts of [Fe']. The [Fe'] values were $0.15 \mathrm{nM}, 0.31 \mathrm{nM}, 0.54 \mathrm{nM}, 0.94 \mathrm{nM}, 1.8 \mathrm{nM}$ and $4.5 \mathrm{nM}$. (B) Nitrogen fixation rates determined by acetylene reduction normalized to $\mu \mathrm{g}$ chl of culture from representatives of both clades of Trichodesmium grown in the same media. (C) The relationship of nitrogen fixation rates defined above with culture growth rates. (D) The ratio of chl/DNA in samples from low and high Fe treatments in both clades of Trichodesmium. In all graphs error bars represent standard error of biological replicates. 


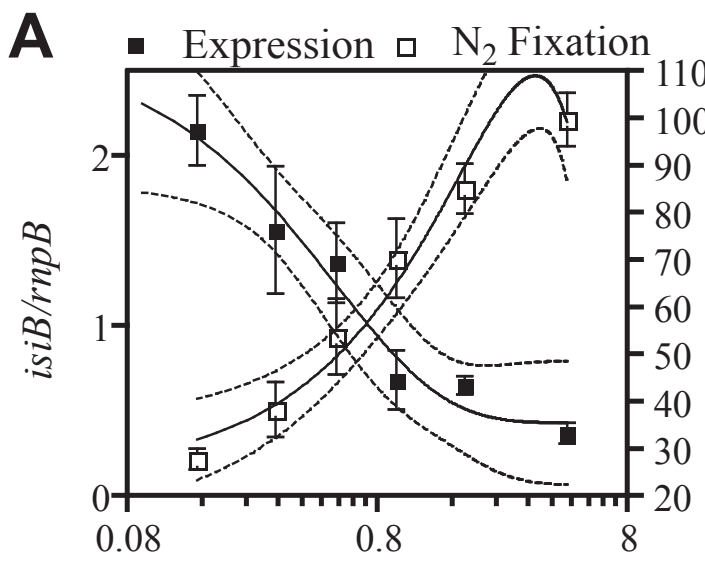

[Fe'] (nM) Log Scale

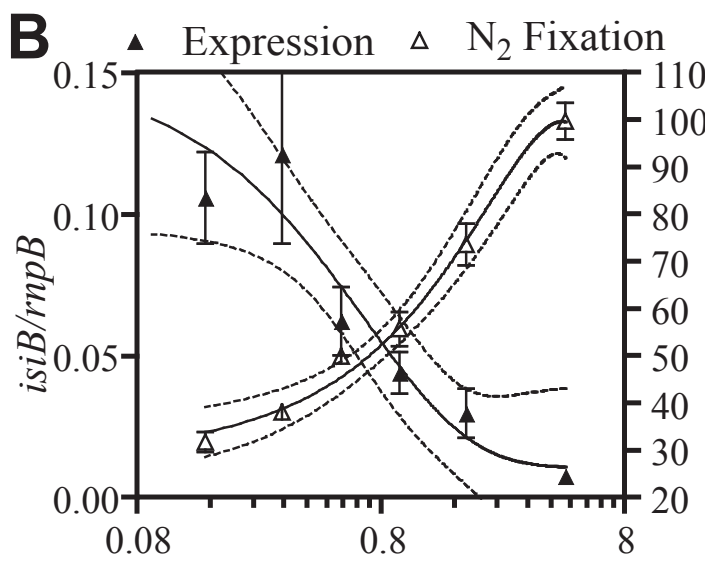

C

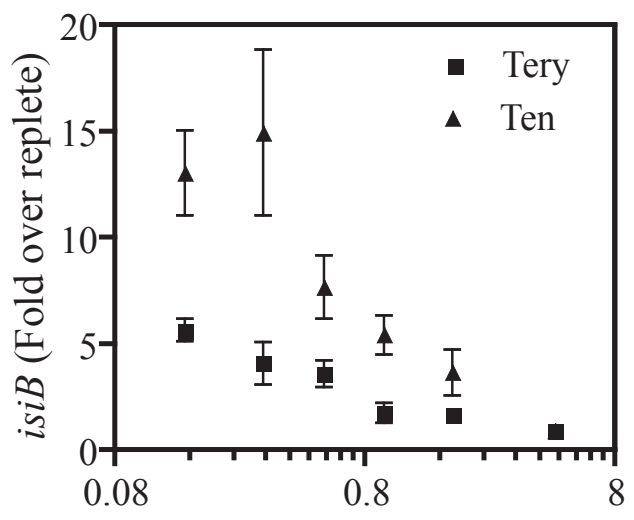

[Fe'] (nM) Log Scale

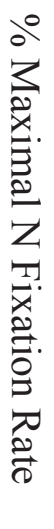

Figure. 5. Changes in $i s i B$ gene expression and $\mathrm{N}_{2}$ fixation in response to growth on different $\mathrm{Fe}$ levels in representatives of both phylogenetic clades of Trichodesmium. In both panels $\mathrm{A}$ and $\mathrm{B}$, gene - expression is shown as a ratio of $i s i B$ 3 gene transcripts divided by the number of $r n p B$ gene transcripts in the closed symbols and $\%$ maximal $\underset{\mathrm{N}}{2}$ fixation rates are shown in the open symbols. (A) The relationship between $i$ siB expression and $\mathrm{N}_{2}$ 을 fixation rates in six $T$. erythraeum $\approx$ cultures (three IMS101 and three तै GBRTRLI101) grown at each [Fe'] treatment. (B) isiB expression and $\mathrm{N}_{2}$ fixation rates measured in three $T$. tenue H9-4 cultures grown at each [Fe'] treatment. (C) The fold increase in expression of isiB relative to expression at replete [Fe'] of 4.5 $\mathrm{nM}$ is shown for both clades. In all three graphs, error bars are standard error based on biological replicates. 


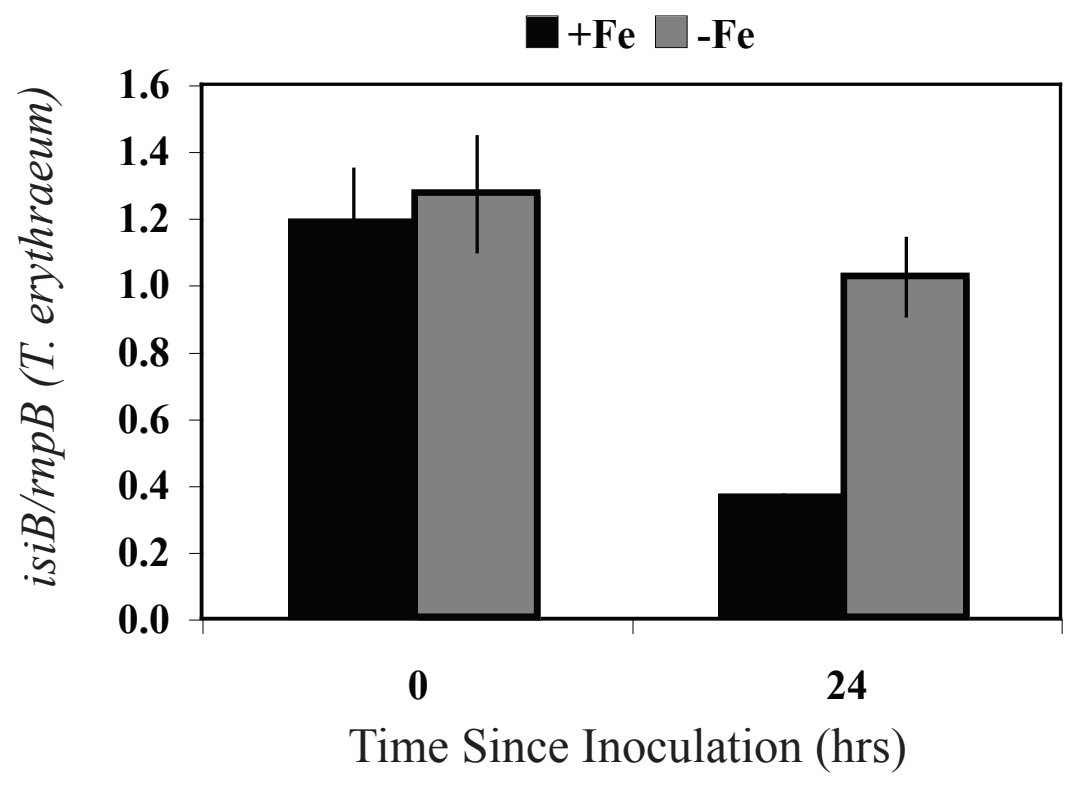

Figure 6. Response of $i s i B$ expression in T. erythraeum to Fe addition. T. erythraeum isiB/rnpB is shown for cultures that had been growing under Fe limited conditions immediately following inoculation into $+\mathrm{Fe}$ or -Fe medium and 24 hours later. Error bars respresent standard error of duplicate biological replicates for the -Fe treatment and quadruple biological replicates for the $+\mathrm{Fe}$ treatment. 


\subsection{REFERENCES}

Altschul, S.F., Gish, W., Miller, W., Myers, E.W., and Lipman, D.J. (1990) Basic Local Alignment Search Tool. J Mol Biol 215: 403-410.

Andrews, S.C., Smith, J.M.A., Hawkins, C., Williams, J.M., Harrison, P.M., and Guest, J.R. (1993) Overproduction, purification and characterization of the bacterioferritin of Escherichia coli and a C-terminally extended variant. Eur J of Biochem 213: 329-338.

Andrews, S.C., Robinson, A.K., and Rodriguez-Quinones, F. (2003) Bacterial iron homeostasis. Fems Microbiol Rev 27: 215-237.

Azam, F. (1998) Microbial Control of Oceanic Carbon Flux: The Plot Thickens. Science 280: 694-696.

Barbeau, K., Rue, E.L., Trick, C.G., Bruland, K.T., and Butler, A. (2003) Photochemical reactivity of siderophores produced by marine heterotrophic bacteria and cyanobacteria based on characteristic Fe(III) binding groups. Limnol Oceanogr 48: 1069-1078.

Bendtsen, J.D., Nielsen, H., von Heijne, G., and Brunak, S. (2004) Improved prediction of signal peptides: SignalP 3.0. J Mol Biol 340: 783-795.

Berman-Frank, I., Quigg, A., Finkel, Z.V., Irwin, A.J., and Haramaty, L. (2007)

Nitrogen-fixation strategies and Fe requirements in cyanobacteria. Limnol Oceanogr 52: 2260-2269.

Berman-Frank, I., Cullen, J.T., Shaked, Y., Sherrell, R.M., and Falkowski, P.G. (2001) Iron availability, cellular iron quotas, and nitrogen fixation in Trichodesmium. Limnol Oceanogr 46: 1249-1260.

Bibby, T.S., Nield, J., and Barber, J. (2001) Iron deficiency induces the formation of an antenna ring around trimeric photosystem I in cyanobacteria. Nature 412: 743.

Brand, L.E. (1991) Minimum iron requirements of marine phytoplankton and the implications for the biogeochemical control of new production. Limnology and Oceanography [Limnol Oceanogr] 36: 1756-1771.

Braun, V. (1995) Energy-coupled transport and signal-transduction through the Gramnegative outer-membrane via Tonb-Exbb-Exbd-dependent receptor proteins. FEMS Microbiol Rev 16: 295-307.

Breitbarth, E., Oschilies, A., and LaRoche, J. (2007) Physiological constraints on the global distribution of Trichodesmium - effect of temperature on diazotrophy.

Biogeosciences 4: 53-61.

Capone, D.G. (1993) Determination of nitrogenase activity in aquatic samples using the acetylene reduction procedure. In Kemp, P.F., Sherr, B.F., Sherr, E.B., and Cole, J. (eds). Lewis, pp. 621-631.

Capone, D.G. (2001) Marine nitrogen fixation: what's the fuss? Curr Opin Microbiol 4: 341-348. 
Capone, D.G., Ferrier, M.D., and Carpenter, E.J. (1994) Amino acid cycling in colonies of the planktonic marine cyanobacterium Trichodesmium thiebautii. Appl Environ Microbiol 60: 3989-3995.

Capone, D.G., Zehr, J.P., Paerl, H.W., Bergman, B., and Carpenter, E.J. (1997)

Trichodesmium, a globally significant marine cyanobacterium. Science 276: 1221-1229.

Carpenter, E.J., O'Neil, J.M., Dawson, R., Capone, D.G., Siddiqui, P.J.A., Roenneberg, T., and Bergman, B. (1993) The tropical diazotrophic phytoplankter Trichodesmium: Biological characteristics of two common species. Mar Ecol Prog Ser 95: 295-304.

Castruita, M., Saito, M., Schottel, P.C., Elmegreen, L.A., Myneni, S., Stiefel, E.I., and Morel, F.M.M. (2006) Overexpression and Characterization of an Iron Storage and DNABinding Dps Protein from Trichodesmium erythraeum. Appl Environ Microbiol 72: 29182924.

Chen, Y.B., Zehr, J.P., and Mellon, M. (1996) Growth and nitrogen fixation of the diazotrophic filamentous nonheterocystous cyanobacterium Trichodesmium sp IMS 101 in defined media: Evidence for a circadian rhythm. J Phycol 32: 916-923.

Davis, C.S., and McGillicuddy, D.J. (2006) Transatlantic Abundance of the $\mathrm{N}_{2}$-Fixing Colonial Cyanobacterium Trichodesmium. Science 312: 1517-1520.

Escolar, L., Perez-Martin, J., and de Lorenzo, V. (1999) Opening the iron box: transcriptional metalloregulation by the Fur protein. J Bacteriol 181: 6223-6229.

Falkowski, P.G. (1997) Evolution of the nitrogen cycle and its influence on the biological sequestration of $\mathrm{CO}_{2}$ in the ocean. Nature 387: 272-275.

Fillat, M.F., Borrias, W.E., and Weisbeek, P.J. (1991) Isolation and overexpression in Escherichia coli of the flavodoxin gene from Anabaena PCC 7119. Biochem J 280: 187191.

Fu, F.X., and Bell, P.R.F. (2003) Growth, $\mathrm{N}_{2}$ fixation and photosynthesis in a cyanobacterium, Trichodesmium sp., under Fe stress. Biotechnol Lett 25: 645-649.

Fulda, S., Huang, F., Nilsson, F., Hagemann, M., and Norling, B. (2000) Proteomics of Synechocystis $s p$. strain PCC 6803. Identification of periplasmic proteins in cells grown at low and high salt concentrations. Eur J Biochem 267: 5900-5907.

Gruber, N., and Sarmiento, J.L. (1997) Global patterns of marine nitrogen fixation and denitrification. Glob Biogeochem Cycles 11: 235-266.

Herbland, A., Lebouteiller, A., and Raimbault, P. (1985) Size Structure of Phytoplankton Biomass in the Equatorial Atlantic-Ocean. Deep-sea Res 32: 819-836.

Hernandez, J.A., Lopez-Gomollon, S., Bes, M.T., Fillat, M.F., and Peleato, M.L. (2004) Three fur homologues from Anabaena sp PCC7120: exploring reciprocal proteinpromoter recognition. FEMS Microbiol Lett 236: 275-282.

Kammler, M., Schon, C., and Hantke, K. (1993) Characterization of the ferrous iron uptake system of Escherichia coli. J Bacteriol 175: 6212-6219. 
Katoh, H., Hagino, N., Grossman, A.R., and Ogawa, T. (2001) Genes essential to iron transport in the cyanobacterium Synechocystis sp. strain PCC 6803. J Bacteriol 183: 2779-2784.

Keren, N., Aurora, R., and Pakrasi, H.B. (2004) Critical roles of bacterioferritins in iron storage and proliferation of cyanobacteria. Plant Physiol 135: 1666-1673.

Koster, W. (2001) ABC transporter-mediated uptake of iron, siderophores, heme and vitamin B-12. Res Microbiol 152: 291-301.

Kupper, H., Setlik, I., Seibert, S., Prasil, O., Setlikova, E., Strittmatter, M. et al. (2008) Iron limitation in the marine cyanobacterium Trichodesmium reveals new insights into regulation of photosynthesis and nitrogen fixation. New Phytol 179: 784-798.

Kustka, A., Sanudo-Wilhelmy, S., Carpenter, E.J., Capone, D.G., and Raven, J.A. (2003) A revised estimate of the iron use efficiency of nitrogen fixation, with special reference to the marine cyanobacterium Trichodesmium spp. (Cyanophyta). J Phycol 39: 12-25.

Larionov, A., Krause, A., and Miller, W. (2005) A standard curve based method for relative real time PCR data processing. Bmc Bioinformatics 6: ARTN 62.

LaRoche, J., Boyd, P.W., McKay, R.M.L., and Geider, R.J. (1996) Flavodoxin as an in situ marker for iron stress in phytoplankton. Nature 382: 802-805.

Leonhardt, K., and Straus, N.A. (1992) An iron stress operon involved in photosynthetic electron transport in the marine cyanobacterium Synechococcus sp. PCC 7002. J Gen Microbiol 138: 1613-1621.

Martiny, A.C., Coleman, M.L., and Chisholm, S.W. (2006) Phosphate acquisition genes in Prochlorococcus ecotypes: Evidence for genome-wide adaptation. P Natl Acad Sci Usa 103: $12552-12557$.

Michel, K.P., Berry, S., Hifney, A., Kruip, J., and Pistorius, E.K. (2003) Adaptation to iron deficiency: a comparison between the cyanobacterium Synechococcus elongatus PCC 7942 wild-type and a DpsA-free mutant. Photosynthesis Research 75: 71-84.

Michel, K.P., and Pistorius, E.K. (2004) Adaptation of the photosynthetic electron transport chain in cyanobacteria to iron deficiency: The function of IdiA and IsiA. Physiol Plant 120: 36-50.

Montoya, J.P., Holl, C.M., Zehr, J.P., Hansen, A., Villareal, T.A., and Capone, D.G. (2004) High rates of $\mathrm{N}_{2}$ fixation by unicellular diazotrophs in the oligotrophic Pacific Ocean. Nature 430: 1027-1031.

Moore, J.K., and Doney, S.C. (2007) Iron availability limits the ocean nitrogen inventory stabilizing feedbacks between marine denitrification and nitrogen fixation. Global Biogeochem Cy 21: ARTN GB2001.

Moore, J.K., Doney, S.C., and Lindsay, K. (2004) Upper ocean ecosystem dynamics and iron cycling in a global three-dimensional model. Global Biogeochem Cy 18: ARTN GB4028. 
Moran, M.A., Buchan, A., Gonzalez, J.M., Heidelberg, J.F., Whitman, W.B., Kiene, R.P. et al. (2004) Genome sequence of Silicibacter pomeroyi reveals adaptations to the marine environment. Nature 432: 910-913.

Mulholland, M.R., and Capone, D.G. (2001) Stoichiometry of nitrogen and carbon utilization in cultured populations of Trichodesmium IMS101: Implications for growth. Limnol Oceanogr 46: 436-443.

Orcutt, K.M., Rasmussen, U., Webb, E.A., Waterbury, J.B., Gundersen, K., and Bergman, B. (2002) Characterization of Trichodesmium spp. by genetic techniques. Appl Environ Microbiol 68: 2236-2245.

Paerl, H.W., Prufert-Bebout, L.E., and Guo, C. (1994) Iron-stimulated $\mathrm{N}_{2}$ fixation and growth in natural and cultured populations of the planktonic marine cyanobacteria Trichodesmium spp. Appl Environ Microbiol 60: 1044-1047.

Palenik, B., Ren, Q., Dupont, C.L., Myers, G.S., Heidelberg, J.F., Badger, J.H. et al. (2006) Genome sequence of Synechococcus CC9311: Insights into adaptation to a coastal environment. PNAS 103: 13555-13559.

Post, A.F., Dedej, Z., Gottlieb, R., Li, H., Thomas, D.N., El-Absawi, M. et al. (2002) Spatial and temporal distribution of Trichodesmium spp. in the stratified Gulf of Aqaba, Red Sea. Marine Ecology-Progress Series 239: 241-250.

Rivers, A.R., Jakuba, R.W., and Webb, E.A. (2009) Iron stress genes in marine Synechococcus and the development of a flow cytometric iron stress assay.

Environmental Microbiology 11: 382-396.

Saito, M.A., Goepfert, T.J., and Ritt, J.T. (2008) Some thoughts on the concept of colimitation: Three definitions and the importance of bioavailability. Limnol Oceanogr 53: $276-290$.

Shanks, A.L., and Reeder, M.L. (1993) Reducing Microzones and Sulfide Productin in Marine Snow. Mar Ecol-prog Ser 96: 43-47.

Shi, T., Sun, Y., and Falkowski, P.G. (2007) Effects of iron limitation on the expression of metabolic genes in the marine cyanobacterium Trichodesmium erythraeum IMS 101. Environmental Microbiology 9: 2945-2956.

Teuber M., G., A. and Neve H. (1992) The Genus Lactococcus. In Balows, A., Trüper, H.G., Dworkin, M., Harder, and W. and Schleifer, K.-H. (eds). New York, N.Y.:Springer-Verlag, pp. 1482-1501.

Thompson, J.D., Gibson, T.J., Plewniak, F., Jeanmougin, F., and Higgins, D.G. (1997) The ClustalX windows interface: flexible strategies for multiple sequence alignment aided by quality analysis tools. Nucleic Acids Res 25: 4876-4882.

Tillett, D., and Neilan, B.A. (2000) Xanthogenate nucleic acid isolation from cultured and environmental cyanobacteria. Journal of Phycology 36: 251-258. 
Vandesompele, J., De Preter, K., Pattyn, F., Poppe, B., Van Roy, N., De Paepe, A., and Speleman, F. (2002) Accurate normalization of real-time quantitative RT-PCR data by geometric averaging of multiple internal control genes. Genome Biol 3: Research0034.10034.11.

Vioque, A. (1997) The RNase P RNA from cyanobacteria: short tandemly repeated repetitive (STRR) sequences are present within the RNase P RNA gene in heterocystforming cyanobacteria. Nucleic Acids Res 25: 3471-3477.

Waterbury, J.B., Watson, S.W., Valois, F.W., and Franks, D.G. (1986) Biological and ecological characterization of the marine unicellular cyanobacterium Synechococcus. In Canadian Bulletin of Fisheries and Aquatic Sciences. Platt, T., and Li, W.K.W. (eds). Ottawa:Dept. of Fisheries and Oceans, pp. 71-120.

Webb, E.A., Moffett, J.W., and Waterbury, J.B. (2001) Iron stress in open-ocean cyanobacteria (Synechococcus, Trichodesmium, and Crocosphaera spp.): identification of the IdiA protein. Appl Environ Microbiol 67: 5444-5452.

Zehr, J.P., Waterbury, J.B., Turner, P.J., Montoya, J.P., Omoregie, E., Steward, G.F. et al. (2001) Unicellular cyanobacteria fix $\mathrm{N}_{2}$ in the subtropical North Pacific Ocean. Nature 412: 635-638.

Zinser, E.R., Coe, A., Johnson, Z.I., Martiny, A.C., Fuller, N.J., Scanlan, D.J., and Chisholm, S.W. (2006) Prochlorococcus Ecotype Abundances in the North Atlantic Ocean As Revealed by an Improved Quantitative PCR Method. Appl Environ Microbiol 72: 723-732. 


\section{Chapter 4: A Molecular Demonstration of Trichodesmium- SPECific Fe limitation Of N $_{2}$ FiXation in the PaCifiC and Atlantic OCEANS}

\subsection{Abstract}

Diazotrophic cyanobacteria (i.e., Trichodesmium) are important contributors to global carbon and nitrogen cycles. Understanding the environmental factors that control their growth and ability to fix $\mathrm{N}_{2}$ is key to developing accurate global ecosystem models to predict the effects of climate change. Iron $(\mathrm{Fe})$ has been shown to be an important element for limiting the growth and $\mathrm{N}_{2}$ fixation of Trichodesmium in the laboratory, but there has been limited work assessing where this factor limits Trichodesmium in situ. We surveyed Trichodesmium populations in both the Atlantic and Pacific Oceans for Fe limitation using a recently developed molecular method involving quantitative reverse transcriptase polymerase chain reaction (qRT-PCR) of the $i s i B$ gene, encoding flavodoxin, in conjunction with measurements of dissolved $\mathrm{Fe}$ and $\mathrm{PO}_{4}$. Fe limitation of Trichodesmium was widespread in the Pacific Ocean and minimal to nonexistent in the

Atlantic Ocean. We found an inverse correlation between expression of the isiB gene and $\mathrm{Fe} / \mathrm{PO}_{4}$ that allowed for the calculation of a critical $\mathrm{Fe} / \mathrm{PO}_{4}$ value associated with $\mathrm{Fe}$ limitation of $\mathrm{N}_{2}$ fixation by Trichodesmium, which closely resembled values used in predictive global ecosystem models (where Fe speciation was ignored). In addition to validating previous models with quantitative evidence of Fe limitation of $\mathrm{N}_{2}$ fixation in the field, the data presented suggests that the majority of dissolved Fe in the open ocean is available to Trichodesmium regardless of speciation.

\subsection{INTRODUCTION}

Diazotrophic cyanobacteria (e.g. Trichodesmium) are not only important contributors to primary production in the upper ocean, but they are also important in the nitrogen $(\mathrm{N})$ cycle by providing "new" $\mathrm{N}$ to the system through $\mathrm{N}_{2}$ fixation (Capone et al., 1997; Montoya et al., 2004). In certain regions of the ocean, it is believed that 
diazotrophy accounts for up to $50 \%$ of the new $\mathrm{N}$ that enters the system (Karl et al., 2002). The $\mathrm{N}$ from $\mathrm{N}_{2}$ fixation is understood to be critical to the carbon (C) and $\mathrm{N}$ cycles both regionally (Zehr et al., 2001) and globally (Capone et al., 1997; Gruber and Sarmiento, 1997). It is also thought that changes in $\mathrm{N}_{2}$ fixation rates can potentially influence $\mathrm{CO}_{2}$ sequestration over geologic time-scales (Capone et al., 1997; Falkowski, 1997; Gruber and Sarmiento, 1997).

For many decades, Trichodesmium was believed to be the only free-living cyanobacterial $\mathrm{N}_{2}$ fixer in the open ocean (Mulholland, 2007). While recent work has revealed that unicellular cyanobacteria capable of fixing $\mathrm{N}$ can be quite prevalent in the ocean (Zehr et al., 2001; Montoya et al., 2004; Grabowski et al., 2008), Trichodesmium is still believed to be a major contributor to marine $\mathrm{N}_{2}$ fixation (LaRoche and Breitbarth, 2005). Despite the importance of Trichodesmium, we still have very limited information about the factors that control its $\mathrm{N}_{2}$ fixation rate and distribution, and how $\mathrm{N}$ fixed by Trichodesmium transfers through the food web (Mulholland, 2007). Culture work has shown that physical factors such as light (Breitbarth et al., 2008) and temperature (Breitbarth et al., 2007) are important for Trichodesmium growth and $\mathrm{N}_{2}$ fixation rates. In addition to these physical factors, culture work, field correlations and qualitative molecular assays have shown that Trichodesmium $\mathrm{N}_{2}$ fixation can be Fe-limited (Berman-Frank et al., 2001; Webb et al., 2001; Fu and Bell, 2003; Kustka et al., 2003b; Berman-Frank et al., 2007; Shi et al., 2007; Kupper et al., 2008), phosphorus (P) limited (Hynes, In Press; Sanudo-Wilhelmy et al., 2001; Dyhrman et al., 2002; Fu et al., 2005; Sohm et al., 2008) or Fe-P co-limited (Mills et al., 2004). What we lack is a quantitative assessment of how these factors might be limiting Trichodesmium $\mathrm{N}_{2}$ fixation and a better understanding of where in the ocean these chemical factors are important.

In the modern ocean, $\mathrm{Fe}$ is not as biologically accessible as it was when cyanobacteria evolved because the thermodynamically stable redox state, Fe(III), has both a low solubility (Liu and Millero, 2002) and is strongly complexed by organic ligands that may render it unavailable to phytoplankton (Rue and Bruland, 1995; Rue and Bruland, 1997). Consequently, $\mathrm{Fe}$ is thought to limit primary production in large areas of 
the oceans, leading to the development of high nutrient low chlorophyll (HNLC) regions (Martin and Fitzwater, 1988; Martin et al., 1991; Coale et al., 1996). Diazotrophic cyanobacteria have a high cellular Fe-requirement associated with the biochemistry of $\mathrm{N}_{2}$ fixation that is hypothesized to be the result of their originating in an Fe-rich anoxic ocean (Kustka et al., 2003a; Kustka et al., 2003b). Biogeochemical models that incorporate measurements of global ocean circulation, dust transport and empirically determined physiological data for Fe limitation of phytoplankton have predicted that Fe limits diazotrophs, like Trichodesmium, in large areas of the ocean (Moore et al., 2004; Moore and Doney, 2007). Using the information that $\mathrm{Fe}$ and $\mathrm{PO}_{4}$ can both limit $\mathrm{N}_{2}$ fixation, a new plan to mitigate rising $\mathrm{CO}_{2}$ proposes using inputs of $\mathrm{Fe}$ and $\mathrm{PO}_{4}$ from the deep ocean to stimulate $\mathrm{N}_{2}$ fixation (Karl and Letelier, 2008). Even as these $\mathrm{CO}_{2}$ mitigation strategies are proposed, we still lack an understanding of how Trichodesmium acquires $\mathrm{Fe}$, what forms of $\mathrm{Fe}$ are bioavailable, how they respond to Fe deprivation and validation of where they are experiencing Fe limitation, findings that are important steps to predicting potential feedbacks on climate change.

Bottle enrichments, fluorescent staining, and chemical quota correlations have been used to make predictions of the factors limiting diazotrophic activity in the oceans (Sanudo-Wilhelmy et al., 2001; Dyhrman et al., 2002; Kustka et al., 2003b; Mills et al., 2004). These studies suggest that the two primary elements limiting Trichodesmium $\mathrm{N}_{2}$ fixation in the oceans are Fe and P. For example, in the Sargasso Sea Trichodesmium is thought to be predominantly $\mathrm{PO}_{4}$ stressed (Sanudo-Wilhelmy et al., 2001; Dyhrman et al., 2002; Sohm and Capone, 2006), findings that agree well with models of the region (Moore et al., 2004; Coles and Hood, 2007). In the equatorial North Atlantic Ocean, models disagree whether $\mathrm{PO}_{4}$ alone (Moore et al., 2004) or Fe- $\mathrm{PO}_{4}$ co-limitation $(\mathrm{Coles}$ and Hood, 2007) are controlling Trichodesmium $\mathrm{N}_{2}$ fixation. Field assessments of Trichodesmium through this region also report a mixture of $\mathrm{PO}_{4}$ limitation (Sanudo-

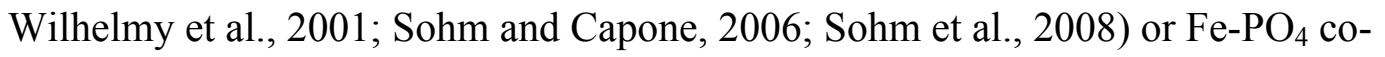
limitation of $\mathrm{N}_{2}$ fixation (Mills et al., 2004). Similar uncertainty exists in the Western Pacific Ocean (including the Western Pacific Warm Pool) as this region of the ocean has 
been understudied with respect to diazotroph assemblages and productivity (Campbell et al., 2005; LaRoche and Breitbarth, 2005). Pigment and flow-cytometric data suggests that cyanobacteria are important phytoplankton throughout the region (Blanchot et al., 1997; Neveux et al., 2006; Matsumoto and Ando, 2009) and there are reports of periodic blooms of Trichodesmium that can be seen via satellite (Dupouy et al., 1988). Model data suggests that $\mathrm{Fe}$ is likely to be the most important limiting nutrient for diazotrophs in the region (Moore et al., 2004), though local to New Caledonia it appears that $\mathrm{PO}_{4}$ limitation may be an important factor to consider as well (Van Den Broeck et al., 2004; Moutin et al., 2005; Rodier and Le Borgne, 2008). Clearly we need more empirical quantitative data to determine which of these factors is controlling $\mathrm{N}_{2}$ fixation by Trichodesmium in the field.

To get a better understanding of in situ Fe limitation of Trichodesmium $\mathrm{N}_{2}$ fixation, we used a recently developed calibrated molecular method looking at expression of the gene encoding flavodoxin, isiB, (Chappell and Webb, submitted) to assess Fe limitation in field samples from around the globe in conjunction with measurements of $\mathrm{PO}_{4}$ and $\mathrm{Fe}$. In addition to looking at locations where we expected to find $\mathrm{Fe}$ limitation, we also explored areas presumed to be $\mathrm{PO}_{4}$ limited and $\mathrm{Fe}-\mathrm{PO}_{4}$ co-limited. In general, we found a much higher prevalence of Fe limitation of Trichodesmium in the Pacific Ocean verses the Atlantic Ocean, with only one sample from the equatorial Atlantic showing evidence of isiB expression above the threshold expression level determined in the laboratory. When we compared the expression data from all the samples with the dissolved $[\mathrm{Fe}]$ and $\left[\mathrm{PO}_{4}\right]$ values from those stations, we found a threshold value of [Fe] above which there is no evidence of Trichodesmium Fe limitation similar to the value of [Fe'] associated with Fe limitation in laboratory cultures, indicating that most of the dissolved $\mathrm{Fe}$ in the open ocean is available to Trichodesmium regardless of ligand speciation. The relationship we determined between isiB expression and the $[\mathrm{Fe}] /\left[\mathrm{PO}_{4}\right]$ ratio, enabled us to calculate an in situ critical $[\mathrm{Fe}] /\left[\mathrm{PO}_{4}\right]$ ratio for Fe limitation, providing vetted values that will be useful for improved models. 


\subsection{Methods}

4.3.1 Dissolved Fe Sampling Procedure. Sampling took place on three cruises, one aboard the R/V Oceanus (cruise OC399-4) between March 22, 2004 and March 30, 2004 (Figure 1A, Stations 4-12), one aboard the R/V Seward Johnson (cruise SJ0609) between July 12, 2006 and July 24, 2006 (Figure 1A, Stations 13-21) and one aboard the R/V Kilo Moana (cruise KM0701) as part of the Western Pacific Warm Pool cruise between January 12, 2007 and February 9, 2007 (Figure 1B). Samples for dissolved Fe and nutrients were collected either using acid cleaned 10-L Teflon-coated Go-Flo bottles (General Oceanics) deployed directly on a Kevlar line (OC399-4) or acid cleaned 5L Teflon-coated exterior spring Niskin bottles (Ocean Test Equipment) deployed either directly on a Kevlar line (SJ0609) or mounted on a powder-coated rosette that was deployed on a Kevlar line (KM0701). After recovery, the bottles were transferred to a trace metal clean "bubble" kept at positive pressure using HEPA filtered air flow in the laboratory of the ship (KM0701) or to a trace metal clean van also supplied with HEPA filtered air on the deck of the ship (OC399-4 and SJ0609). The headspace of each bottle was pressurized with $0.2 \mu \mathrm{m}$ filtered ultra high purity (UHP) nitrogen pushing the water through a $142 \mathrm{~mm} 0.4 \mu \mathrm{m}$ acid-cleaned polycarbonate filter held in a polycarbonate filter sandwich (Geotech Environmental Equipment, Inc.). Water for dissolved Fe analysis was collected in acid-cleaned $250 \mathrm{ml}$ low-density polyethylene (LDPE) bottles and acidified to $\mathrm{pH} 1.7$ with concentrated high purity $\mathrm{HCl}$ (Seastar). Water for nutrient analysis was collected in $10 \% \mathrm{HCl}$ cleaned high-density polyethylene (HDPE) bottles (OC399-4) or 10\% HCl cleaned polypropylene $50 \mathrm{ml}$ tubes (SJ0609 and KM0701) and immediately frozen at $-20^{\circ} \mathrm{C}$ for later analysis. Analysis of the $\mathrm{PO}_{4}$ concentrations from the Sargasso Sea cruise was reported in (Jakuba et al., 2008). Samples from SJ0609 and KM0701 were sent to the College of Oceanic and Atmospheric Sciences, Oregon State University and dissolved inorganic phosphorus (DIP) was analyzed using a Technicon AutoAnalyzer II by J. Jennings with a detection level of $6 \mathrm{nmol} \mathrm{L}^{-1}$.

4.3.2 Dissolved Fe Analysis. Fe in the seawater samples was determined using isotope dilution and magnesium hydroxide preconcentration followed by analysis using 
inductively coupled mass spectrometry (Wu and Boyle, 1998; Saito and Schneider, 2006). Roughly $13.5 \mathrm{ml}$ of sample (exact volume determined gravimetrically) was poured into a $15 \mathrm{ml}$ polypropylene centrifuge tube (Globe Scientific Inc.) and equilibrated with a ${ }^{57} \mathrm{Fe}$ spike $(\sim 0.4 \mathrm{nM})$ overnight. The following day, the $\mathrm{Mg}(\mathrm{OH})_{2}$ and metals were precipitated out of the sample by the addition of a small amount ( 100 $\mu$ l) of high-purity ammonium hydroxide (Seastar Chemicals Inc.). Following ammonium hydroxide addition, the tubes were left undisturbed for $90 \mathrm{~s}$ and inverted multiple times to fully mix them. After an additional $90 \mathrm{~s}$, the tubes were centrifuged at $3000 \mathrm{x}$ g for 3 minutes and the sample was decanted off. The tubes were then spun at $3000 \mathrm{x} g$ for an additional 3 minutes forming a compact pellet, following which the remaining liquid was shaken off. The sample pellets were kept dry until the day of analysis (from a day to a week). On the morning of analysis, pellets were resuspended in 1-2 $\mathrm{ml} 0.8 \mathrm{~N}$ Nitric Acid (Seastar). Samples were analyzed on a Thermo-Finnigan Element 2 (E2) inductively coupled mass spectrometer (ICP-MS) in medium resolution mode. A procedural blank was determined by processing $1 \mathrm{ml}$ of low Fe seawater (which provides a negligible amount of $\mathrm{Fe}$ ) and calculating its $\mathrm{Fe}$ value as though it were a $13.5 \mathrm{ml}$ sample.

4.3.3 Collection of Trichodesmium Samples. A $130 \mu \mathrm{m}$-phytoplankton net (SeaGear Corporation, Florida) was towed using a $30 \mathrm{~m}$ line at the surface for 10-20 minutes. Immediately following the return to the surface, the contents of the tow were taken into the air-conditioned laboratory aboard the ship so that the Trichodesmium colonies could be separated from the other plankton using polypropylene bulb transfer pipettes. Colonies were transferred from the bulk solution into clean $0.4 \mu \mathrm{m}$ filtered microwavesterilized seawater, then they were filtered onto $5 \mu \mathrm{m}$ polycarbonate filters and stored in liquid $\mathrm{N}_{2}$ until RNA processing and analysis. On OC399-4, $200 \mathrm{ml}$ of the bulk net tow was filtered onto $5 \mu \mathrm{m}$ polycarbonate filters and preserved in liquid $\mathrm{N}_{2}$ without separation and rinsing.

4.3.4 Nitrogen Fixation Measurements. We measured $\mathrm{N}_{2}$ fixation rates on samples from two stations on cruise OC399-4 and five stations on KM0701. Net tows to collect samples were performed immediately before time zero of each $\mathrm{N}_{2}$ fixation 
incubation experiment, which were targeted for 1100, 1200 and $1300 \mathrm{hrs}$ local time. 10 20 colonies were placed in $30 \mathrm{ml}$ of filtered seawater in $75 \mathrm{ml}$ Nalgene $\mathbb{R}$ polycarbonate bottles (Nalge Nunc International Corporation, Rochester, NY). $\mathrm{N}_{2}$ fixation rates were measured using the acetylene reduction assay (Capone, 1993) using a Shimadzu GC-8A gas chromatograph with ethylene peaks integrated by a Shimadzu CR8A Chromatopac. $\mathrm{N}_{2}$ fixation rate measurements were based on a linear regression of ethylene concentrations immediately following acetylene addition and measurements made at one and two hours after addition. Two to three replicate bottles were used for each incubation experiment and two replicate samplings of the headspace of each bottle was used for each time point. Results were normalized to $\mathrm{Chl} a$ measured using standard techniques (Herbland et al., 1985).

4.3.5 RNA Extraction and cDNA Synthesis. RNA was extracted using the Ribo-Pure $^{\mathrm{TM}}$-Bacteria kit (Ambion Inc., Austin, TX) including the optional DNase-I treatment. Total RNA extracts were quantified using a NanoDrop ${ }^{\circledR}$ ND-1000 Full Spectrum UV/Vis Spectrophotometer (NanoDrop Technologies, Wilmington, DE). Normalized quantities of total RNA extracts were then converted into cDNA using the iScript cDNA synthesis kit (Bio-Rad Laboratories, Hercules, CA). As a negative control for later RT-PCR reactions, normalized total RNA was also put through the iScript cDNA synthesis without the addition of the reverse transcriptase enzyme (later referred to as noRT).

4.3.6 Quantitative PCR Analysis of Gene Expression. Separate qPCR primer sets for the Trichodesmium erythraeum clade (Tery) and the Trichodesmium tenue clade (Ten) designed and tested previously (Chappell and Webb, submitted) are relisted here (Table 1). qPCR primers were designed for our target Fe stress response gene, isiB, and a RNA normalization control gene, $\operatorname{rnp} B$. Because the majority of samples did not have a significant amount of $T$. erythraeum clade RNA according to $r n p B$ analysis of the cDNA (Table 2), we only report expression results for the $T$. tenue clade. $\%$ Tery $=[(\#$ copies of Tery clade $r n p B) /(\#$ copies of Tery + Ten clade $r n p B)] \times 100$. Relative expression of $i s i B$ verses $r n p B$ was determined using absolute quantification of each gene and dividing the 
$i s i B$ gene copy number by the $r n p B$ gene copy number determined for each cDNA sample (Applied Biosystems User Bulletin \#2: http://dna-9.int-

med.uiowa.edu/RealtimePCRdocs/Compar_Anal_Bulletin2.pdf) (Larionov et al., 2005).

The standards used for absolute quantification were cloned PCR products prepared as described in chapter two of this thesis and (Zinser et al., 2006) using the TOPO TA Cloning ${ }^{\circledR}$ Kit for Sequencing (Invitrogen Corporation, Carlsbad, CA). qPCR reactions were done on a 7500 Fast Real-Time PCR System (Applied Biosystems Inc., Foster City, CA) using PowerSYBR ${ }^{\circledR}$ Green PCR Master Mix (Applied Biosystems Inc., Foster City, $\mathrm{CA})$ at $1 \mathrm{x}$ concentration in a $20 \mu \mathrm{l}$ reaction with a final cDNA concentration of 1-2 nM and a final primer concentration of $200 \mathrm{nM}$. Cycler conditions were $50^{\circ} \mathrm{C}$ for $2 \mathrm{~min}, 95^{\circ} \mathrm{C}$ for $10 \mathrm{~min}$; 40 cycles of $95^{\circ} \mathrm{C}$ for $15 \mathrm{sec}, 55^{\circ} \mathrm{C}$ for $1 \mathrm{~min}$ with fluorescence being read at $55^{\circ} \mathrm{C}$ followed by dissociation curve analysis from $60^{\circ} \mathrm{C}$ to $95^{\circ} \mathrm{C}$.

4.3.7 DNA qPCR Test for Specificity of Primers. Where the biomass on the sample was high enough that the entire filter was not used for RNA extraction, DNA was extracted from a portion of the filter used for RNA extraction (OC399-4). Otherwise, DNA was extracted from an alternate bulk filter collected at the same station (SJ0609 and KM0701). DNA was extracted using the Mo Bio PowerPlant ${ }^{\mathrm{TM}}$ DNA extraction kit (Mo Bio Laboratories, Inc. Carlsbad, CA) following manufacturers guidelines including the optional DNA Clean-Up protocol. Following dilution of the DNA samples to $\sim 0.5 \mathrm{ng} / \mu \mathrm{l}$, $2 \mu 1$ of DNA was run in triplicate $20 \mu \mathrm{l}$ qPCR reactions with both sets of primers (six reactions total) to ensure that the ratio of $i s i B$ to $r n p B$ in the DNA was the same as that found for cultured representatives (i.e., 1:1). This control was used to ensure that our primers were equally efficient with field populations of Trichodesmium as they had been with laboratory cultures.

\subsection{RESUlts}

4.4.1 Sampling Locations. Figure 1A shows the cruise track and station locations where Trichodesmium colonies were present for the two Atlantic Ocean cruises, OC399-4 (stations 4-12) and SJ0609 (stations 13-21). The station numbers for OC399-4 
are a subset of the stations referred to in Jakuba et al (2008) and retain the same numbering scheme. SJ0609 was the second half of a two-leg transit across the equatorial Atlantic Ocean and retains the numbering scheme of the entire cruise. The cruise track for the Western Pacific Warm Pool cruise is shown in Figure 1B. The station numbering is the same as that of Hynes et al (in press) and Chapter 2 of this thesis. In all cases, the only numbered stations are the ones where expression data is reported. With the exception of OC399-4, where there was a large portion of the cruise that was out of the temperature range for Trichodesmium that has been completely left off the map, all stations from each cruise are marked along the cruise-track by a point even if they are not numbered.

4.4.2 $\mathrm{Fe}, \mathrm{PO}_{4}$ and Expression Data. The station location, total dissolved [Fe], $\left[\mathrm{PO}_{4}\right],[\mathrm{Fe}] /\left[\mathrm{PO}_{4}\right]$, the expression ratio isiB/rnpB and percent $T$. erythraeum for all stations where detectable levels of Trichodesmium were found are listed in Table 2. [Fe] and $\left[\mathrm{PO}_{4}\right]$ values are reported for the surface sample from each station, which was taken at a depth of $10 \mathrm{~m}$ for OC399-4 and $15 \mathrm{~m}$ for the other two cruises. The [ $\left.\mathrm{PO}_{4}\right]$ values from OC399-4 are reprinted from Jakuba et al (Jakuba et al., 2008). A subset of these $\mathrm{PO}_{4}$ values were also reported in Dyhrman et al (Dyhrman et al., 2006). The [PO values from KM0701 are the same as those graphed in Hynes et al (in press). OC399-4 stations are abbreviated with S for Sargasso Sea, SJ0609 stations are abbreviated with E for the Equatorial Atlantic Ocean and KM0701 stations are abbreviated with WP for the Western Pacific Ocean. The $[\mathrm{Fe}]$ and $\left[\mathrm{PO}_{4}\right]$ values are also shown in two bar graphs, one for the two Atlantic cruises, OC399-4 (S) and SJ0609 (E), (Figure 2A), and one for the Pacific cruise, KM0701, (Figure 2B). The cruise where [Fe] was most variable was in the Equatorial Atlantic Ocean. SJ0609 had the station with the highest [Fe] value of 1.89 $\mathrm{nM}$ on the western side of the basin at Station E21 where surface salinity measurements indicate that we were sampling in the Amazon River plume. At E21, the surface salinity measured by the CTD was 32.5 , which rose to 36 by a depth of $50 \mathrm{~m}$. With the exception of Station E20, which also had a small lens of low salinity water rising from 33.0 to 35.8 by a depth of $17 \mathrm{~m}$, surface salinities for the remainder of the transect were between 35.5 
and 36.1. SJ0609 also had one of the two stations with the lowest [Fe] of $0.09 \mathrm{nM}$, which was by the equator. The Western Pacific Ocean also had a range of [Fe], with a high value of $0.95 \mathrm{nM}$ close to the islands approaching New Caledonia, but otherwise low [Fe] $\sim 0.2 \mathrm{nM}$. The Sargasso Sea had consistently high [Fe] values ranging from $0.82 \mathrm{nM}$ to $1.17 \mathrm{nM}$. The $\left[\mathrm{PO}_{4}\right]$ values from the three cruises spanned a very large range, from below $1.4 \mathrm{nM}$ in the Sargasso Sea to $324 \mathrm{nM}$ in the Western Pacific, which resulted in a range of $\log _{10}[\mathrm{Fe}] /\left[\mathrm{PO}_{4}\right]$ from -3.5 in the Western Pacific to -0.13 in the Sargasso Sea.

Analysis of the copy numbers of $r n p B$ from the two clades in each cDNA sample (clade specific rnpB/total Trichodesmium rnpB), showed that the Ten clade dominated the cDNA in our samples (Table 2). As Tery cDNA was rarely detectable, we only report $i s i B$ expression data for the Ten clade. The Ten clade $i s i B$ expression, which is listed as $\log _{10}(i s i B / r n p B)$, also showed a large range from -3.4 in the Sargasso Sea to 0.33 in the Western Pacific. Many of the stations from the Western Pacific and one station from the Equatorial Atlantic had expression values above the value associated with a $50 \%$ reduction in $\mathrm{N}_{2}$ fixation in cultured T. tenue of isiB/rnpB $=0.062+/-0.017$ or $\log _{10}$ $($ isiB/rnpB $)=-1.24+/-0.1$ (Chappell and Webb, submitted).

We plotted total dissolved [Fe] verses $\log _{10}($ isiB/rnpB) (Figure $3 \mathrm{~A})$ and $\log _{10}$ $\left([\mathrm{Fe}] /\left[\mathrm{PO}_{4}\right]\right)$ verses $\log _{10}($ isiB/rnpB $)$ (Figure 3B). In each plot, the dashed line at $\log _{10}$ $($ isiB/rnpB $)=-1.2$ shows the critical value for $\log _{10}($ isiB/rnpB $)$ associated with a $50 \%$ reduction in $\mathrm{N}_{2}$ fixation rates for the Ten clade (Chappell and Webb, submitted). As shown in Figure 3A, the highest [Fe] value associated with expression above this threshold is $0.63 \mathrm{nM}+/-0.02 \mathrm{nM}$. A linear relationship was defined by plotting $\log _{10}$ $\left([\mathrm{Fe}] /\left[\mathrm{PO}_{4}\right]\right)$ verses $\log _{10}($ isiB/rnpB $)\left(\right.$ Figure 3B). The equation for this line is $\log _{10}$ $($ isiB/rnpB $)=(-0.67+/-0.13) \times \log _{10}\left([\mathrm{Fe}] /\left[\mathrm{PO}_{4}\right]\right)+(-2.7+/-0.27)$, which has an $\mathrm{R}^{2}$ value of 0.57 . According to this equation, the critical $[\mathrm{Fe}] /\left[\mathrm{PO}_{4}\right]$ value associated with a $50 \%$ reduction in $\mathrm{N}_{2}$ fixation by Trichodesmium in the field is $0.005+/-0.007 \mathrm{~mol} / \mathrm{mol}$ or $\leq$ $0.012 \mathrm{~mol} / \mathrm{mol}$.

We observed a linear relationship between $\log _{10}($ isiB/rnpB $)$ and $\mathrm{N}_{2}$ fixation rates from the subset of stations on KM0701 and OC399-4 where both parameters were 
measured (Figure 4). There was only one station from the cruise in the Sargasso Sea where we had measurable $i s i B$ expression and measured $\mathrm{N}_{2}$ fixation rates. There was a second station with $i s i B$ expression that was below detection, which we gave the value for $\log _{10}(i s i B / r n p B)=-3.42$, which appears to be the basal expression of $i s i B$ in the field. Excluding the data from the Sargasso Sea (SS) does not considerably alter the slope of the line associated with this relationship and only the line inclusive of the SS data is plotted (Figure 4). The linear relationship with the SS stations included is: nmol N fixed/hr/ $/$ g chl $=(-1.73+/-0.41) \times\left(\log _{10}(\right.$ isiB/rnpB $\left.)\right)+(1.41+/-0.77)$, which has an $\mathrm{R}^{2}$ value of 0.77 . The linear relationship with just the samples from KM0701 is: $\mathrm{nmol} \mathrm{N}$ fixed $/ \mathrm{hr} / \mu \mathrm{g} \mathrm{chl}=(-2.00+/-0.79) \times\left(\log _{10}(\right.$ isiB/rnpB $\left.)\right)+(1.35+/-0.95)$, which has an $\mathrm{R}^{2}$ value of 0.68 .

\subsection{DISCUSSION}

A number of studies have established the importance of Fe limitation to Trichodesmium $\mathrm{N}_{2}$ fixation in the laboratory (Chappell and Webb, submitted; BermanFrank et al., 2001; Webb et al., 2001; Fu and Bell, 2003; Kustka et al., 2003a; Kustka et al., 2003b; Berman-Frank et al., 2007; Shi et al., 2007; Kupper et al., 2008). Recently these efforts have focused on developing molecular methods that can be used to evaluate Fe limitation at the cellular level (Chappell and Webb, submitted; Webb et al., 2001; Shi et al., 2007). The information available on the factors (i.e., Fe) controlling Trichodesmium $\mathrm{N}_{2}$ fixation and growth has proved invaluable for modeling regions of the ocean (Moore et al., 2004; Coles and Hood, 2007; Moore and Doney, 2007). Though models can be useful tools, empirical verification is required to prove where $\mathrm{Fe}$ is important in controlling Trichodesmium $\mathrm{N}_{2}$ fixation and determine what parameter of $\mathrm{Fe}$ (i.e., total, free, inorganically-bound $\mathrm{Fe}$ ) is important to measure for predicting where $\mathrm{Fe}$ limitation might be occurring. The development of a calibrated molecular method to evaluate Fe limitation of $\mathrm{N}_{2}$ fixation in Trichodesmium spp. (Chappell and Webb, submitted) provided a technique capable of achieving this goal. This study represents the 
first quantitative assessment of Fe limitation in field populations of Trichodesmium through areas predicted to be Fe limited, $\mathrm{PO}_{4}$ limited and $\mathrm{Fe}-\mathrm{PO}_{4}$ co-limited.

\subsubsection{Ten clade predominance in open ocean populations of Trichodesmium.}

Representatives from the Ten clade were the principal component of Trichodesmium cDNA at most stations (Table 2). These results are consistent with reports based on morphology from previous field studies that Trichodesmium thiebautii, which is a representative from the Ten clade, is the dominant Trichodesmium in the open ocean (Carpenter and Price, 1977; Sohm et al., 2008). While our results indicate that cDNA was mostly from the Ten clade, this does not necessarily mean that representatives from the Tery clade were not present at some or even many of the stations. We looked at cDNA, so there is the possibility that there was Tery clade DNA present. If the Tery cells were dormant or growing slower for some reason, it would result in a much smaller amount of Tery clade cDNA, which might have been below the detection limit of our assay. Also, we were focusing on picked colonies not free trichomes. There is the possibility that we might have missed some Tery clade cDNA if the organisms were living as free trichomes and not colonies. While we may have missed some of the diversity of the Trichodesmium in the field, the net tow allowed us to get a concentrated sample of Trichodesmium to ensure that we had enough biomass for our downstream analyses. Given the dominance of the Ten clade and that Tery clade cDNA was not detected in most of our samples, the remainder of the paper deals only with Ten clade.

4.5.2 Basin-wide differences in Fe limitation of Trichodesmium. Most of the stations exhibiting Fe limitation were in the Pacific Ocean (Table 2, Figure 3). Low isiB expression in samples from the Sargasso Sea cruise is understandable, given the very low values of $\left[\mathrm{PO}_{4}\right]$ combined with the very high values of $[\mathrm{Fe}]$ measured (Table 2, Figure 2A). These results agree with previous work suggesting that Trichodesmium in this region are $\mathrm{PO}_{4}$ stressed (Sanudo-Wilhelmy et al., 2001; Dyhrman et al., 2002; Sohm and Capone, 2006). The only station in the North Atlantic where we found Trichodesmium $i s i B$ expression levels indicative of Fe limitation of $\mathrm{N}_{2}$ fixation was EA18, which was a station close to the equator where $[\mathrm{Fe}]$ was low compared to other parts of the cruise 
(Table 2, Figure 2A). The high $\left[\mathrm{PO}_{4}\right]$ and low $[\mathrm{Fe}]$ at this station could have been the result of equatorial upwelling having brought nutrient rich water to the surface ocean, which resulted in a draw down of surface $[\mathrm{Fe}]$ by biological activity. If upwelling is what caused high $\left[\mathrm{PO}_{4}\right]$ and low $[\mathrm{Fe}]$ at stations 16,17 and 18 (Figure 2A), it may not have been recent, as the surface temperatures were not low (all three stations had near surface temperatures between $27^{\circ} \mathrm{C}$ and $28.5^{\circ} \mathrm{C}$ ), which is consistent with the rest of the cruise and does not suggest active upwelling of colder deep water. The data from this cruise is in good agreement with previous work suggesting that the equatorial North Atlantic is predominantly $\mathrm{PO}_{4}$ stressed (Sanudo-Wilhelmy et al., 2001; Sanudo-Wilhelmy et al., 2001; Dyhrman et al., 2002; Dyhrman et al., 2002; Sohm and Capone, 2006; Sohm and Capone, 2006; Webb et al., 2007; Sohm et al., 2008; Sohm et al., 2008). The evidence we have showing Fe limitation near the equator supports the hypothesis that parts of the North Atlantic have the potential to shift between $\mathrm{PO}_{4}$ and Fe limitation (Mills et al., 2004; Coles and Hood, 2007). Further study in this region using a combination of the technique used in this study and a complimentary one for $\mathrm{PO}_{4}$ stress of Trichodesmium could prove to be a useful way to help determine what drives this shift. Even without such a metric, the data we have at hand shows that Fe limitation of $\mathrm{N}_{2}$ fixation by Trichodesmium can occur in the North Atlantic Ocean.

The level of $i s i B$ expression we measured in the Pacific Ocean was generally higher than that of the Atlantic and above the Fe limitation threshold value for the Ten clade (Figure 3), indicating that the Ten clade of Trichodesmium was experiencing Fe limitation over much of that cruise. This is in agreement with model data looking at what controls diazotroph growth in the oceans (Moore et al., 2004). There is some data suggesting that parts of the southwestern Pacific Ocean are $\mathrm{PO}_{4}$ stressed (Moutin et al., 2005). This hypothesis is based on $\mathrm{PO}_{4}$ turnover rates, low seasonal $\mathrm{PO}_{4}$ concentrations and a study of bloom dynamics in the coastal region of New Caledonia (Van Den Broeck et al., 2004; Moutin et al., 2005; Rodier and Le Borgne, 2008). Our data do not completely rule out the possibility that $\mathrm{PO}_{4}$ may be playing a role in this region, but suggest that this effect might be more local to the region immediately surrounding New 
Caledonia and that in the region between New Caledonia and Australia Fe limitation or Fe- $\mathrm{PO}_{4}$ co-limitation is occurring. The especially high $\mathrm{Fe} / \mathrm{P}$ ratio of the terrigenous inputs to the coastal area immediately off of New Caledonia as a result of the lateritic soils would be a very good explanation of this phenomenon (Tenorio et al., 2005). During the WP cruise, there was some evidence of $\mathrm{P}$ stress using enzyme-labelled fluorescence (ELF), which targets alkaline phosphatase activity of Trichodesmium colonies though the labeling was minimal in comparison to other regions (Hynes, In Press). There is the possibility of Fe- $\mathrm{PO}_{4}$ co-limitation of Trichodesmium at two of these stations, WP21 and WP26, where there was some evidence of ELF labeling and isiB expression was above the threshold indicative of $\mathrm{Fe}$ limitation of $\mathrm{N}_{2}$ fixation. While at station WP17, close to the islands of Vanuatu, there was no evidence of Fe limitation, but there was ELF labeling of Trichodesmium. Taken together these data suggest that Fe and $\mathrm{P}$ both have the potential to be stressors of Trichodesmium in the Pacific Ocean.

However, one problem in comparing results from the ELF assay with our isiB expression data is that the ELF assay is not quantitative. Thus, while it indicates that some portion of the Trichodesmium population in a given sample is $\mathrm{P}$ stressed, it cannot be used as a metric for $\mathrm{P}$ limitation in the same way as our $i s i B$ expression assay can be used as a metric for Fe limitation of $\mathrm{N}_{2}$ fixation. While the non-quantitative nature of the ELF assay limits our ability to say anything conclusive about $\mathrm{Fe}-\mathrm{PO}_{4}$ co-limitation in the area, our isiB expression data for Trichodesmium clearly points to the importance of $\mathrm{Fe}$ in the region.

4.5.3 Relationship between isiB expression and dissolved Fe. Looking at the relationship between $i s i B$ expression and total dissolved Fe (Figure 3A), we see that there is no evidence of $i s i B$ expression above the Fe limitation threshold when [Fe] (total dissolved $<0.4 \mu \mathrm{m}$ filtered $\mathrm{Fe}$ ) is greater than $0.63 \mathrm{nM}+/-0.02 \mathrm{nM}$. This value is within error of the value of [Fe'] (total inorganically bound $\mathrm{Fe}$ ) that was associated with $\mathrm{Fe}$ limitation in cultured populations of Trichodesmium, $0.7 \mathrm{nM}+/-0.1 \mathrm{nM}$ (Chappell and Webb, submitted), without adjusting for ligand-specific Fe speciation effects. When $\mathrm{Fe}$ speciation effects are taken into account, estimates of [Fe'] are $\sim 3$ orders of magnitude 
below [Fe] in the western Pacific transect (Chapter 2, this thesis). This implies that most if not all of the dissolved Fe in the surface oceans is available to Trichodesmium, even that bound to organic ligands. We do acknowledge certain concerns associated with extrapolating data from laboratory culture studies to the behavior of an organism in the field. For example, laboratory cultures are grown at nutrient and biomass levels much higher than those found in the open ocean. However, we took care to avoid a "blown buffer" scenario, which happens when culture biomass is high enough that the Fe needed is higher than that released by dissociation with EDTA and results in [Fe'] being lower than what would be calculated based on equilibrium dynamics (Saito et al., 2008). Thus, we believe that the EDTA buffer system we used kept the [Fe'] in the steady state at biologically relevant levels and as such it is reasonable to extrapolate to the field. Furthermore, these data are not completely unexpected as there is genomic evidence to support that Trichodesmium has the ability to take up siderophore-bound Fe using a TonB-ExbBD protein complex (Chappell and Webb, submitted) as well as field data showing that certain types of Fe:ligand complexes (i.e., siderophores) are available to Trichodesmium colonies (Achilles et al., 2003). Our results cannot ascertain the mechanism by which this $\mathrm{Fe}$ is available to Trichodesmium. For example, we cannot rule out the possibility that the availability of this ligand-bound Fe is controlled by photochemical release of Fe from ligands (Barbeau et al., 2003; Barbeau, 2006) instead of cellular uptake of the ligand bound $\mathrm{Fe}$. Additionally it is also possible that cell-surface reduction of ligand-bound Fe is involved (Maldonado and Price, 2001), though this mechanism has yet to be confirmed in Trichodesmium. Finally, it is also possible that interactions between Trichodesmium and the microbial consortium associated with its colonies could be facilitating the uptake of organically bound Fe. Regardless of the uncertainty associated with the cellular mechanism, our data show that total dissolved Fe measurements provide useful information on where Trichodesmium is Fe limited in the field.

4.5.4 Relationship between isiB expression and $\mathrm{Fe} / \mathrm{P}$. Even more striking than the relationship between isiB expression and [Fe], which is not as robust at both high $\mathrm{Fe}$ 
and low Fe values, is the relationship between $i s i B$ expression and the $[\mathrm{Fe}] /\left[\mathrm{PO}_{4}\right]$ ratio. The relationship between these two parameters is linear on a log-log plot throughout the entire range of samples (Figure 3B). Given the importance of both $\mathrm{Fe}$ and $\mathrm{PO}_{4}$ as potential limiting nutrients for Trichodesmium (Berman-Frank et al., 2001; Fu and Bell, 2003; Kustka et al., 2003b; Fu et al., 2005), it is not surprising that the ratio of $[\mathrm{Fe}] /\left[\mathrm{PO}_{4}\right]$ would play a role in determining whether or not Trichodesmium was Fe limited, $\mathrm{PO}_{4}$ limited, or potentially co-limited. While we acknowledge that an $\mathrm{R}^{2}$ value of 0.57 is not the strongest correlation, there are a variety of reasons to explain why cellular level Fe limitation of $\mathrm{N}_{2}$ fixation could be offset from measured $[\mathrm{Fe}] /\left[\mathrm{PO}_{4}\right]$ values. These discrepancies are part of the reason that a molecular diagnostic for Fe limitation in Trichodesmium is so important. We know that Trichodesmium has the capacity to store $\mathrm{Fe}$ (Castruita et al., 2006), thus a low Fe value or low $\mathrm{Fe} / \mathrm{PO}_{4}$ value may not be associated with a high expression value if the Trichodesmium has stored $\mathrm{Fe}$ and the extracellular $\mathrm{Fe}$ levels just dropped. A higher expression level than would be predicted based on $\mathrm{Fe} / \mathrm{PO}_{4}$ could be a result of a recent Fe deposition event that the organism has not had the ability to respond to by turning off the expression of the Fe stress genes. With those caveats aside, when we use the linear regression to determine the $[\mathrm{Fe}] /\left[\mathrm{PO}_{4}\right]$ that is associated with Fe limitation in field populations of Trichodesmium, we determine that Fe limitation is likely to occur below a dissolved $[\mathrm{Fe}] /\left[\mathrm{PO}_{4}\right]$ ratio of $0.005+/-0.007 \mathrm{~mol} / \mathrm{mol}$. We acknowledge that there is a large amount of error associated with this value, which propagates from our extrapolation of three different regressions: [Fe'] verses \% maximal $\mathrm{N}_{2}$ fixation rates (culture data), [Fe'] verses $i s i B$ expression (culture data) and $i s i B$ expression verses $[\mathrm{Fe}] /\left[\mathrm{PO}_{4}\right]$ (field data). However, we feel that we can at least place an upper limit for the critical dissolved $[\mathrm{Fe}] /\left[\mathrm{PO}_{4}\right]$ value of $0.012 \mathrm{~mol} / \mathrm{mol}$, a value that is only slightly lower than the critical $\mathrm{Fe} / \mathrm{PO}_{4}$ value associated with a transition between $\mathrm{Fe}$ and $\mathrm{PO}_{4}$ limitation in diazotrophs in the Moore et al model of 2004. In the model, the limiting nutrient is determined by comparing the predicted concentration of various nutrients with the half-saturation constants for uptake of each nutrient. Whichever nutrient is in lowest concentration with respect to the half saturation constant is 
determined to be the limiting nutrient at that point. The critical value for $\mathrm{Fe} / \mathrm{PO}_{4}$ is, in essence, the ratio of the half-saturation constants for $\mathrm{Fe}$ and $\mathrm{PO}_{4}, 0.0133 \mathrm{~mol} / \mathrm{mol}$ (Moore et al., 2004), which is close enough to our calculated upper bound of the critical Fe/ $\mathrm{PO}_{4}$ ratio of $0.012 \mathrm{~mol} / \mathrm{mol}$ that our data can be interpreted as an empirical validation of the model parameters.

4.5.5 Relationship between $i s i B$ expression and $N_{2}$ fixation rates. We found an inverse relationship between $i s i B$ expression and $\mathrm{N}_{2}$ fixation rates in the field (Figure 4). This shows that $i s i B$ expression is a good marker for Fe limitation of in situ Trichodesmium $\mathrm{N}_{2}$ fixation. We are unable to comment on the validity of using $i s i B$ as an in situ marker for growth limitation of Trichodesmium as we did not measure C fixation on the cruise and our culture data shows that increases in $i s i B$ expression and decreases in $\mathrm{N}_{2}$ fixation occur before Trichodesmium growth rates are significantly impacted (Chappell and Webb, submitted). However, the correlation between isiB expression and $\mathrm{N}_{2}$ fixation rates in the field enables us to translate $i s i B$ expression values into $\mathrm{N}_{2}$ fixation rates and is supported by previous data linking $i s i B$ expression and $\mathrm{N}_{2}$ fixation rates in laboratory culture experiments (Chappell and Webb, submitted).

\subsection{CONCLUSION}

The data presented in this chapter validates model predictions and demonstrates that $\mathrm{Fe}$ is an important limiting nutrient for $\mathrm{N}_{2}$ fixation of Trichodesmium in the Pacific Ocean while Fe limitation is minimal in the North Atlantic Ocean. The relationship between $i s i B$ expression and $[\mathrm{Fe}] /\left[\mathrm{PO}_{4}\right]$ we observed allows us to determine a critical $[\mathrm{Fe}] /\left[\mathrm{PO}_{4}\right]$ value that is associated with a shift to Fe limitation, which additionally validates the parameters used in model predictions. The close relationship between both the $[\mathrm{Fe}]$ value in the field and the [Fe'] value from the laboratory experiments associated with the onset of Fe limitation suggests that most if not all of the dissolved Fe in the open ocean is available to Trichodesmium regardless of whether or not it is bound to organic ligands. These results mark an improvement of our understanding of what form of $\mathrm{Fe}$ is 
controlling Trichodesmium $\mathrm{N}_{2}$ fixation in the open ocean as well as provide the first empirical data for where Fe limitation of Trichodesmium $\mathrm{N}_{2}$ fixation is occurring.

\subsection{ACKNOWLEDGEMENTS}

This work was supported by a National Science Foundation Chemical Oceanography Program grant OCE-0623499 to Eric A. Webb, James W. Moffett, and the University of Southern California and National Science Foundation Biological Oceanography Program grant OCE-0220945 to E.A.W. and the Woods Hole Oceanographic Institution. Funding for P.D.C was supplied by the Woods Hole Oceanographic Institution Academic Programs Office, the Center for Environmental Bioinorganic Chemistry at Princeton University, and a National Defense Science and Engineering Graduate Fellowship.

The author would like to thank chief scientist Jim Moffett and the captain and crew of the R/V Oceanus cruise OCE399-4, chief scientists John Zehr and Joe Montoya and the captain and crew of the R/V Seward Johnson cruise SJ0609, and Zachary Johnson and Erik Zinser and the captain and crew of the R/V Kilo Moana cruise KM0701. The author also wishes to thank Annette Hynes for assistance with Trichodesmium sample collection and $\mathrm{N}_{2}$ fixation measurements and Rachel Wisniewski Jakuba for providing $\mathrm{PO}_{4}$ values from OCE399-4. The author wants to thank Tyler Goepfert, Whitney Krey, Dan Ohnemus and Andrew Rose for assistance with sample collection and Brian Wilson for technical support in the laboratory. The author is grateful for the considerable assistance provided by E.A.W and J.W.M. in the field, the laboratory and the editing of this manuscript. 
Table 1. Primers used in Gene Expression Experiments

\begin{tabular}{|c|c|c|c|}
\hline Primer Name & 5' Primer & 3' Primer & $\begin{array}{l}\text { Target } \\
\text { Size } \\
\text { (BP) }\end{array}$ \\
\hline $\begin{array}{c}i s i B \text { QPCR } \\
\text { (Ten) }\end{array}$ & AAGTGACTGGGCTGGTTTC & CAATAGTAGTACCTCCTTTCTCAG & 167 \\
\hline $\begin{array}{c}\text { isiB QPCR } \\
\text { (Tery) }\end{array}$ & AAAGTGACTGGAGTGGTTTC & GTAGTACCTCCAAGCCCA & 163 \\
\hline $\begin{array}{c}r n p B \text { QPCR } \\
\text { (Ten) }\end{array}$ & GAATCTATGAACGCAACGGAAC & ACCAGCAGTGTCGTGAGG & 102 \\
\hline $\begin{array}{c}\text { rnpB QPCR } \\
\text { (Tery) }\end{array}$ & ACCAACCATTGTTCCTTCG & CAAGCCTGCTGGATAACG & 199 \\
\hline
\end{tabular}


Table 2. Near surface (10-15m) data from stations on all three cruises where isiB expression of Trichodesmium was measured. Standard deviation of triplicate technical replicates are given for $[\mathrm{Fe}]$ and and the isiB/rnpB ratio and $\left[\mathrm{PO}_{4}\right]$ from OC399-4 (S) and duplicate technical replicates for $\left[\mathrm{PO}_{4}\right]$ from SJ0609 (E) and KM0701 (WP). BDL $=i s i B$ expression was below detection level in the sample.

\begin{tabular}{|c|c|c|c|c|c|c|c|}
\hline & at & & & & & & $\% \mathrm{~T}$ \\
\hline S4 & 25.40 & 61.15 & $.17+/-0.04$ & $0.0037+/-0.00$ & $-0.50+/-$ & $-1.96+/-$ & .05 \\
\hline S6 & 22.80 & & $.04+/-0.08$ & & 43 & & 03 \\
\hline S7 & .00 & 7.00 & & $0.0136+/-0.00$ & $-1.07+$ & $-2.34+1$ & 0.01 \\
\hline S8 & & & & & & & 0.00 \\
\hline S9 & 00 & & & & & & 0.00 \\
\hline $\mathrm{S} 10$ & 20.00 & -45.90 & $1.01+/-0.04$ & $0.0058+/-0.0049^{\mathrm{ii}}$ & $-0.76+/-0.37$ & BDL & 0.00 \\
\hline & 97 & -46.90 & & & -0.23 & -2.21 & 0.24 \\
\hline & & -49.68 & & & & & 0.00 \\
\hline & & & & & & & 00 \\
\hline & 60 & -30.80 & & & & $-1.99+$ & 0.00 \\
\hline & & -32.90 & & & -2.6 & $-1.40+$ & 0.00 \\
\hline & & & & & & & 0.00 \\
\hline & & & & & & & \\
\hline & 5.60 & -45.60 & & c & -1.7 & $-1.80+/$ & 0.52 \\
\hline & 50 & -49.20 & & $0.068+/-$ & $-1.56+$ & $-1.54+/$ & 0.14 \\
\hline W & 0.37 & -179.64 & & $0.324+/-0$ & $-3.48+$ & $0.33+/-$ & 58.81 \\
\hline WP14 & -9.25 & 170.00 & & 0 & & & 0.00 \\
\hline WP15 & -12.58 & 169.86 & $1+/-0.03$ & & & $-1.72+/-0.01$ & 0.05 \\
\hline WP16 & -15.89 & 169.72 & $0.29+/-0.03$ & & $-2.76+/-0$ & $-0.14+/$ & 0.39 \\
\hline WP16a & -15.98 & 169.77 & & $0.148+/-$ & $-2.37+/-0$ & $-0.70+/-$ & 16.94 \\
\hline & -19.23 & 69.58 & $0.95+/$ & 127 & -2.16 & $-1.66+/-$ & 0.14 \\
\hline & -21.62 & & & & & $-1.29+/-0.02$ & 1.13 \\
\hline & -25.67 & 165.42 & & $0.102+/-0.002^{\mathrm{iii}}$ & $-3.04+/-0.10$ & $-0.56+/-0.05$ & 0.41 \\
\hline WP21 & -29.04 & 164.34 & $0.24+/-0.02$ & & $-2.32+/-0.04$ & $0.13+/-0.04$ & 0.00 \\
\hline WP26 & -32.42 & 159.09 & $0.20+/-0.02$ & $0.084+/-0.002^{\mathrm{iii}}$ & $-2.623+/-0.05$ & $-0.63+/-0.03$ & 0.02 \\
\hline
\end{tabular}

${ }^{\mathrm{i}} \mathrm{PO} 4$ values from Jakuba et al 2008, $\mathrm{PO}_{4}$ values in Dyhrman et al 2006 and Jakuba et al 2008, ${ }^{\mathrm{iii}} \mathrm{PO}_{4}$ values from Hynes et al, in press. 

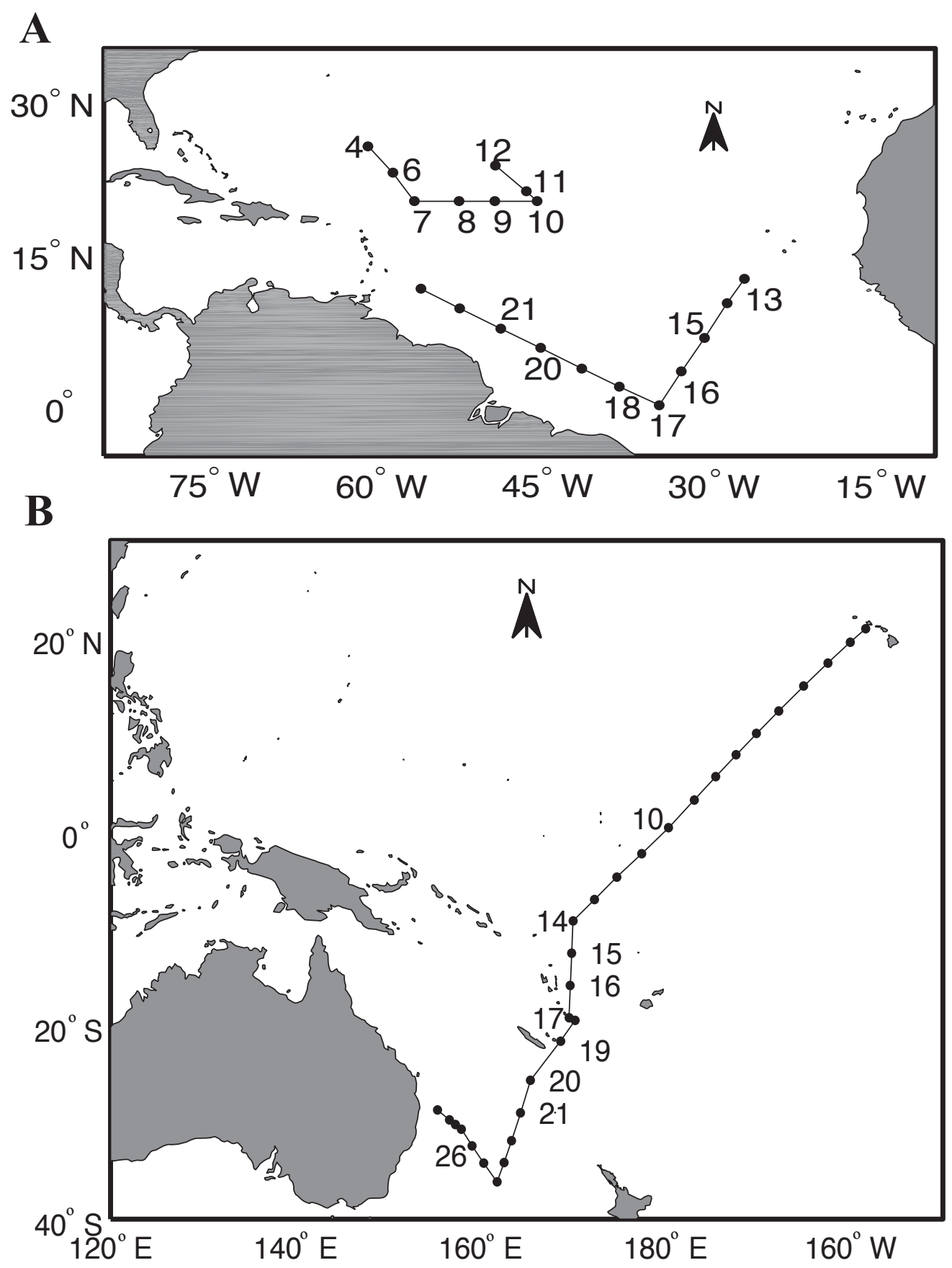

Figure 1. Map of cruise tracks. A. OC399-4 (stations 4-12) in the Sargasso Sea in March 2004. SJ0609 (stations 13-21) east-to-west transect across the equatorial Atlantic Ocean in July 2006. B. KM0701 north-to-south transect through the Western Pacific Warm Pool during January and February 2007. 
A
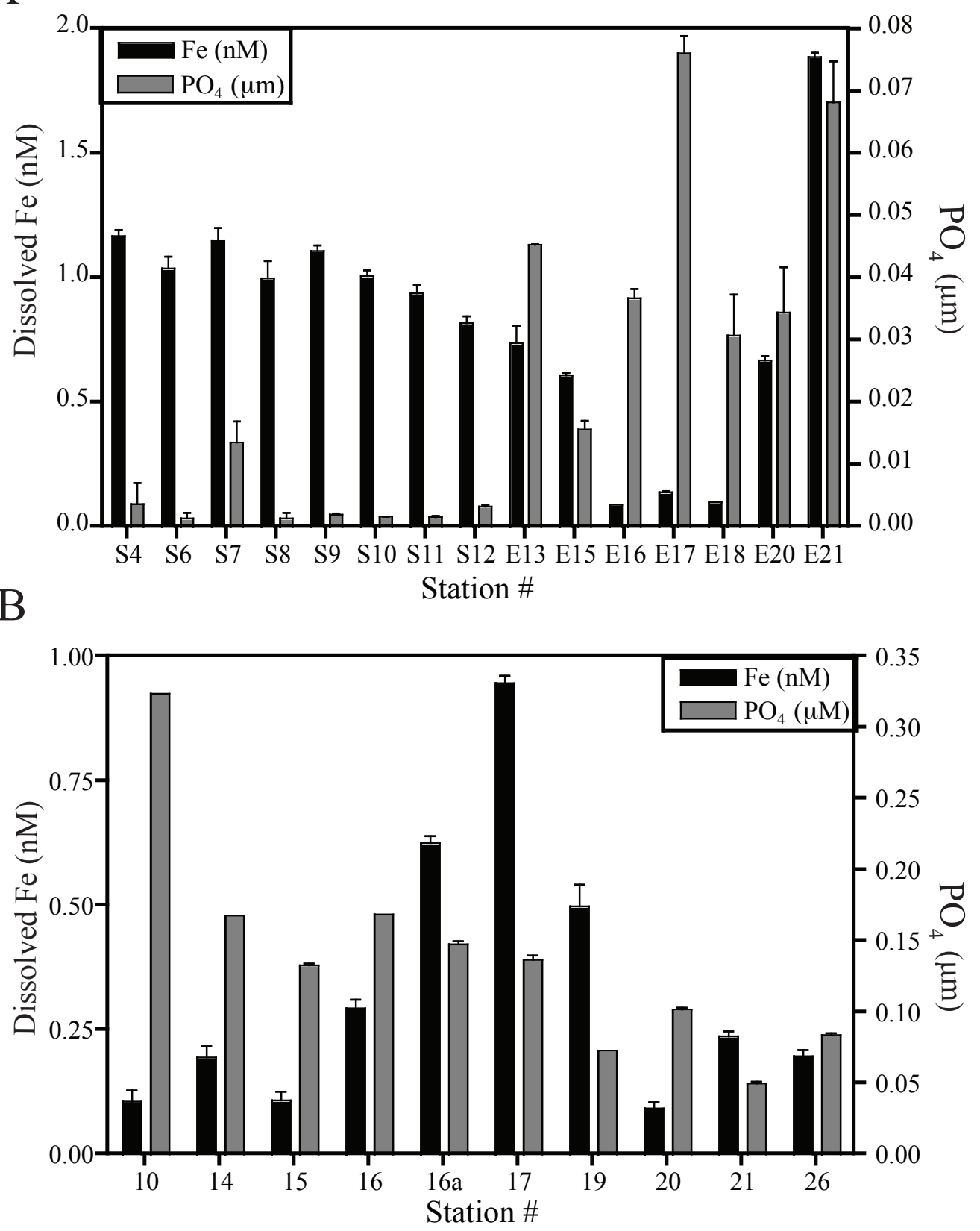

Figure 2. Dissolved $\left(<0.4 \mu \mathrm{m}\right.$ filtered) $\mathrm{Fe}$ and $\mathrm{PO}_{4}$ measured in surface seawater samples from the Atlantic Ocean (A) and Pacific Ocean (B). Station numbers correspond to stations locations listed in Table 2 and plotted in Figure 1. Error bars represent the standard deviation of duplicate $\left(\mathrm{PO}_{4}\right)$ and triplicate (Fe) samples. 


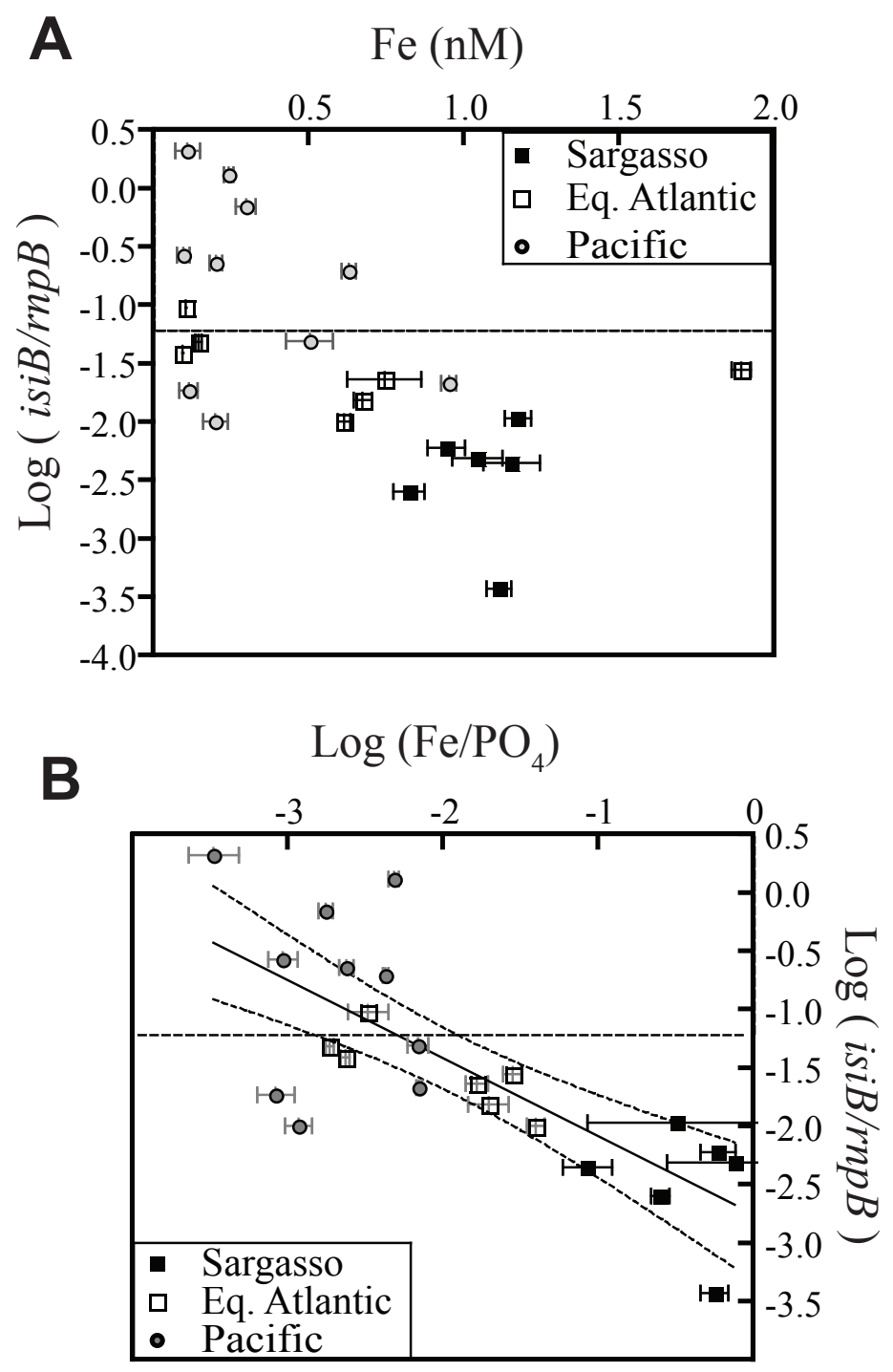

Figure 3. Relationships between $\log (i \operatorname{siB} / \mathrm{rnpB})$ and both dissolved [Fe] (A) and $\log \left([\mathrm{Fe}] /\left[\mathrm{PO}_{4}\right]\right)(\mathrm{B})$. A dashed line is placed on each plot at the value $\log (i \operatorname{siB} / \operatorname{rnp} B)=-1.2$, which is the value associated with a $50 \%$ reduction in $\mathrm{N}_{2}$ fixation in Trichodesmium from previous work (Chappell and Webb submitted). The solid line in (B) represents the linear regression of $\log \left([\mathrm{Fe}] /\left[\mathrm{PO}_{4}\right]\right)$ verses $\log (i \operatorname{siB} / r n p B)$ with the dashed curves on either side representing the $95 \%$ confidence intervals. In both plots, error bars represent the standard deviation of triplicate analyses. 


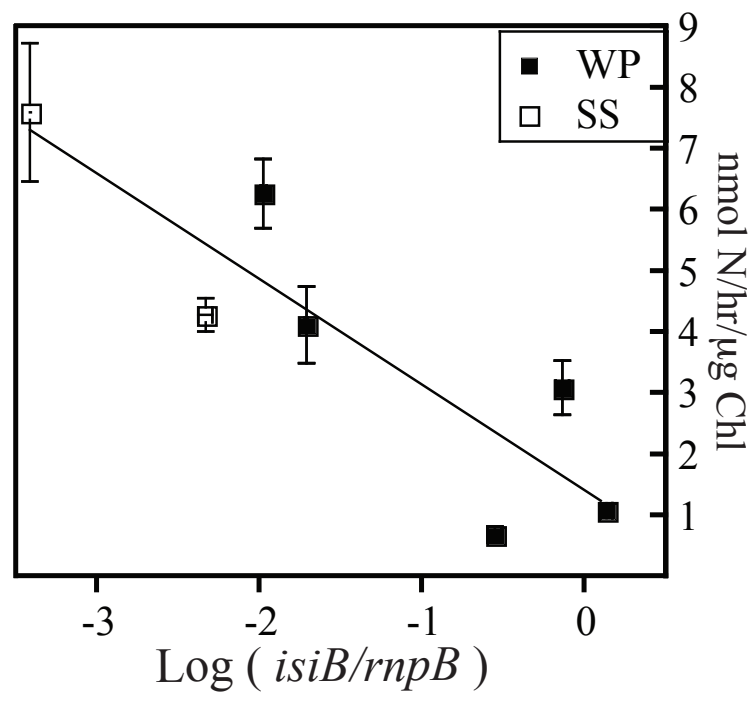

Figure 4. Relationship between $\log ($ isiB/rnpB $)$ and $\mathrm{N}_{2}$ fixation rates measured at two stations from the Sargasso Sea (SS7, SS10) and five stations from the Western Pacific $(14,15,16,20,21)$. The linear relationship between $\log ($ isiB/rnpB $)$ and $\mathrm{nmol} \mathrm{N} / \mathrm{hr} / \mu \mathrm{g} \mathrm{Chl}$ for just the Western Pacific Ocean samples is plotted as a solid line. The same relationship including the data from Sargasso Sea is plotted as a dashed line. 


\subsection{REFERENCES}

Achilles, K.M., Church, T.M., Wilhelm, S.W., Luther, G.W., and Hutchins, D.A. (2003) Bioavailability of iron to Trichodesmium colonies in the western subtropical Atlantic Ocean. Limnol Oceanogr 48: 2250-2255.

Barbeau, K. (2006) Photochemistry of organic iron(III) complexing ligands in oceanic systems. Photochem Photobiol 82: 1505-1516.

Barbeau, K., Rue, E.L., Trick, C.G., Bruland, K.T., and Butler, A. (2003) Photochemical reactivity of siderophores produced by marine heterotrophic bacteria and cyanobacteria based on characteristic Fe(III) binding groups. Limnol Oceanogr 48: 1069-1078.

Berman-Frank, I., Quigg, A., Finkel, Z.V., Irwin, A.J., and Haramaty, L. (2007)

Nitrogen-fixation strategies and Fe requirements in cyanobacteria. Limnol Oceanogr 52: 2260-2269.

Berman-Frank, I., Cullen, J.T., Shaked, Y., Sherrell, R.M., and Falkowski, P.G. (2001) Iron availability, cellular iron quotas, and nitrogen fixation in Trichodesmium. Limnol Oceanogr 46: 1249-1260.

Blanchot, J., Andre, J.M., Navarette, C., and Neveux, J. (1997) Picophytoplankton dynamics in the equatorial Pacific: diel cycling from flow-cytometer observations. $\mathrm{Cr}$ Acad Sci Iii-vie 320: 925-931.

Breitbarth, E., Wohlers, J., Klas, J., LaRoche, J., and Peeken, I. (2008) Nitrogen fixation and growth rates of Trichodesmium IMS-101 as a function of light intensity. Mar Ecolprog Ser 359: 25-36.

Breitbarth, E., Oschilies, A., and LaRoche, J. (2007) Physiological constraints on the global distribution of Trichodesmium - effect of temperature on diazotrophy. Biogeosciences 4: 53-61.

Campbell, L., Carpenter, E.J., Montoya, J.P., Kustka, A.B., and Capone, D.G. (2005) Picoplankton community structure within and outside a Trichodesmium bloom in the southwestern Pacific Ocean. Vie Milieu 55: 185-195.

Capone, D.G. (1993) Determination of nitrogenase activity in aquatic samples using the acetylene reduction procedure. In Kemp, P.F., Sherr, B.F., Sherr, E.B., and Cole, J. (eds). Lewis, pp. 621-631.

Capone, D.G., Zehr, J.P., Paerl, H.W., Bergman, B., and Carpenter, E.J. (1997)

Trichodesmium, a globally significant marine cyanobacterium. Science 276: 1221-1229.

Carpenter, E.J., and Price, C.C. (1977) Nitrogen Fixation, distribution and production of Oscillatoria (Trichodesmium) spp. in the Western Sargasso and Caribbean Seas. Limnol Oceanogr 22: 60-72.

Castruita, M., Saito, M., Schottel, P.C., Elmegreen, L.A., Myneni, S., Stiefel, E.I., and Morel, F.M.M. (2006) Overexpression and Characterization of an Iron Storage and DNA- 
Binding Dps Protein from Trichodesmium erythraeum. Appl Environ Microbiol 72: 29182924.

Chappell, P.D., and Webb, E.A. (submitted) A Molecular Assessment of the Iron Stress Response in the Two Phylogenetic Clades of Trichodesmium. Environmental Microbiology

Coale, K.H., Johnson, K.S., Fitzwater, S.E., Gordon, R.M., Tanner, S., Chavez, F.P. et al. (1996) A massive phytoplankton bloom induced by an ecosystem-scale iron fertilization experiment in the Equatorial Pacific Ocean. Nature 383: 495-501.

Coles, V.J., and Hood, R.R. (2007) Modeling the impact of iron and phosphorus limitations on nitrogen fixation in the Atlantic Ocean. Biogeosciences 4: 455-479.

Dupouy, C., Petit, M., and Dandonneau, Y. (1988) Satellite Detected Cyanobacteria Bloom in the Southwestern Tropical Pacific - Implication for Oceanic Nitrogen-Fixation. Int J Remote Sens 9: 389-396.

Dyhrman, S.T., Webb, E.A., Anderson, D.M., Moffett, J.W., and Waterbury, J.B. (2002) Cell specific detection of phosphate stress in Trichodesmium from the Western North Atlantic. Limnol Oceanogr 47: 1832-1836.

Dyhrman, S.T., Chappell, P.D., Haley, S.T., Moffett, J.W., Orchard, E.D., Waterbury, J.B., and Webb, E.A. (2006) Phosphonate utilization by the globally important marine diazotroph Trichodesmium. Nature 439: 68-71.

Falkowski, P.G. (1997) Evolution of the nitrogen cycle and its influence on the biological sequestration of $\mathrm{CO}_{2}$ in the ocean. Nature 387: 272-275.

Fu, F.X., Zhang, Y.H., Bell, P.R.F., and Hutchins, D.A. (2005) Phosphate uptake and growth kinetics of Trichodesmium (Cyanobacteria) isolates from the North Atlantic Ocean and the Great Barrier Reef, Australia. Journal of Phycology 41: 62-73.

Fu, F.X., and Bell, P.R.F. (2003) Growth, $\mathrm{N}_{2}$ fixation and photosynthesis in a cyanobacterium, Trichodesmium sp., under Fe stress. Biotechnol Lett 25: 645-649.

Grabowski, M.N.W., Church, M.J., and Karl, D.M. (2008) Nitrogen fixation rates and controls at Stn ALOHA. Aquat Microb Ecol 52: 175-183.

Gruber, N., and Sarmiento, J.L. (1997) Global patterns of marine nitrogen fixation and denitrification. Glob Biogeochem Cycles 11: 235-266.

Herbland, A., Lebouteiller, A., and Raimbault, P. (1985) Size Structure of Phytoplankton Biomass in the Equatorial Atlantic-Ocean. Deep-sea Res 32: 819-836.

Hynes, A.M., Chappell, P.D., Dyhrman, S.T., Doney, S.C. and Webb, E. A. (In Press) Cross-basin comparison of phosphorus stress and nitrogen fixation in Trichodesmium. Limnol Oceanogr

Jakuba, R.W., Moffett, J.W., and Dyhrman, S.T. (2008) Evidence for the linked biogeochemical cycling of zinc, cobalt, and phosphorus in the western North Atlantic Ocean. Global Biogeochem Cy 22: ARTN GB4012. 
Karl, D., Michaels, A., Bergman, B., Capone, D., Carpenter, E., Letelier, R. et al. (2002) Dinitrogen fixation in the world's oceans. Biogeochemistry 57: 47-+.

Karl, D.M., and Letelier, R.M. (2008) Nitrogen fixation-enhanced carbon sequestration in low nitrate, low chlorophyll seascapes. Mar Ecol-prog Ser 364: 257-268.

Kupper, H., Setlik, I., Seibert, S., Prasil, O., Setlikova, E., Strittmatter, M. et al. (2008) Iron limitation in the marine cyanobacterium Trichodesmium reveals new insights into regulation of photosynthesis and nitrogen fixation. New Phytol 179: 784-798.

Kustka, A., Sanudo-Wilhelmy, S., Carpenter, E.J., Capone, D.G., and Raven, J.A. (2003a) A revised estimate of the iron use efficiency of nitrogen fixation, with special reference to the marine cyanobacterium Trichodesmium spp. (Cyanophyta). J Phycol 39: $12-25$.

Kustka, A.B., Sanudo-Wilhelmy, S.A., Carpenter, E.J., Capone, D., Burns, J., and Sunda, W.G. (2003b) Iron requirements for dinitrogen- and ammonium-supported growth in cultures of Trichodesmium (IMS 101): Comparison with nitrogen fixation rates and iron: carbon ratios of field populations. Limnology and Oceanography 48: 1869-1884.

Larionov, A., Krause, A., and Miller, W. (2005) A standard curve based method for relative real time PCR data processing. Bmc Bioinformatics 6: ARTN 62.

LaRoche, J., and Breitbarth, E. (2005) Importance of the diazotrophs as a source of new nitrogen in the ocean. Journal of Sea Research 53: 67-91.

Liu, X.W., and Millero, F.J. (2002) The solubility of iron in seawater. Mar Chem 77: 4354.

Maldonado, M.T., and Price, N.M. (2001) Reduction and transport of organically bound iron by Thalassiosira oceanica (Bacillariophyceae). J Phycol 37: 298-309.

Martin, J.H., Gordon, R.M., and Fitzwater, S.E. (1991) The Case for Iron.

LimnolOceanogr 36: 1793-1802.

Martin, J.H., and Fitzwater, S.E. (1988) Iron-Deficiency Limits Phytoplankton Growth in the Northeast Pacific Subarctic. Nature 331: 341-343.

Matsumoto, K., and Ando, K. (2009) Use of cyanobacterial pigments to characterize the ocean surface mixed layer in the western Pacific warm pool. J Marine Syst 75: 245-252.

Mills, M.M., Ridame, C., Davey, M., La Roche, J., and Geider, R.J. (2004) Iron and phosphorus co-limit nitrogen fixation in the eastern tropical North Atlantic. Nature 429: 292-294.

Montoya, J.P., Holl, C.M., Zehr, J.P., Hansen, A., Villareal, T.A., and Capone, D.G. (2004) High rates of $\mathrm{N}_{2}$ fixation by unicellular diazotrophs in the oligotrophic Pacific Ocean. Nature 430: 1027-1031.

Moore, J.K., and Doney, S.C. (2007) Iron availability limits the ocean nitrogen inventory stabilizing feedbacks between marine denitrification and nitrogen fixation. Global Biogeochem Cy 21: ARTN GB2001. 
Moore, J.K., Doney, S.C., and Lindsay, K. (2004) Upper ocean ecosystem dynamics and iron cycling in a global three-dimensional model. Global Biogeochem Cy 18: ARTN GB4028.

Moutin, T., Van Den Broeck, N., Beker, B., Dupouy, C., Rimmelin, P., and Le Bouteiller, A. (2005) Phosphate availability controls Trichodesmium spp. biomass in the SW Pacific Ocean. Marine Ecology-Progress Series 297: 15-21.

Mulholland, M.R. (2007) The fate of nitrogen fixed by diazotrophs in the ocean. Biogeosciences 4: 37-51.

Neveux, J., Tenorio, M.M.B., Dupouy, C., and Villareal, T.A. (2006) Spectral diversity of phycoerythrins and diazotroph abundance in tropical waters. Limnol Oceanogr 51: 1689-1698.

Rodier, M., and Le Borgne, R. (2008) Population dynamics and environmental conditions affecting Trichodesmium spp. (filamentous cyanobacteria) blooms in the south-west lagoon of New Caledonia. J Exp Mar Biol Ecol 358: 20-32.

Rue, E.L., and Bruland, K.W. (1995) Complexation of iron(III) by natural organic ligands in the Central North Pacific as determined by a new competitive ligand equilibration/adsorptive cathodic stripping voltammetric method. Mar Chem 50: 117-138.

Rue, E.L., and Bruland, K.W. (1997) The role of organic complexation on ambient iron chemistry in the equatorial Pacific Ocean and the response of a mesoscale iron addition experiment. Limnol Oceanogr 42: 901-910.

Saito, M.A., Goepfert, T.J., and Ritt, J.T. (2008) Some thoughts on the concept of colimitation: Three definitions and the importance of bioavailability. Limnol Oceanogr 53: 276-290.

Saito, M.A., and Schneider, D.L. (2006) Examination of precipitation chemistry and improvements in precision using the $\mathrm{Mg}(\mathrm{OH})(2)$ preconcentration inductively coupled plasma mass spectrometry (ICP-MS) method for high-throughput analysis of open-ocean Fe and Mn in seawater. Anal Chim Acta 565: 222-233.

Sanudo-Wilhelmy, S.A., Kustka, A.B., Gobler, C.J., Hutchins, D.A., Yang, M., Lwiza, K. et al. (2001) Phosphorus limitation of nitrogen fixation by Trichodesmium in the central Atlantic Ocean. Nature 411: 66-69.

Shi, T., Sun, Y., and Falkowski, P.G. (2007) Effects of iron limitation on the expression of metabolic genes in the marine cyanobacterium Trichodesmium erythraeum IMS 101. Environmental Microbiology 9: 2945-2956.

Sohm, J.A., and Capone, D.G. (2006) Phosphorus dynamics of the tropical and subtropical North Atlantic: Trichodesmium spp. versus bulk plankton. Mar Ecol-prog Ser 317: 21-28.

Sohm, J.A., Mahaffey, C., and Capone, D.G. (2008) Assessment of relative phosphorus limitation of Trichodesmium spp. in the North Pacific, North Atlantic, and the north coast of Australia. Limnol Oceanogr 53: 2495-2502. 
Tenorio, M.M.B., Le Borgne, R., Rodier, M., and Neveux, J. (2005) The impact of terrigeneous inputs on the Bay of Ouinne (New Caledonia) phytoplankton communities: A spectrofluorometric and microscopic approach. Estuarine Coastal And Shelf Science 64: 531-545.

Van Den Broeck, N., Moutin, T., Rodier, M., and Le Bouteiller, A. (2004) Seasonal variations of phosphate availability in the SW Pacific Ocean near New Caledonia. Marine Ecology-Progress Series 268: 1-12.

Webb, E.A., Moffett, J.W., and Waterbury, J.B. (2001) Iron stress in open-ocean cyanobacteria (Synechococcus, Trichodesmium, and Crocosphaera spp.): identification of the IdiA protein. Appl Environ Microbiol 67: 5444-5452.

Webb, E.A., Jakuba, R.W., Moffett, J.W., and Dyhrman, S.T. (2007) Molecular assessment of phosphorus and iron physiology in Trichodesmium populations from the western Central and western South Atlantic. Limnol Oceanogr 52: 2221-2232.

Wu, J., and Boyle, E.A. (1998) Determination of trace levels of iron in seawater by isotope dilution high resolution ICPMS. Anal Chim Acta 267: 183-191.

Zehr, J.P., Waterbury, J.B., Turner, P.J., Montoya, J.P., Omoregie, E., Steward, G.F. et al. (2001) Unicellular cyanobacteria fix $\mathrm{N}_{2}$ in the subtropical North Pacific Ocean. Nature 412: 635-638.

Zinser, E.R., Coe, A., Johnson, Z.I., Martiny, A.C., Fuller, N.J., Scanlan, D.J., and Chisholm, S.W. (2006) Prochlorococcus Ecotype Abundances in the North Atlantic Ocean As Revealed by an Improved Quantitative PCR Method. Appl Environ Microbiol 72: 723-732. 


\section{Chapter 5. SUMmary}

\subsection{SUMMARY}

This thesis sheds light on the role that iron $(\mathrm{Fe})$ plays in controlling nitrogen $(\mathrm{N})$ fixation in Trichodesmium as well as providing data to increase our understanding of $\mathrm{Fe}$ chemistry in the understudied region of the southwestern Pacific Ocean. It is the first demonstration using a calibrated molecular method to show Fe limitation of Trichodesmium in the field. As is generally the case with a study of this kind, in addition to answering questions, the data points to new questions that need to be answered.

The data presented in Chapter 2 is a contribution to the growing dataset of dissolved $\mathrm{Fe}$ and $\mathrm{Fe}$ speciation in the surface ocean. It covers a region where there is limited data on trace metal concentrations, which receives very low dust deposition (Duce and Tindale, 1991; Jickells, 1999; Wagener et al., 2008). The profiles of dissolved $\mathrm{Fe}([\mathrm{Fe}])$ are well in line with previous work showing low Fe $(\sim 0.2 \mathrm{nM})$ in the surface ocean, a small subsurface maximum in $\mathrm{Fe}(\sim 0.4 \mathrm{nM})$ (Bruland et al., 1994; Wu et al., 2001; Boyle et al., 2005) and an increase in Fe below the euphotic zone to values that can range between $0.4 \mathrm{nM}$ and $1 \mathrm{nM}$ (Bruland et al., 1994; Johnson et al., 1997; Wu et al., 2001; Boyle et al., 2005; Johnson et al., 2007). Values for both the total amount of ligand present $([\mathrm{L}]=0.44-2.2)$ and the conditional binding constant $\left(\mathrm{K}_{\mathrm{Fe}^{\prime}, \mathrm{L}}=10^{11.7}-10^{12.9}\right)$ are within the range of reported values from other open ocean studies of $[\mathrm{L}]$ ranging from $0.33-2.5 \mathrm{nM}$ and $\mathrm{K}_{\mathrm{Fe}^{\prime}, \mathrm{L}}$ ranging from $10^{10.6}-10^{13.9}$ (Rue and Bruland, 1995; van den Berg, 1995; Rue and Bruland, 1997; Boye et al., 2001; Powell and Donat, 2001; Boye et al., 2003; Croot et al., 2004; Boye et al., 2005; Cullen et al., 2006; van den Berg, 2006; Buck and Bruland, 2007; Kondo et al., 2007; Kondo et al., 2008; Rijkenberg et al., 2008). While calculations of $[\mathrm{L}]$ appear to be associated with a small range of values, calculations of $\mathrm{K}_{\mathrm{Fe}^{\prime}, \mathrm{L}}$ appear to be much more variable as is evident from the wide range of values reported in the literature. It is unclear whether these differences are a result of true variability of the stability constants of ligands present in given samples or have to do with analytical or mathematical differences in how this value is determined. Given the

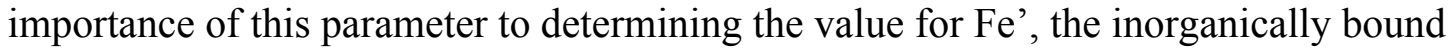


fraction of dissolved Fe that is though to be an important variable in determining $\mathrm{Fe}$ bioavailability, accurate measurements of $\mathrm{K}_{\mathrm{Fe}, \mathrm{L}}$ are critical. A complicating factor in comparing Fe speciation data from different studies is that there are many competitive ligands used to generate the data and forms of mathematical analysis that people use to interpret their data and there has not been significant effort made to standardize these measurements. The intercalibration of Fe speciation methods, which is proposed as part of GEOTRACES, should help alleviate any concerns about the ability to compare results between groups.

That caveat aside, by comparing the multitude of Fe speciation studies that have been done throughout the world's oceans, it is becoming apparent that there are specific relationships governing ligand concentration in the surface ocean, which appear to be related to the amount of total dissolved $\mathrm{Fe}([\mathrm{Fe}])$ present in a given sample and unrelated to biological parameters (Buck and Bruland, 2007; Chapter 2). This relationship suggests that at higher values of [Fe], biological factors are less involved in controlling [L] than their role as siderophores might imply. This does not mean that Fe binding ligands are not siderophores; it could have to do with different factors such as association with colloidal Fe and/or the type of organic ligand present resulting in a protection from $\mathrm{UV}$ degradation of ligands. More data on the composition of ligands in the field such as the recent study in the North Atlantic looking at ferrioxiamines (Mawji et al., 2008) in addition to other ligand classes could help answer if ligand composition is the predominant factor governing this relationship. In addition, studies looking at UV degradation of ligands in the field focusing on the colloidal verses soluble fraction of the Fe-ligand pool could also help answer the question of what is driving the relationship between $[\mathrm{Fe}]$ and $[\mathrm{L}]$ in samples with higher Fe.

Another factor that is apparent from the data presented in Chapter 2, is that the inorganically bound fraction of $\mathrm{Fe}\left(\left[\mathrm{Fe}^{\prime}\right]\right)$ predicted based on these data is vanishingly small $(<1 \mathrm{pM})$. It is much lower than the value of [Fe'] associated with Fe limitation in many species of phytoplankton (Brand, 1991; Chapter 3). In light of recent work suggesting that many organisms are capable of taking up Fe from organic ligands 
(Hutchins et al., 1999; Maldonado and Price, 2001; Soria-Dengg et al., 2001; Achilles et al., 2003; Shaked et al., 2005), the usefulness of determining bulk Fe speciation in field samples to approximate bioavailable Fe is called into question. It may be more useful to improve methods to identify and measure the concentration of specific ligands, similarly to what has recently been done with ferrioxiamines (Mawji et al., 2008) and test the bioavailability of $\mathrm{Fe}$ bound to them to various phytoplankton groups, although that is a very labor-intensive proposition.

Limited information regarding the bioavailability of different forms of Fe was one of the driving reasons behind the goal of developing a molecular method to assess $\mathrm{Fe}$ limitation of Trichodesmium in the field. Because of research suggesting that there were differences in $\mathrm{N}_{2}$ fixation rates between different species (Carpenter et al., 1993) and a growing body of work separating the cultured representatives of the Trichodesmium genus into two distinct clades (Orcutt et al., 2002; Annette Hynes, personal communication), merely looking at Fe limitation in Trichodesmium erythraeum seemed unlikely to ensure that the method would prove useful in the field. The work presented in Chapter 3 of this thesis shows clade-specific responses to growth under different Fe and temperature conditions. In light of results from Chapter 4 that indicate that representatives of the Trichodesmium tenue (Ten) clade are the most abundant or at least the most active in the open ocean, it is important that future work to evaluate how different physical and chemical factors affect Trichodesmium focus on representatives of the Ten clade in addition to the T. erythraeum (Tery) clade.

In addition to evaluating the differential responses to $\mathrm{Fe}$ and temperature between the two phylogenetic clades of Trichodesmium, Chapter 3 included the development of a calibrated molecular method to assess clade-specific Fe limitation of $\mathrm{N}_{2}$ fixation. This is the first calibrated molecular method for Fe limitation and the first method to evaluate $\mathrm{Fe}$ limitation that enables for the distinction between the two clades. In addition to the gene predicted to encode for flavodoxin, isiB (Leonhardt and Straus, 1992), which is the gene used in the molecular assay, two other genes that could potentially be of interest in future molecular assays were identified. One, idiA, is predicted to encode for a protein involved 
in a high-affinity ATP-driven Fe (III) uptake system (Michel et al., 1996), and the other, $f e o B$, is predicted to encode for a protein involved in Fe (II) uptake (Kammler et al., 1993). The data in Chapter 3 showed that these two genes were also expressed during $\mathrm{Fe}$ limitation of axenic T. erythraeum (IMS101) and well conserved across the Trichodesmium genus. Developing a similar qPCR method for one or both of these genes could provide additional information about the timing and control of transcription of the Fe stress response. For example, one gene might be turned on earlier than the others with the onset of Fe limitation or turned off with a different response time following the alleviation of Fe limitation. An experiment looking at how the expression of one or all of the genes responds to long-term Fe deprivation, beyond what is necessary to draw down Fe that has been stored within the cell, could provide useful information about how Trichodesmium adapts to growth in low Fe environments. While these additional experiments could provide useful information, they were unnecessary to accomplish the goal of this work, which was to design a clade-specific RNA normalized assay for $\mathrm{Fe}$ limitation of Trichodesmium $\mathrm{N}_{2}$ fixation and use it to assess Fe limitation of Trichodesmium in the field.

The ability to distinguish between the two clades, enabled not only the quantification of the levels of Fe limitation associated with $\mathrm{N}_{2}$ fixation in the field, but also the determination of the relative contribution of the two clades to the active population of Trichodesmium. The field data indicates that the Ten clade is the dominant active form of Trichodesmium in the field. One important caveat to this conclusion is that the samples focused on Trichodesmium colonies, which were collected in a manner that selected against the collection of individual trichomes. It may be that looking at the cDNA extracted from a specific volume of water and collected using a filter that would catch free trichomes in addition to colonies would indicate that the Tery clade is quantitatively important. If nothing else, the data suggests that the colonial forms of Trichodesmium in the open ocean areas sampled in this study are from the Ten clade. In the future, it might also prove useful to compare the relative messenger RNA (mRNA) data that the assay provides with a quantitative measurement of DNA from these stations. 
This could be used to determine if Tery clade representatives are present in a dormant form or at very low levels compared to the Ten clade in most of the open ocean, which may enable the Tery clade to become a more significant component of the Trichodesmium population when conditions change. Comparing that information with auxiliary data such as nutrient and Fe concentrations could help determine which factors are controlling niche differentiation between the clades.

The data in Chapter 4 represents the first survey quantifying Fe limitation of $\mathrm{N}_{2}$ fixation of Trichodesmium in open ocean gyres. The data supports model predictions that there is widespread Fe limitation of Trichodesmium $\mathrm{N}_{2}$ fixation in the Pacific Ocean (Moore et al., 2004). In comparing results of the [Fe] value associated with Fe limitation in the field with the [Fe'] value that found to be limiting in the lab, it appears that all the dissolved [Fe] may be available to Trichodesmium, including the Fe that is bound to organic ligands. In addition, by evaluating $i s i B$ expression in regions of varying $\mathrm{Fe}$ and phosphorus (P) concentrations and not just focusing on areas believed to be Fe stressed, it appears that there is a relationship between $i s i B$ expression and Fe:P. This relationship allowed for the determination of a critical Fe:P value that defines where Fe limitation of Trichodesmium commences. This value is in good agreement with the value that was used to predict that Fe was the controlling factor in the Pacific Ocean (Moore et al., 2004). In light of this data suggesting that $\mathrm{Fe} / \mathrm{P}$ is what drives the transition to $\mathrm{Fe}$ limitation, a corresponding method looking at $\mathrm{P}$ limitation would help determine if there are areas where co-limitation of Trichodesmium populations is occurring and what the boundaries of $\mathrm{Fe} / \mathrm{P}$ are that are associated with Fe-P co-limitation.

In conclusion, this thesis has provided data on Fe chemistry for a region where there are few measurements. It has confirmed that Fe ligands are prevalent even in low dust regions, though the data in Chapter 4 suggests that these measurements may prove unnecessary to attempts to predict Fe limitation of Trichodesmium. Determining that there are differences in the way that representatives from the two phylogenetic clades respond to chemical and physical factors and that representatives of the Ten clade are the predominant active Trichodesmium spp. in the open ocean are discoveries that will need 
to be taken into account in future studies. The development of a method that can be used to assess Fe limitation of Trichodesmium in the field in a quantitative manner has provided empirical data that support model predictions of Fe limitation of Trichodesmium. Combining this method with a similar method designed to look at $\mathrm{P}$ limitation would be the best way to evaluate where these two chemical factors are controlling Trichodesmium $\mathrm{N}_{2}$ fixation and to answer questions regarding Fe-P colimitation. Developing similar methods for other important groups of phytoplankton could help answer questions about where Fe limitation is truly important in the ocean without having to deal with complications associated with what form of $\mathrm{Fe}$ is bioavailable to a given species. 


\subsection{REFERENCES}

Achilles, K.M., Church, T.M., Wilhelm, S.W., Luther, G.W., and Hutchins, D.A. (2003) Bioavailability of iron to Trichodesmium colonies in the western subtropical Atlantic Ocean. Limnol Oceanogr 48: 2250-2255.

Boye, M., Aldrich, A.P., van den Berg, C.M.G., de Jong, J.T.M., Veldhuis, M., and de Baar, H.J.W. (2003) Horizontal gradient of the chemical speciation of iron in surface waters of the northeast Atlantic Ocean. Mar Chem 80: 129-143-PII S03044203(02)00102-0.

Boye, M., Nishioka, J., Croot, P.L., Laan, P., Timmermans, K.R., and de Baar, H.J.W. (2005) Major deviations of iron complexation during 22 days of a mesoscale iron enrichment in the open Southern Ocean. Mar Chem 96: 257-271.

Boye, M., van den Berg, C.M.G., de Jong, J.T.M., Leach, H., Croot, P., and de Baar, H.J.W. (2001) Organic complexation of iron in the Southern Ocean. Deep Sea Research 48: 1477-1497.

Boyle, E.A., Bergquist, B.A., Kayser, R.A., and Mahowald, N. (2005) Iron, manganese, and lead at Hawaii Ocean Time-series station ALOHA: Temporal variability and an intermediate water hydrothermal plume (vol 69, pg 933, 2005). Geochim Cosmochim Ac 69: $5165-5166$.

Brand, L.E. (1991) Minimum iron requirements of marine phytoplankton and the implications for the biogeochemical control of new production. Limnology and Oceanography [Limnol Oceanogr] 36: 1756-1771.

Bruland, K.W., Orians, K.J., and Cowen, J.P. (1994) Reactive Trace-Metals in the Stratified Central North Pacific. Geochim Cosmochim Ac 58: 3171-3182.

Buck, K.N., and Bruland, K.W. (2007) The physicochemical speciation of dissolved iron in the Bering Sea, Alaska. Limnol Oceanogr 52: 1800-1808.

Carpenter, E.J., O'Neil, J.M., Dawson, R., Capone, D.G., Siddiqui, P.J.A., Roenneberg, T., and Bergman, B. (1993) The tropical diazotrophic phytoplankter Trichodesmium: Biological characteristics of two common species. Mar Ecol Prog Ser 95: 295-304.

Croot, P.L., Andersson, K., Ozturk, M., and Turner, D.R. (2004) The distribution and specification of iron along 6 degrees E in the Southern Ocean. Deep-sea Res Pt Ii 51: 2857-2879.

Cullen, J.T., Bergquist, B.A., and Moffett, J.W . (2006) Thermodynamic characterization of the partitioning of iron between soluble and colloidal species in the Atlantic Ocean. Mar Chem 98: 295-303.

Duce, R.A., and Tindale, N.W. (1991) Atmospheric Transport of Iron and its Deposition in the Ocean. Limnol Oceanogr 36: 1715-1726. 
Hutchins, D.A., Witter, A.E., Butler, A., and Luther, G.W., III (1999) Competition among marine phytoplankton for different chelated iron species. Nature 400: 858-861.

Jickells, T.D. (1999) The inputs of dust derived elements to the Sargasso Sea: A synthesis. Mar Chem 68: 5-14.

Johnson, K.S., Boyle, E., Bruland, K.W., Coale, K.H., Measures, C.I., Moffett, J.W. et al. (2007) Developing Standards for Dissolved Iron in Seawater. EOS 88: 131-132.

Johnson, K.S., Gordon, R.M., and Coale, K.H. (1997) What controls dissolved iron concentrations in the world ocean? Mar Chem 57: 137-161.

Kammler, M., Schon, C., and Hantke, K. (1993) Characterization of the ferrous iron uptake system of Escherichia coli. J Bacteriol 175: 6212-6219.

Kondo, Y., Takeda, S., and Furuya, K. (2007) Distribution and speciation of dissolved iron in the Sulu Sea and its adjacent waters. Deep-sea Res Pt Ii 54: 60-80.

Kondo, Y., Takeda, S., Nishioka, J., Obata, H., Furuya, K., Johnson, W.K., and Wong, C.S. (2008) Organic iron(III) complexing ligands during an iron enrichment experiment in the western subarctic North Pacific. Geophys Res Lett 35: ARTN L12601.

Leonhardt, K., and Straus, N.A. (1992) An iron stress operon involved in photosynthetic electron transport in the marine cyanobacterium Synechococcus sp. PCC 7002. J Gen Microbiol 138: 1613-1621.

Maldonado, M.T., and Price, N.M. (2001) Reduction and transport of organically bound iron by Thalassiosira oceanica (Bacillariophyceae). J Phycol 37: 298-309.

Mawji, E., Gledhill, M., Milton, J.A., Tarran, G.A., Ussher, S., Thompson, A. et al. (2008) Hydroxamate Siderophores: Occurrence and Importance in the Atlantic Ocean. Environ Sci Technol 42: 8675-8680.

Michel, K.P., Thole, H.H., and Pistorius, E.K. (1996) IdiA, a 34 kDa protein in the cyanobacteria Synechococcus sp. strains PCC 6301 and PCC 7942, is required for growth under iron and manganese limitations. Microbiol 142: 2635-2645.

Moore, J.K., Doney, S.C., and Lindsay, K. (2004) Upper ocean ecosystem dynamics and iron cycling in a global three-dimensional model. Global Biogeochem Cy 18: ARTN GB4028.

Orcutt, K.M., Rasmussen, U., Webb, E.A., Waterbury, J.B., Gundersen, K., and Bergman, B. (2002) Characterization of Trichodesmium spp. by genetic techniques. Appl Environ Microbiol 68: 2236-2245.

Powell, R.T., and Donat, J.R. (2001) Organic complexation and speciation of iron in the South and Equatorial Atlantic. Deep-sea Res Pt Ii 48: 2877-2893.

Rijkenberg, M.J.A., Powell, C.F., Dall'Osto, M., Nielsdottir, M.C., Patey, M.D., Hill, P.G. et al. (2008) Changes in iron speciation following a Saharan dust event in the tropical North Atlantic Ocean. Mar Chem 110: 56-67. 
Rue, E.L., and Bruland, K.W. (1995) Complexation of iron(III) by natural organic ligands in the Central North Pacific as determined by a new competitive ligand equilibration/adsorptive cathodic stripping voltammetric method. Mar Chem 50: 117-138.

Rue, E.L., and Bruland, K.W. (1997) The role of organic complexation on ambient iron chemistry in the equatorial Pacific Ocean and the response of a mesoscale iron addition experiment. Limnol Oceanogr 42: 901-910.

Shaked, Y., Kustka, A.B., and Morel, F.M.M. (2005) A general kinetic model for iron acquisition by eukaryotic phytoplankton. Limnol Oceanogr 50: 872-882.

Soria-Dengg, S., Reissbrodt, R., and Horstmann, U. (2001) Siderophores in marine, coastal waters and their relevance for iron uptake by phytoplankton: experiments with the diatom Phaeodactylum tricornutum. Mar Ecol-prog Ser 220: 73-82.

van den Berg, C.M.G. (1995) Evidence for Organic Complexation of Iron in Seawater. Mar Chem 50: 139-157.

van den Berg, C.M.G. (2006) Chemical speciation of iron in seawater by cathodic stripping voltammetry with dihydroxynaphthalene. Anal Chem 78: 156-163.

Wagener, T., Guieu, C., Losno, R., Bonnet, S., and Mahowald, N. (2008) Revisiting atmospheric dust export to the Southern Hemisphere ocean: Biogeochemical implications. Global Biogeochem Cy 22: ARTN GB2006.

Wu, J., Boyle, E., Sunda, W., and Wen, L. (2001) Soluble and colloidal iron in the oligotrophic North Atlantic and North Pacific. Science 293: 847-849. 


\section{Appendix A: Table of Fe Speciation Raw Data}

Table A1. Selected raw data from Chapter 2 titrations

\begin{tabular}{|c|c|c|c|c|c|}
\hline \multicolumn{6}{|c|}{ Station $1115 \mathrm{~m}$} \\
\hline $\mathrm{Fe}_{\text {total }}(\mathrm{nM})$ & Current (nA) & $\mathrm{Fe}^{\prime}$ & $\mathrm{FeL}$ & $\mathrm{FeL} / \mathrm{Fe}^{\prime}$ & $\mathrm{Fe}^{\prime} / \mathrm{FeL}$ \\
\hline 0.11 & 0.7 & 0.0004 & 0.05 & 125.5 & 0.0080 \\
\hline 0.61 & 2.0 & 0.0011 & 0.43 & 409.4 & 0.0024 \\
\hline 0.86 & 5.1 & 0.0027 & 0.41 & 152.0 & 0.0066 \\
\hline 1.61 & 11.0 & 0.0058 & 0.64 & 110.1 & 0.0091 \\
\hline 3.11 & 27.0 & 0.0142 & 0.73 & 51.2 & 0.0195 \\
\hline 5.11 & 49.0 & 0.0258 & 0.79 & 30.6 & 0.0326 \\
\hline 8.11 & 84.0 & 0.0443 & 0.71 & 16.0 & 0.0625 \\
\hline \multicolumn{6}{|c|}{ Station $1315 \mathrm{~m}$} \\
\hline $\mathrm{Fe}_{\text {total }}(\mathrm{nM})$ & Current (nA) & $\mathrm{Fe}^{\prime}$ & $\mathrm{FeL}$ & $\mathrm{FeL} / \mathrm{Fe}^{\prime}$ & $\mathrm{Fe}^{\prime} / \mathrm{FeL}$ \\
\hline 0.32 & 1.5 & 0.0013 & 0.09 & 66.8 & 0.0150 \\
\hline 0.57 & 1.5 & 0.0013 & 0.34 & 252.3 & 0.0040 \\
\hline 0.82 & 3.5 & 0.0031 & 0.29 & 92.2 & 0.0108 \\
\hline 1.07 & 4.2 & 0.0038 & 0.43 & 115.3 & 0.0087 \\
\hline 1.82 & 9.8 & 0.0088 & 0.34 & 39.2 & 0.0255 \\
\hline 3.32 & 19.0 & 0.0171 & 0.46 & 27.2 & 0.0367 \\
\hline 5.32 & 33.0 & 0.0296 & 0.36 & 12.3 & 0.0814 \\
\hline \multicolumn{6}{|c|}{ Station $1415 \mathrm{~m}$} \\
\hline $\mathrm{Fe}_{\text {total }}(\mathrm{nM})$ & Current (nA) & $\mathrm{Fe}^{\prime}$ & $\mathrm{FeL}$ & $\mathrm{FeL} / \mathrm{Fe}^{\prime}$ & $\mathrm{Fe}^{\prime} / \mathrm{FeL}$ \\
\hline 0.20 & 0.4 & 0.0002 & 0.16 & 696.1 & 0.0014 \\
\hline 0.45 & 1.1 & 0.0006 & 0.34 & 547.2 & 0.0018 \\
\hline 0.70 & 1.6 & 0.0009 & 0.54 & 599.2 & 0.0017 \\
\hline 0.95 & 2.4 & 0.0014 & 0.72 & 527.3 & 0.0019 \\
\hline 1.20 & 3.4 & 0.0019 & 0.87 & 452.6 & 0.0022 \\
\hline 2.20 & 8.3 & 0.0047 & 1.41 & 299.0 & 0.0033 \\
\hline 3.20 & 19.0 & 0.0108 & 1.39 & 129.3 & 0.0077 \\
\hline 8.20 & 72.0 & 0.0409 & 1.37 & 33.5 & 0.0298 \\
\hline
\end{tabular}


Table A1. Continued

\begin{tabular}{|c|c|c|c|c|c|}
\hline \multicolumn{6}{|c|}{ Station $16 \mathrm{a} 7 \mathrm{~m}$} \\
\hline $\mathrm{Fe}_{\text {total }}(\mathrm{nM})$ & Current (nA) & $\mathrm{Fe}^{\prime}$ & $\mathrm{FeL}$ & $\mathrm{FeL} / \mathrm{Fe}^{\prime}$ & $\mathrm{Fe}^{\prime} / \mathrm{FeL}$ \\
\hline 0.61 & 0.6 & 0.0004 & 0.54 & 1364.5 & 0.0007 \\
\hline 0.86 & 1.5 & 0.0010 & 0.69 & 696.2 & 0.0014 \\
\hline 1.11 & 3.1 & 0.0021 & 0.77 & 372.0 & 0.0027 \\
\hline 1.36 & 3.6 & 0.0024 & 0.96 & 401.6 & 0.0025 \\
\hline 1.61 & 6.0 & 0.0040 & 0.94 & 236.8 & 0.0042 \\
\hline 2.61 & 8.9 & 0.0059 & 1.62 & 274.2 & 0.0036 \\
\hline 3.61 & 17.0 & 0.0113 & 1.72 & 152.4 & 0.0066 \\
\hline 5.61 & 35.0 & 0.0233 & 1.72 & 74.1 & 0.0135 \\
\hline 8.61 & 63.0 & 0.0419 & 1.62 & 38.6 & 0.0259 \\
\hline \multicolumn{6}{|c|}{ Station $1915 \mathrm{~m}$} \\
\hline $\mathrm{Fe}_{\text {total }}(\mathrm{nM})$ & Current (nA) & $\mathrm{Fe}^{\prime}$ & $\mathrm{FeL}$ & $\mathrm{FeL} / \mathrm{Fe}^{\prime}$ & $\mathrm{Fe}^{\prime} / \mathrm{FeL}$ \\
\hline 0.50 & 0.8 & 0.0004 & 0.43 & 10122.0 & 0.0009 \\
\hline 0.75 & 1.5 & 0.0007 & 0.63 & 864.9 & 0.0012 \\
\hline 1.00 & 1.0 & 0.0005 & 0.92 & 1897.4 & 0.0005 \\
\hline 1.25 & 4.4 & 0.0021 & 0.89 & 419.6 & 0.0024 \\
\hline 2.00 & 12.0 & 0.0058 & 1.03 & 177.2 & 0.0056 \\
\hline 5.50 & 54.0 & 0.0261 & 1.14 & 43.4 & 0.0230 \\
\hline 8.50 & 93.0 & 0.0450 & 0.98 & 21.9 & 0.0458 \\
\hline \multicolumn{6}{|c|}{ Station $2615 \mathrm{~m}$} \\
\hline $\mathrm{Fe}_{\text {total }}(\mathrm{nM})$ & Current (nA) & $\mathrm{Fe}^{\prime}$ & $\mathrm{FeL}$ & $\mathrm{FeL} / \mathrm{Fe}^{\prime}$ & $\mathrm{Fe}^{\prime} / \mathrm{FeL}$ \\
\hline 0.26 & 0.2 & 0.0001 & 0.24 & 2324.2 & 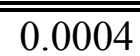 \\
\hline 0.51 & 0.5 & 0.0003 & 0.47 & 1784.0 & 0.0006 \\
\hline 0.76 & 1.5 & 0.0008 & 0.63 & 801.5 & 0.0012 \\
\hline 1.01 & 2.9 & 0.0015 & 0.76 & 498.5 & 0.0020 \\
\hline 1.26 & 5.5 & 0.0029 & 0.78 & 270.7 & 0.0037 \\
\hline 1.76 & 10.0 & 0.0052 & 0.89 & 169.2 & 0.0059 \\
\hline 2.26 & 17.0 & 0.0089 & 0.77 & 86.9 & 0.0115 \\
\hline
\end{tabular}




\section{APPENDIX B: DEPTH ProfiLeS FROM SJ0609 (ChAPTER 4)}

Table 1. Dissolved ( $<0.4 \mu \mathrm{m}$ filtered) Fe for Station

16 (Latitude: 3.30 Longitude: -32.90), Station 17

(Latitude:0.01 Longitude: -34.90) and Station 18

(Latitude: 1.80 Longitude: -38.50$)$.

\begin{tabular}{cccc}
\hline Station & Depth $(\mathrm{m})$ & Fe $(\mathrm{nM})$ & Stdev \\
\hline \hline 16 & 15 & 0.09 & 0.00 \\
16 & 30 & 0.16 & 0.00 \\
16 & 60 & 0.17 & 0.00 \\
16 & 90 & 0.22 & 0.01 \\
16 & 120 & 0.72 & 0.00 \\
16 & 150 & 0.86 & 0.00 \\
16 & 220 & 0.70 & 0.00 \\
16 & 250 & 0.77 & 0.02 \\
17 & 12 & 0.14 & 0.00 \\
17 & 30 & 0.08 & 0.01 \\
17 & 60 & 0.18 & 0.09 \\
17 & 90 & 0.49 & 0.02 \\
17 & 150 & 0.56 & 0.01 \\
17 & 290 & 0.99 & 0.01 \\
18 & 15 & 0.10 & 0.00 \\
18 & 30 & 0.24 & 0.00 \\
18 & 60 & 0.23 & 0.01 \\
18 & 90 & 0.32 & 0.02 \\
18 & 120 & 0.67 & 0.00 \\
18 & 150 & 0.55 & 0.02 \\
18 & 220 & 0.54 & 0.01 \\
18 & 290 & 0.49 & 0.00 \\
\hline
\end{tabular}




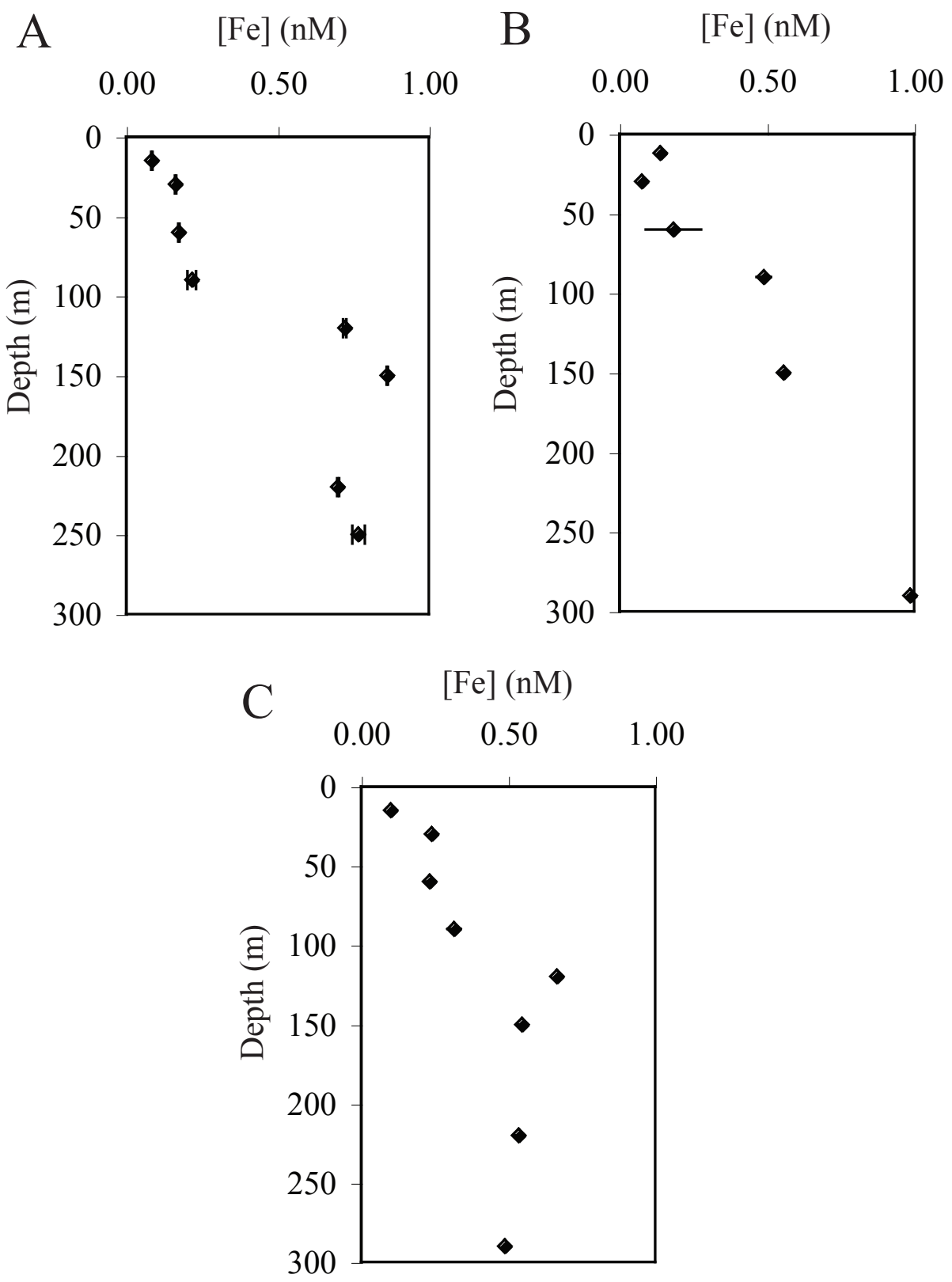

Figure 1. Dissolved Fe $(<0.4 \mu \mathrm{m}$ filtered $)$ depth profiles from three stations from cruise SJ0609. (A) Station 16. (B) Station 17. (C) Station 18. Error bars are standard deviations of triplicate analyses. 